\title{
WASTEWATER TREATMENT WITH ALGAE
}

\section{Dimitar Valev}





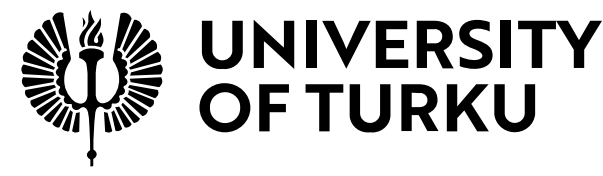

\section{WASTEWATER TREATMENT WITH ALGAE}

\author{
Dimitar Valev
}




\title{
University of Turku
}

Faculty of Science and Engineering

Department of Biochemistry /

Molecular Plant Biology

Doctoral programme in Molecular Life Sciences

\section{Supervised by}

Dr. Esa Tyystjärvi

Department of Biochemistry /

Molecular Plant Biology,

University of Turku, FI-20014

Turku, Finland

Dr. Taras Antal

Department of Botany and Plant Ecology

Pskov State University

Pskov 180000

Russia

\section{Reviewed by}

Professor Amit Bhatnagar

Water Chemistry \& Microbiology

University of Eastern Finland

Kuopio, Finland
Dr. Taina Tyystjärvi

Department of Biochemistry /

Molecular Plant Biology,

University of Turku, FI-20014

Turku, Finland

\section{Opponent}

\author{
Professor Ondřej Prášil \\ Centre Algatech \\ Institute of Microbiology, The Czech \\ Academy of Sciences \\ Třeboň, Czech Republic
}
Professor Koenraad Muylaert Laboratory of Aquatic Biology KU Leuven
Kortrijk, Belgium

The originality of this publication has been checked in accordance with the University of Turku quality assurance system using the Turnitin OriginalityCheck service.

ISBN 978-951-29-8094-9 (PRINT)

ISBN 978-951-29-8095-6 (PDF)

ISSN 0082-7002 (Painettu/Print)

ISSN 2343-3175 (Sähköinen/Online)

Painosalama Oy, Turku, Finland 2020 


\author{
UNIVERSITY OF TURKU \\ Faculty of Science and Engineering \\ Department of Biochemistry \\ Molecular Plant Biology \\ DIMITAR VALEV: Wastewater treatment with algae \\ Doctoral Dissertation, $118 \mathrm{pp}$. \\ Doctoral Programme in Molecular Life Sciences \\ June 2020
}

\title{
ABSTRACT
}

Microalgae have been under investigation as alternatives for wastewater treatment for the last 60 years. However, we are yet to see an algal based process to be trusted as a treatment strategy on a large scale. At present, recycling of the wastewaters and nutrient utilization have been solidified as main objectives in wastewater treatment in European Union. The metabolism of microalgae and cyanobacteria enables them to assimilate and store inorganic nutrients in their biomass. Therefore, under the new wastewater treatment objectives microalgae might present a promising solution.

The present work investigates the possibility of using algal biomass grown in wastewater for the production of a high value compound eicosapentaenoic acid (EPA), a type of Omega-3 fatty acid. The heterokont microalgae Nannochloropsis oculata (Eustigmataceae) were successfully grown in wastewaters from a paper/pulp mill, and we show that EPA content stayed at the same level as in microalgae grown in control conditions.

Furthermore, a stable wastewater treatment process was established in an upscale tubular photobioreactor (PBR) with the microalgae Ettlia oleoabundans (Chlorophyceae), achieving $99.6 \%$ and $75 \%$ phosphate and ammonium removal efficiencies, respectively. The work points out the importance of wastewater pretreatment and wastewater optimization in order to achieve a reliable wastewater treatment process with microalgae.

Finally, the cyanobacterium Synechocystis sp. PCC6803 and its sigma factor mutants were investigated in order to evaluate potential stress induced by the wastewaters. The experiments revealed that sigma factor D (sigD) may play an important role in acclimation to wastewaters and its over expression might give an edge of the photosynthetic cells used for wastewater treatment in outdoor conditions. 


\section{TURUN YLIOPISTO}

Luonnontieteiden ja tekniikan tiedekunta

Biokemian laitos

Molekulaarinen kasvibiologia

DIMITAR VALEV: Wastewater treatment with algae

Väitöskirja, $118 \mathrm{~s}$.

Molekulaaristen biotieteiden tohtoriohjelma

Kesäkuu 2020

\section{TIIVISTELMÄ}

Levien käyttöä vaihtoehtoisena jätevedenpuhdistusmenetelmä on tutkittu jo 60 vuoden ajan, mutta suurimittakaavainen leväprosessi ei silti ole vielä missään käytössä. Euroopan Unioni pitää jätevesien kierrätystä ja niiden sisältämien ravinteiden talteenottoa jätevedenpuhdistuksen tärkeimpinä päämäärinä. Levät ja syanobakteerit ovat lupaava ratkaisuvaihtoehto jätevedenpuhdistukseen, koska niiden aineenvaihdunta mahdollistaa epäorgaanisten ravinteiden assimilaation ja varastoitumisen biomassaan.

Käsillä olevassa työssä tutkittiin mahdollisuutta jätevedessä tuotettavan leväbiomassan käyttämiseen eikosapentaeenihapon (EPA) tuottamiseen. EPA on markkina-arvoltaan merkittävä omega-3-rasvahappo. Heterokonta-ryhmään kuuluvan Eustigmataceae-heimon Nannochloropsis oculata -levää kasvatettiin onnistuneesti selluloosa- ja paperitehtaan jätevedessä, ja EPA:n määrä biomassassa säilyi levissä samalla tasolla kuin kontrollioloissa kasvatetuissa levissä.

Työssä rakennettiin stabiili jätevedenpuhdistusprosessi, jossa Ettlia oleoabundans -nimistä viherlevää (Chlorophyceae) kasvatettiin suuressa putkifotobioreaktorissa. Prosessi poisti jäteveden fosfaatista $99.6 \%$ ja ammoniumista 75 $\%$. Työ osoitti, että jäteveden esikäsittely ja ravinnepitoisuuden optimointi ovat toimivan käsittelyprosessin edellytyksiä.

Lopuksi työssä tutkittiin myös Synechocystis sp. PCC6803 -syanobakteerin ja erityisesti sen sigmatekijämutanttien toimivuutta jätevedenpuhdistuksessa erityisesti jäteveden aiheuttaman stressin kannalta. Kokeet osoittivat sigD-sigmatekijän näyttelevän tärkeää roolia syanobakteerin akklimaatiossa. Työn perusteella SigD:n ylituotto voisi parantaa syanobakteerin käyttömahdollisuuksia ulko-olosuhteissa. 


\section{Table of Contents}

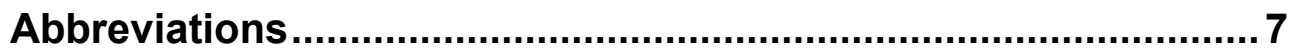

List of Original Publications .....................................................10

1 INTRODUCTION ................................................................ 11

1.1 Origins, and health and environmental impacts of wastewaters . 11

1.2 Constituents and characterization of wastewaters .................. 11

1.2.1 Physical characteristics ......................................... 11

1.2.2 Chemical characteristics......................................... 12

1.2.2.1 Inorganic chemical characteristics ............... 12

1.2.2.2 Organic chemical characteristics................... 13

1.2.3 Biological characteristics ..................................... 14

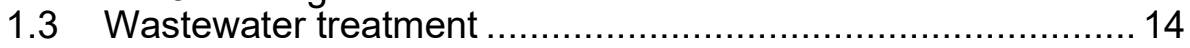

1.3.1 Physical methods …........................................... 15

1.3.2 Chemical methods.................................................. 15

1.3.3 Biological methods ............................................. 16

1.4 Requirements define technology ........................................ 18

1.5 Photoautotrophic microalgae and cyanobacteria........................ 19

1.5.1 Oxygenic photosynthesis...................................... 19

1.5.1.1 Light driven redox reactions of photosynthesis ... 19

1.5.1.2 Carbon fixation reactions ............................. 20

1.6 Nutrient requirements of photoautotrophic microbes …............ 21

1.6.1 Macronutrients................................................... 21

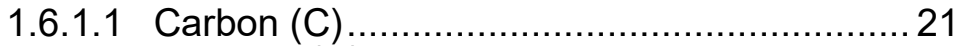

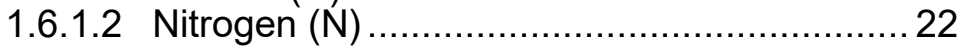

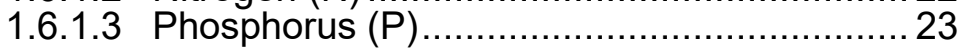

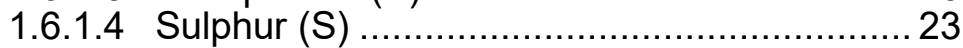

1.6.2 Metal micronutrients involved in photosynthesis ........... 24

1.7 Biotechnological application of microalgae and cyanobacteria ... 25

1.8 PBRs for suspended growth ............................................ 26

1.8.1 Open systems ...................................................... 26

1.8.2 Closed PBRs ....................................................... 27

1.9 Genetically modified photoautotrophs.................................. 27

1.10 Photoautotrophs in wastewater treatment ............................ 29

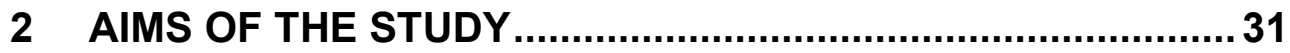

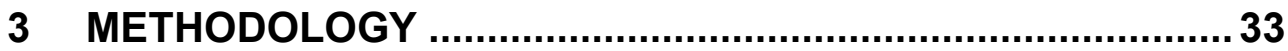

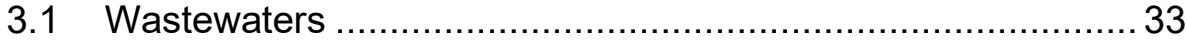

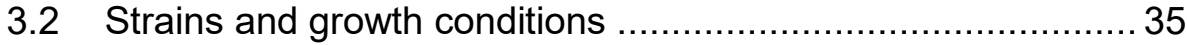


3.2.1 Nannochloropsis oculata .......................................... 35

3.2.2 Ettlia oleoabundans............................................ 36

3.2.3 Synechocystis sp. PCC6803 ................................ 37

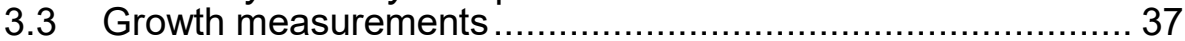

3.4 Biomass Dry Weight Analysis.......................................... 38

3.5 Nutrient content and removal efficiency............................... 38

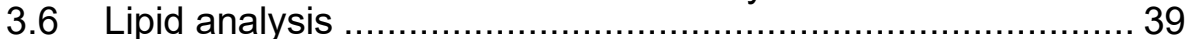

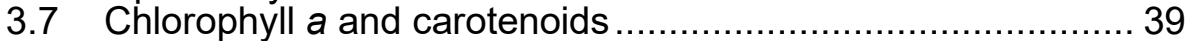

3.8 Photosynthesis measurements ......................................... 39

3.9 Statistical analysis ....................................................... 40

4 OVERVIEW OF RESULTS................................................... 41

4.1 Construction of a pilot scale tubular PBR .......................... 41

4.2 Pre-treating and testing wastewaters as growth media for microalgae ............................................................... 43

4.2.1 Removing solids from wastewaters ........................ 43

4.2.2 Ammonium contents of different wastewaters and their ability to sustain algal growth ............................. 46

4.3 Biomass and EPA production of Nannochloropsis oculata in digester effluent based media

4.4 Wastewater treatment with E. oleoabundans in a pilot scale tubular PBR

4.4.1 Optimizing wastewater pre-treatment for up-scale experiments

4.4.2 Wastewater optimization for stable algal growth ........... 54

4.4.3 Achieving a stable wastewater treatment process ........ 55

4.5 Potential of Synechocystis sp. PCC 6803 and its regulatory sigma factor mutants for wastewater purification .................... 56

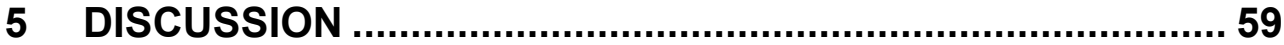

5.1 Up-scale PBR as an experimental set up for wastewater treatment........................................................................ 59

5.2 Importance of wastewater pre-treatment

5.3 Wastewater optimization for a stable alga-based wastewater treatment process ............................................................ 62

5.3.1 Fluctuations in wastewaters composition......................62 62

5.3.2 Ammonium toxicity .............................................. 63

5.3.3 Importance of continuous growth experiments for determining nutrient deprivation 64

5.4 Cultivation of Nannochloropsis oculata in wastewater for EPA production

5.5 Wastewater treatment with Ettlia oleoabundans in a pilot scale tubular PBR ......................................................... 67

5.6 Synechocystis sp. 6803 mutants grown in wastewater............ 68

6 CONCLUSION AND FUTURE PERSPECTIVES ..................... 70

7 ACKNOWLEDGEMENTS ................................................... 72

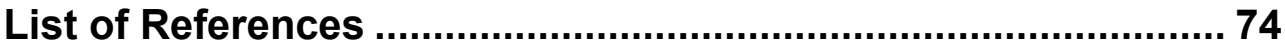

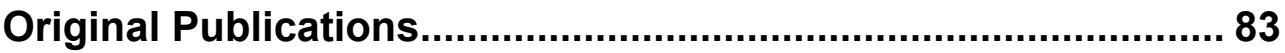




\section{Abbreviations}

2-OG 2-Oxoglutarate

3-PGA 3-Phosphoglyceric acid

ADP Adenosine-5'-diphosphate

ASW Artificial seawater medium

ATP Adenosine-5'-triphosphate

BG-11 Freshwater growth medium for cyanobacteria

BOD Biological oxygen demand

CA Carbonic anhydrase

$\mathrm{Ci}$ Inorganic carbon

CCM Carbon concentrating mechanism

CE Cholesteryl esters

COD Chemical oxygen demand

CS Control strain

cyt $b_{6} f \quad$ Cytochrome $b_{6} f$ complex

DE Pre-treated (Coagulation/flocculation + activated charcoal + sterilization with $0.2 \mu \mathrm{m}$ filter) digest effluent

DE medium A medium containing $25 \% \mathrm{DE}$ and $75 \%$ wastewater treatment plant effluent

DER Raw digest effluent (pre-treatment only by coagulation/flocculation)

DW Distilled water

DHA Docosahexaenoic acid

EPA Eicosapentaenoic acid

ETR Electron transfer rate

ETRmax Maximum electron transfer rate

EU European Union

$\mathrm{F}_{0} \quad$ Minimum fluorescence measured from dark adapted sample

$\mathrm{F}_{0}$, $\quad$ Minimum fluorescence measured during illumination of the sample

$\mathrm{F}_{\mathrm{M}} \quad$ Maximum fluorescence measured from dark adapted sample

$\mathrm{F}_{\mathrm{M}}$, Maximum fluorescence measured during illumination of the sample

$\mathrm{F}_{\mathrm{t}} \quad$ Fluorescence measured before a saturating pulse, during illumination

FD Ferredoxin 
FDS Fixed dissolved solids

FM' $\quad$ Fluorescence intensity measured during a saturating pulse of light

FS Fluorescence intensity measured before a saturating pulse

FSS Fixed suspended solids

GA3P Glyceraldehyde 3-phosphate

GAC Granulated activated carbon

GL Glycolipids

GMO Genetically modified organism

GS-GOGAT Glutamate synthase-glutamine-oxoglutarate aminotransferase

Gln Glutamine

Glu Glutamate

HEPES 4-(2-hydroxyethyl)-1-piperazineethanesulfonic acid

HRAP High rate algal ponds

Inorg. P Inorganic phosphorus

KA2 Landfill leachate used in the experiments

LHC I Light harvesting complex associated with Photosystem I

LHC II Light harvesting complex associated with Photosystem II

$\mathrm{NADP}^{+} \quad$ Oxidized nicotinamide adenine dinucleotide phosphate

NADPH Reduced nicotinamide adenine dinucleotide phosphate

NPQ Non-photochemical quenching

NiR Nitrite reductase

NR Nitrate reductase

NRE Nutrient removal efficiency

$\mathrm{O}_{2 \text { in }} \quad$ Oxygen sensor measuring oxygen concentration after degassing in the up- scale photobireactor

$\mathrm{O}_{2 \text { out }} \quad$ Oxygen sensor measuring oxygen concentration before degassing in the up- scale photobireactor

OD\# Optical density at wavelength \#, in nm

OEC Oxygen evolving complex

Org. P Organic phosphorus

P680 Photosystem I reaction centre

P700 Photosystem II reaction centre

PAC Powdered activated carbon

PBR Photobioreactor

PC Plastocyanin

PL Phospholipids

PPDF Photosynthetic photon flux density

$\mathrm{PQH}_{2} \quad$ Fully reduced plastoquinone B

PS I Photosystem one

PS II Photosystem two 


$\begin{array}{ll}\text { PVDF } & \text { Polyvinylidene difluoride } \\ \text { QA }_{\text {A }} & \text { Plastoquinone A, electron acceptor of PS II } \\ \text { QB }_{\text {B }} & \text { Plastoquinone B, electron acceptor of PS II } \\ \text { qP } & \text { Photochemical quenching coefficient } \\ \text { RNA } & \text { Ribonucleic acid } \\ \text { RNAP } & \text { Ribonucleic acid polymerase } \\ \text { RuBisCo } & \text { Ribulose bisphosphate carboxylase } \\ \text { RuBP } & \text { Ribulose bisphosphate } \\ \text { SOD } & \text { Superoxide dismutase } \\ \text { TAG } & \text { Triacylglycerol } \\ \text { TAL1 } & \text { Mix of all wastewater's streams generated in solid waste treatment } \\ & \text { plant } \\ \text { TAN } & \text { Total ammonia nitrogen } \\ \text { TDS } & \text { Total dissolved solids } \\ \text { TFA } & \text { Total fatty acids } \\ \text { TIN } & \text { Total inorganic nitrogen } \\ \text { TKN } & \text { Total Kjeldahl nitrogen } \\ \text { TN } & \text { Total nitrogen } \\ \text { TOC } & \text { Total organic carbon } \\ \text { TP } & \text { Total phosphorus } \\ \text { TS } & \text { Total solids } \\ \text { TSS } & \text { Total suspended solids } \\ \text { UV } & \text { Ultraviolet } \\ \text { VDS } & \text { Volatile dissolved solid } \\ \text { VFA } & \text { Volatile fatty acids } \\ \text { VSS } & \text { Volatile suspended solids } \\ \text { WWTP } & \text { Wastewater treatment plant } \\ \text { WWTPE } & \text { Wastewater treatment plant effluent }\end{array}$




\section{List of Original Publications}

This thesis is composed of the following scientific articles, referred to in the text by their Roman numerals.

I Polishchuk A*, Valev D*, Tarvainen M, Mishra M, Kinnunen V, Antal T, Yang B, Rintala J, Tyystjärvi E (2015) Cultivation of Nannochloropsis for EPA production in wastewaters of paper and pulp industry. Bioresource Technology 193: 469-476* Shared first authorship

II Valev D, Silva Santos H, Tyystjärvi E (2020) Stable wastewater treatment with Neochloris oleoabundans in a tubular photobioreactor. Journal of Applied Phycology 32: 399-410.

III Valev D, Kurkela J, Tyystjärvi E, Tyystjärvi T (2020) Testing the potential of regulatory sigma factor mutants for wastewater purification or bioreactor run in high light. Current Microbiology, in press.

Paper I has been reprinted by a kind permission from Elsevier. Papers II and III have been published with a Creative Commons Attribution 4.0 International (CC BY 4.0) Licence (http://creativecommons.org/licences/by/4.0/). 


\section{INTRODUCTION}

\subsection{Origins, and health and environmental impacts of wastewaters}

Wastewaters originate from various sources from household, hotels and manufacturing to agriculture and solid waste treatment. Wastewater can be categorized as commercial, industrial, domestic or municipal (Metcalf \& Eddy et al. 2004; Lofrano and Brown 2010). All four groups have complex constituents and may contain toxic compounds and pathogens, hence the necessity of proper treatment and disposal. Usually wastewaters are disposed in natural water bodies where organic constituents cause growth of heterotrophic bacteria, depriving water of $\mathrm{O}_{2}$. Furthermore, wastewaters may contain high levels of ammonia/ammonium proven to be toxic for aquatic life (Thurston et al. 1981; Wang 1991). Discharge of wastewaters in water bodies used as a drinking water source may harm human health. Mortality caused by diseases is known to increase with the lack of wastewater treatment (Naik and Stenstrom 2012).

\subsection{Constituents and characterization of wastewaters}

\subsubsection{Physical characteristics}

Typical physical characteristics of wastewater are total solids (TS), turbidity, colour, temperature and conductivity. TS include colloidal particles, floatable, settleable and suspended particles as well as substances that can precipitate from the liquid. Usually TS are measured by evaporating the water from a wastewater sample and measuring the residual matter. However, TS consist of multiple solids fractions (Fig. 1). 


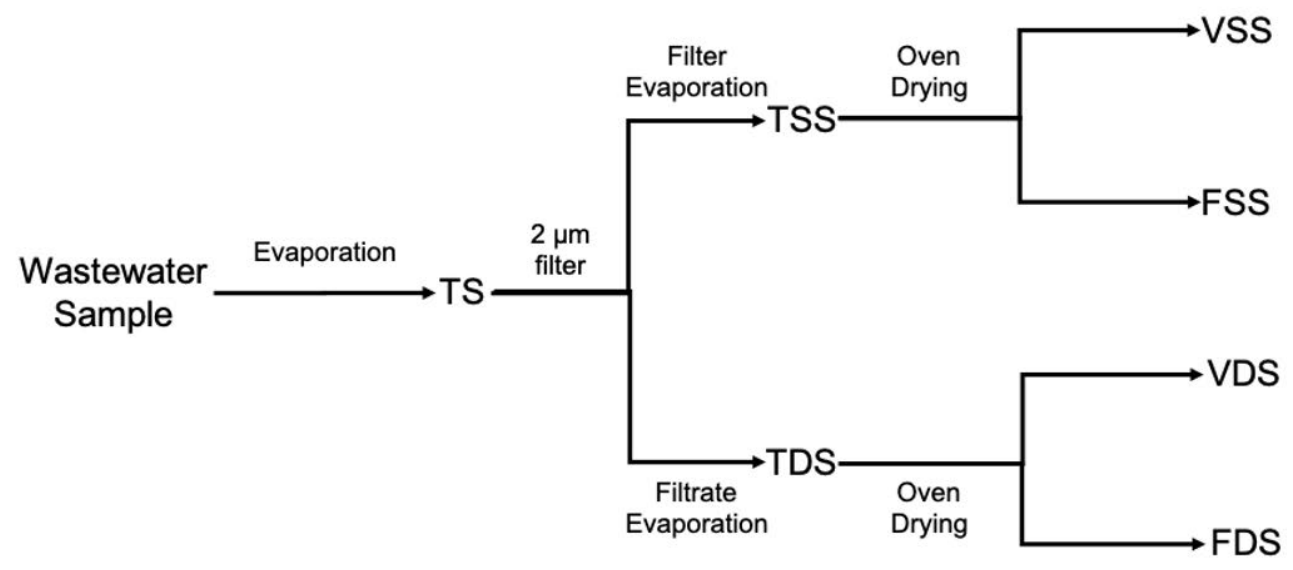

Figure 1. Different fractions originating from the total solids (TS) present in a wastewater sample. TSS - total suspended solids; TDS - total dissolved solids; VSS - volatile suspended solids; FSS - fixed suspended solids; VDS - volatile dissolved solids; FDS - fixed dissolved solids.

Total suspended solids (TSS) and total dissolved solids (TDS) can be separated by passing wastewater through $2.0 \mu \mathrm{m}$ filter (Metcalf \& Eddy et al. 2004, Chapter 2). Furthermore, after drying those two fractions at $500 \pm 50^{\circ} \mathrm{C}$, four more fractions will be obtained: volatile suspended solids (VSS) and fixed suspended solids (FSS) from the TSS fraction and volatile dissolved solids (VDS) and fixed dissolved solids (FDS) from the TDS fraction.

\subsubsection{Chemical characteristics}

\subsubsection{Inorganic chemical characteristics}

This group includes inorganic non-metallic constituents (nitrogen, phosphorus and sulphur compounds, ions like chloride, hydroxide, carbonate, bicarbonate, hydrogen ions) and metallic constituents. Nutrients, mainly nitrogen and phosphorus, are the primary reasons why wastewater treatment is necessary, as wastewaters containing those nutrients cause eutrophication.

Wastewaters can contain different forms of nitrogen. From wastewater treatment perspective, the ones of most importance are ammonium $\left(\mathrm{NH}_{4}{ }^{+}\right)$, ammonia $\left(\mathrm{NH}_{3}\right)$, nitrate $\left(\mathrm{NO}_{3}{ }^{-}\right)$, nitrite $\left(\mathrm{NO}_{2}{ }^{-}\right)$, and organic nitrogen. Wastewaters can be characterized on the basis of their nitrogen content by total ammonia nitrogen (TAN), which is the sum of the concentrations of $\mathrm{NH}_{3}$ and $\mathrm{NH}_{4}^{+}$; total inorganic nitrogen (TIN), which is the sum of the concentrations of $\mathrm{NH}_{3}, \mathrm{NH}_{4}{ }^{+}, \mathrm{NO}_{3}{ }^{-}$and $\mathrm{NO}_{2}{ }^{-}$; total Kjeldahl nitrogen (TKN), giving the total concentration of organic $\mathrm{N}$ and TAN; organic $\mathrm{N}$ is the 
difference of TKN and TAN; and total nitrogen (TN) is the sum of organic $\mathrm{N}$ and TIN.

Phosphorus in wastewater is characterized by three fractions - inorganic phosphorus (Inorg. P), such as orthophosphates $\mathrm{PO}_{4}{ }^{3-}, \mathrm{HPO}_{4}{ }^{2-}, \mathrm{H}_{2} \mathrm{PO}_{4}{ }^{-}$and $\mathrm{H}_{3} \mathrm{PO}_{4}$, present at $\mathrm{pH}<2,12$, organic phosphorus (Org. P) and Total phosphorus (TP), which is the sum of the concentrations of Inorg. P and Org. P.

From the non-metallic constituents, the ones determining the $\mathrm{pH}$ of a wastewater are of high importance. Those characteristics are crucial in the operation of a wastewater treatment process.

Metallic constituents are often related to toxic effects over aquatic life, and their determination is important for designing an adequate process for their removal. Small concentrations of iron, copper, manganese and other metallic nutrients may promote harmful algal blooms when discharged (Sunda 2006; Kudela et al. 2010).

\subsubsection{Organic chemical characteristics}

Usually when discussing wastewaters and their treatment, one of the main concerns for the environment is the presence of organic pollutants in the wastewater. Their characterization in wastewater treatment is done by an analysis that measures a group of organic pollutants that have similar properties, referred to as aggregate organic constituents, and by analysis targeting specific organic molecules.

Methods for measurement of aggregate organic constituents are chemical oxygen demand (COD), biological oxygen demand (BOD), and total organic carbon (TOC). COD is determined by an indirect titrimetric method with dichromate as oxidizing agent, and COD indicates the amount of oxygen necessary to oxidize the organic constituents (Equation 1).

$\mathrm{C}_{n} \mathrm{H}_{a} \mathrm{O}_{b} \mathrm{~N}_{c}+d \mathrm{Cr}_{2} \mathrm{O}_{7}^{2-}+(8 d+c) \mathrm{H}^{+} \rightarrow n \mathrm{CO}_{2}+\frac{a+8 d-3 c}{2} \mathrm{H}_{2} \mathrm{O}+c \mathrm{NH}_{4}^{+}+2 d \mathrm{Cr}^{3+}$ where $d=\frac{2 n}{3}+\frac{a}{6}-\frac{b}{3}-\frac{c}{2}$

COD measurement can be completed in $15 \mathrm{~min}$ to $2.5 \mathrm{~h}$ However, since this method uses a strong oxidant, inorganic substances may also contribute to COD, and non-biodegradable organic substances also will be oxidized. Therefore, COD analysis might be misleading for designing biological wastewater treatment. Consequently, BOD characterization of wastewaters has been adopted as more accurate indication of biological treatability of wastewaters. BOD methods are performed in a bottle, where a wastewater sample is enriched with additional nutrients and oxygen, promoting biological growth. The bottles can also be inoculated with additional microorganisms. Before closing the bottle, oxygen concentration is measured, and the closed bottle is incubated for either $5\left(\mathrm{BOD}_{5}\right)$ or 
$7\left(\mathrm{BOD}_{7}\right)$ days. After the growth period, residual oxygen indicates the amount that was used during aerobic degradation of the organic pollutants. The main disadvantages of BOD characterization, when compared with COD, are the complexity and duration of the testing.

TOC methods, in turn, apply heat, oxygen, chemical oxidizing agents or their combination to convert organic carbon to $\mathrm{CO}_{2}$. TOC measurements are fast $-5-10$ minutes. If a relationship between TOC and BOD can be established, then TOC measurements can be used during wastewater plant operation.

\subsubsection{Biological characteristics}

Wastewater are characterized biologically by the presence and number of coliform organisms, other bacteria, protozoa, viruses as well as toxicity. Special attention is paid to pathogenic microorganisms such as bacteria like Salmonella, Escherichia coli, Vibrio cholerae, the protozoa species Cryptosporidium parvum, Cyclospora, Giardia lamblia, helminths from the Taenia family, as well as the Schistosoma family. Common approaches for determination of pathogenic organisms are use of an indicator microorganism, direct count, membrane filtration and fluorescence methods.

Wastewater toxicity is defined by concentrations of compounds present. Substances such as ammonium can be toxic when present in high concentrations, which also can be species dependent. As it will be later shown in this thesis, ammonium can be utilized be microalgae only when it is available below certain concentration threshold, otherwise it is toxic to the microalgal culture. Other substances like arsenic, heavy metals and pesticide residues can be acutely or chronically toxic at low concentrations. Determination of toxicity of a wastewater is crucial due to the potential damage to the environment that it can cause. Furthermore, it is essential to determine toxic concentrations of compounds in the wastewater if a biological step is planned for the treatment. Sensitive aquatic species like micro or macro algae, or small minnow fishes, are often applied in determining the presence of substances at toxic concentration levels.

\subsection{Wastewater treatment}

The most common, simplified wastewater treatment process scheme generally consists of three main treatment stages, known as primary, secondary and tertiary treatment (Fig. 2). Primary treatment removes large size pollutants such as gravel and rocks from the wastewater. The secondary treatment is the main purification process, where suspended organic and inorganic pollutants are utilized or removed. Tertiary treatment is final adjustment and disinfection of the wastewater before discharge. 


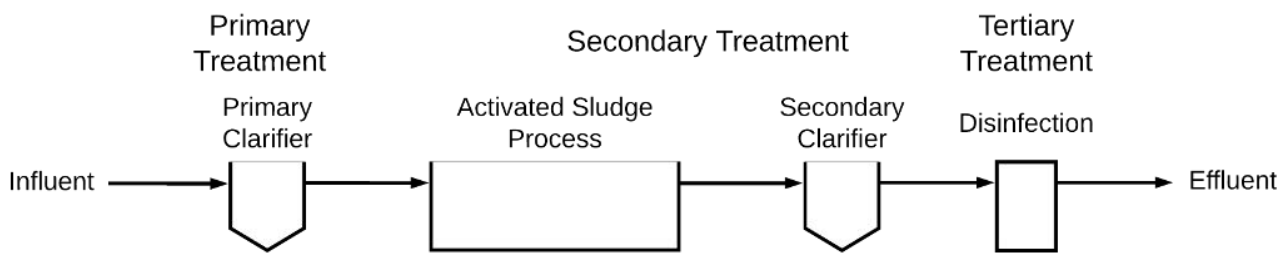

Figure 2. A simplified wastewater treatment process scheme consisting of Primary, Secondary and Tertiary treatment stages.

Three different groups of methods can be applied for wastewater treatment: physical methods, referred as unit operations, and chemical and biological methods, referred as unit processes.

\subsubsection{Physical methods}

Physical methods include mixing, aeration, sedimentation, and air stripping. Primary treatment applies different screeners and filtration approaches for the removal of coarse to fine solids such as plastic bags, sticks, grid, sand, macroalgae etc. In some cases, grinders are used to minimize the size of bigger solids. Physical methods used in the primary treatment prolong the lifespan of the equipment of the wastewater treatment plant and increase the efficiency of the subsequent process. Gravity separation by sedimentation in the primary settler is commonly used for separation of suspended and colloidal particles. In secondary treatment, a secondary settler is used to separate wastewater from the activated sludge coming from the biological treatment step (Fig. 2). In such a case, settling also concentrates the sludge, making it easier to handle and dispose. Unit operations like UV radiation and filtration are used in final tertiary treatment for disinfecting wastewater prior to discharge. Settlers can be used in combination with chemical methods, especially in coagulation/flocculation processes.

\subsubsection{Chemical methods}

Chemical unit processes, just like physical unit operations, can be applied to enhance primary treatment, main process or the tertiary stage of wastewater treatment. Typical chemical methods are precipitation, coagulation, flocculation, oxidation, advanced oxidation, ion exchange, disinfection, neutralization and scale control.

Chemical coagulants and flocculants can speed up sedimentation and removal of suspended particles during primary treatment. Removal of organic pollutants, inorganic constituents such as $\mathrm{NH}_{4}{ }^{+}$and $\mathrm{PO}_{4}{ }^{3-}$, as well as heavy metals can be achieved by applying different methods such as ion exchange, chemical oxidation and precipitation strategies instead of a secondary treatment. In a tertiary treatment, ozonation and chlorination are commonly used for disinfection. Chemical neutralization methods are applied for $\mathrm{pH}$ adjustment, which is crucial at different 
stages of the wastewater treatment. Chemical methods are used to control scale formation caused by $\mathrm{CaCO}_{3}$. For example, hydrochloric acid can be used to convert $\mathrm{CaCO}_{3}$ to $\mathrm{CO}_{2}$ to prolong the lifetime of the wastewater treatment plant.

The versatility of chemical wastewater treatment processes allows them to be designed and applied in combination with biological unit processes for a broad variety of wastewater types. In some cases, chemical methods can work as a standalone wastewater treatment process.

\subsubsection{Biological methods}

Biological methods are very common as secondary treatment due to less chemicals used during process, less accumulation of waste solids and consumption of less energy than chemical methods. Biological methods are applied only when the wastewater contains biodegradable organic compounds as main pollutants. These methods utilize microorganisms for the degradation of organic molecules and for nutrient removal.

The main goals the biological methods are to reduce the organic constituents either by biological oxidation or mineralization, and to remove or utilize nutrients such as inorganic nitrogen, inorganic phosphorus or specific micronutrients. Suspended non-biodegradable solids are trapped by the bacterial biomass during the biological treatment. The design of a wastewater treatment process, especially for industrial wastewaters or municipal wastewaters containing industrial waste streams, requires careful consideration. Inorganic and organic compounds might be toxic for the microorganisms that normally take part in the biological treatment.

Biological treatment can be divided to aerobic and anaerobic processes on the basis of the metabolic requirements of the microorganisms used in the process. Aerobic and anaerobic processes can be used as standalone methods or designed to work together when metabolic by-products of one process can be used as substrates for the other.

Activated sludge process is the most common biological suspended growth process (Fig. 2). By definition, it is a process where active microbial biomass is produced by aerobic degradation of organic material (Ardern and Lockett 1914). Historically the first one to be investigated was a plug-flow reactor. At a later stage, complete-mix reactors were also adopted. Furthermore, a combination of reactors, referred to as staged process, was implemented as well.

With the advance of technology and wastewater treatment engineering, activated sludge treatment was also implemented in inorganic nutrient removal processes. Staged reactors can be combined with subsequent aerobic and anaerobic conditions, useful in removal of nutrients. A typical example is a nitrification/denitrification process, schematically shown in Figure 3. This process combines the operation of two different types of bacteria: nitrifiers oxidize $\mathrm{NH}_{4}{ }^{+}$to $\mathrm{NO}_{3}{ }^{-}$, and denitrifiers reduce nitrate to nitrogen gas that escapes to the atmosphere. 
As shown in Figure 3, water is recycled from the aerobic part of a staged bioreactor to the anaerobic part. This internal recycling is necessary because nitrification occurs under aerobic conditions whereas denitrification takes place under anaerobic conditions. The design is done in this particular manner to give the more slowly metabolizing anaerobic organisms a chance to utilize the necessary amount of organic material before the aerobic stage, where heterotrophic bacteria can rapidly degrade organic compounds.

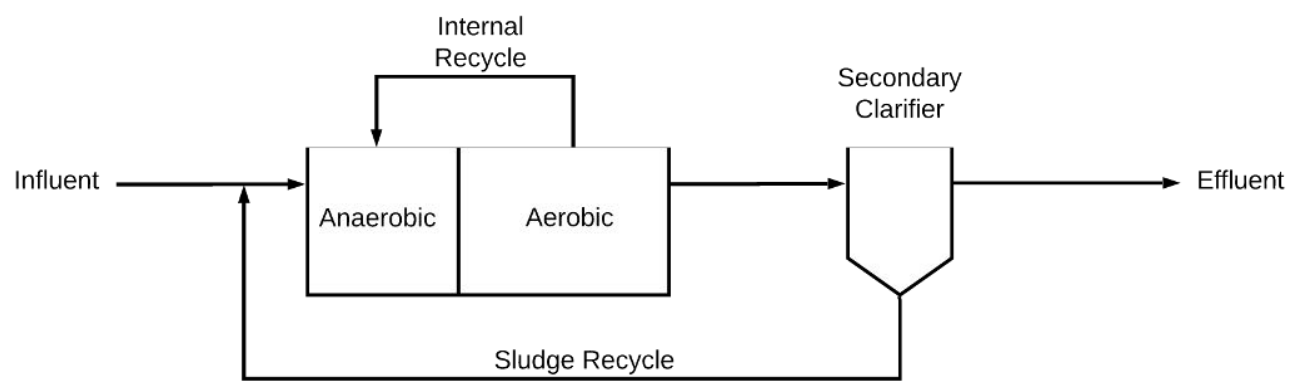

Figure 3. Simplified scheme of activated sludge process with a nitrification/denitrification step, applied via an internal recycle between the aerobic and anaerobic part of the activated sludge process.

During activated sludge process, a large amount of microbial biomass is accumulated and usually industries have to transport the biomass and dispose it to landfill, which adds to the maintenance costs. No major improvement has taken place in aerobic wastewater treatment practices since its discovery by Ardern and Lockett in 1914.

Anaerobic processes implement anaerobic bacteria, and the process can be summarized with Equation 2:

$$
\mathrm{C}_{6} \mathrm{H}_{12} \mathrm{O}_{6} \rightarrow 3 \mathrm{CO}_{2}+3 \mathrm{CH}_{4}
$$

An anaerobic process goes through four distinctive stages: hydrolysis, acidogenesis, acetogenesis and methanogenesis.

Facultative and anaerobic bacteria hydrolyse the complex organic constituents of the wastewater to small molecules such as fatty acids, amino acids and simple sugars. Acidogenic fermentative bacteria further break down those compounds to volatile fatty acids (VFA), ammonia, $\mathrm{CO}_{2}$ and $\mathrm{H}_{2} \mathrm{~S}$. Acetogens advance the oxidation of the VFA formed by the acidogenic bacteria to acetic acid and $\mathrm{H}_{2}$. The final stage involves methanogenic bacteria, which use the products from the previous stage to produce $\mathrm{CH}_{4}, \mathrm{CO}_{2}$ and $\mathrm{H}_{2} \mathrm{O}$.

In general, anaerobic processes are used in wastewaters with high concentration of organic constituents. There are several advantages of anaerobic processes over aerobic ones. As discussed, they can operate with highly polluted waters, which 
results in smaller volumes and smaller land use for the process, when compared with the activated sludge process. They are energetically more efficient than the activated sludge process. Furthermore, less sludge is produced, as anaerobic metabolism is slower and results in less biomass synthesis. Anaerobic bacteria require less nutrients for growth, which makes them applicable in cases where wastewaters lack nutrients for aerobic bacterial growth. Due to the complexity of the whole process, including different types of anaerobic bacteria, many by-products and different operating parameters, anaerobic processes can be extremely sensitive to variations in temperature and $\mathrm{pH}$. Anaerobic treatment is known for slow start up, due to the slow growth of anaerobic bacteria (Lettinga et al. 1980). Furthermore, anaerobic wastewater treatment requires further treatment of the effluent, since anaerobic bacteria involved are not efficient in inorganic nutrient removal.

\subsection{Requirements define technology}

Wastewater treatment has been designed to purify water mainly based on COD and TSS and pathogen content (Metcalf \& Eddy et al. 2004). Wastewater treatment legislation has prioritized the reduction of TOC, TN and TP content of the effluent (Metcalf \& Eddy et al. 2004). This has created the emergence of biological methods for wastewater treatment. The current European Union (EU) urban wastewater treatment directive (UWWTD) defines strict discharge parameters of WWTP effluent (91/271/EEC 1991) (Table 1).

Table 1. Wastewater discharge parameters according to the UWWTD from 1991.

\begin{tabular}{cc}
\hline Parameter & Concentration $\mathrm{m} \mathrm{L}^{-1}$ \\
\hline COD & 125 \\
$\mathrm{BOD}_{5}$ & 25 \\
TSS & 35 \\
TN & 15 \\
TP & 2 \\
\hline
\end{tabular}

The current challenges of the wastewater treatment come with the new demanding requirements, addressing climate changes, carbon footprint and establishment of circular economy. Lower energy input, nutrient recovery, minimizing chemicals use and wastewater recycling are the main objectives of the current WWT engineering. Wastewater treatment processes and plants are aging, and the existing technology has limitations in performance and energy consumption. Still, the old technology is in use, and it has been challenging to comply with the new strategy. 


\subsection{Photoautotrophic microalgae and cyanobacteria}

\subsubsection{Oxygenic photosynthesis}

\subsubsection{Light driven redox reactions of photosynthesis}

Light reactions of photosynthesis take place in the thylakoid membranes of cyanobacteria and chloroplasts. Figure 4 shows a simplified scheme of the light reactions. A central role in photosynthesis is played by two protein-pigment complexes, Photosystem I (PS I) and Photosystem II (PS II). PS I and PS II are associated with light-harvesting complexes (LHC). In eukaryotes, chlorophylls and carotenoids participate in light harvesting, whereas in cyanobacteria also bilins are important light harvesting pigments. PS II contains in its reaction centre a group of chlorophylls called P680, absorbing $680 \mathrm{~nm}$ photons. PS I's reaction centre chlorophyll dimer absorbs $700 \mathrm{~nm}$ photons and is therefore called P700.

The pigment molecules in LHCs are capable of absorbing higher energy photons from a broad visible light spectral range. The pigment molecules of LHCs transfer the excitation energy to P680 and P700 via resonance (Clegg et al. 2010).

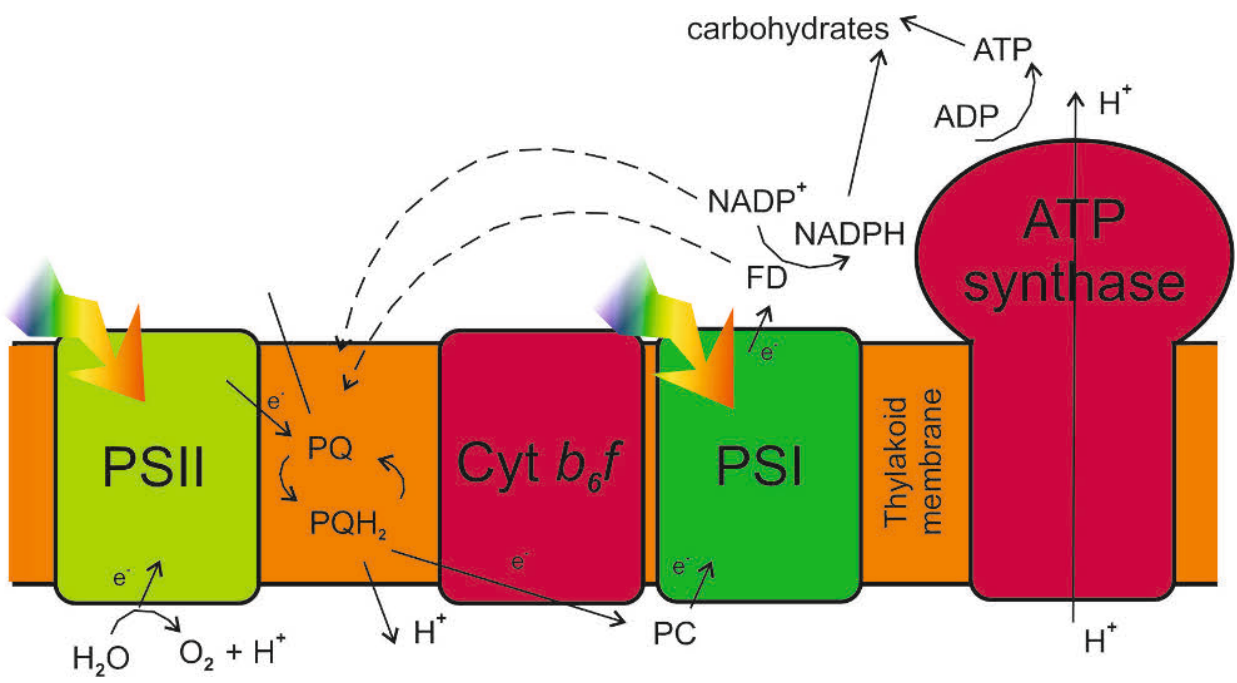

Figure 4. Simplified model of the photosynthetic apparatus consisting of two photosystems (PS I and PS II), cytochrome $b_{6} f$ complex (Cyt $b_{6} f$ ) and adenosine triphosphate synthase (ATP synthase). The figure has been provided by Heta Mattila.

In oxygenic photosynthesis, oxygen evolving complex (OEC) oxidizes water to oxygen, four protons and four electrons. This reaction takes place in PS II on the side that faces the thylakoid lumen. OEC is a manganese containing cofactor of PS II. 
Theoretically a minimum of 4 photons are necessary to oxidize 2 water molecules to one molecule of oxygen. This generates 4 protons that will accumulate in the lumen. The electrons from this reaction are used to reduce the $\mathrm{P} 680^{+}$, hence the driving force for the water oxidation reaction is photon absorption by LHC II and consequent oxidation of P680. Electrons from water oxidation are carried via an electron transfer chain. Differences in redox potentials of the carriers enables electron transport via oxidation-reduction reactions. Electrons from excited P680 are carried inside PS II via plastoquinone molecules $\mathrm{Q}_{\mathrm{A}}$ and $\mathrm{Q}_{\mathrm{B}}$. $\mathrm{Q}_{\mathrm{B}}$ needs two electrons to be fully reduced. Once fully reduced $\mathrm{Q}_{\mathrm{B}}$, called plastoquinol $\left(\mathrm{PQH}_{2}\right)$, is released and diffuses through the thylakoid membrane to cytochrome $b_{6} f$ complex (Fig. 4). The cytochrome $\mathrm{b}_{6} f$ complex acts as a mediator between PS II and PS I, by transferring the electrons from plastoquinol to the water soluble plastocyanin (PC) on the luminal side. PC reduces P700 of PS I, after light induced charge separation. The electrons from P700 through series of reduction-oxidation reactions, are carried to ferredoxin (FD). FerrodoxinNADP reductase catalyses the reduction of $\mathrm{NADP}^{+}$to NADPH by FD. During the electron transfer, a proton gradient accumulates across the thylakoid membrane. This gradient is utilized by the ATP-synthase.

\subsubsection{Carbon fixation reactions}

The ATP and NADPH produced during the light-driven reactions of photosynthesis are utilized in the Calvin- Benson cycle (Fig. 5).

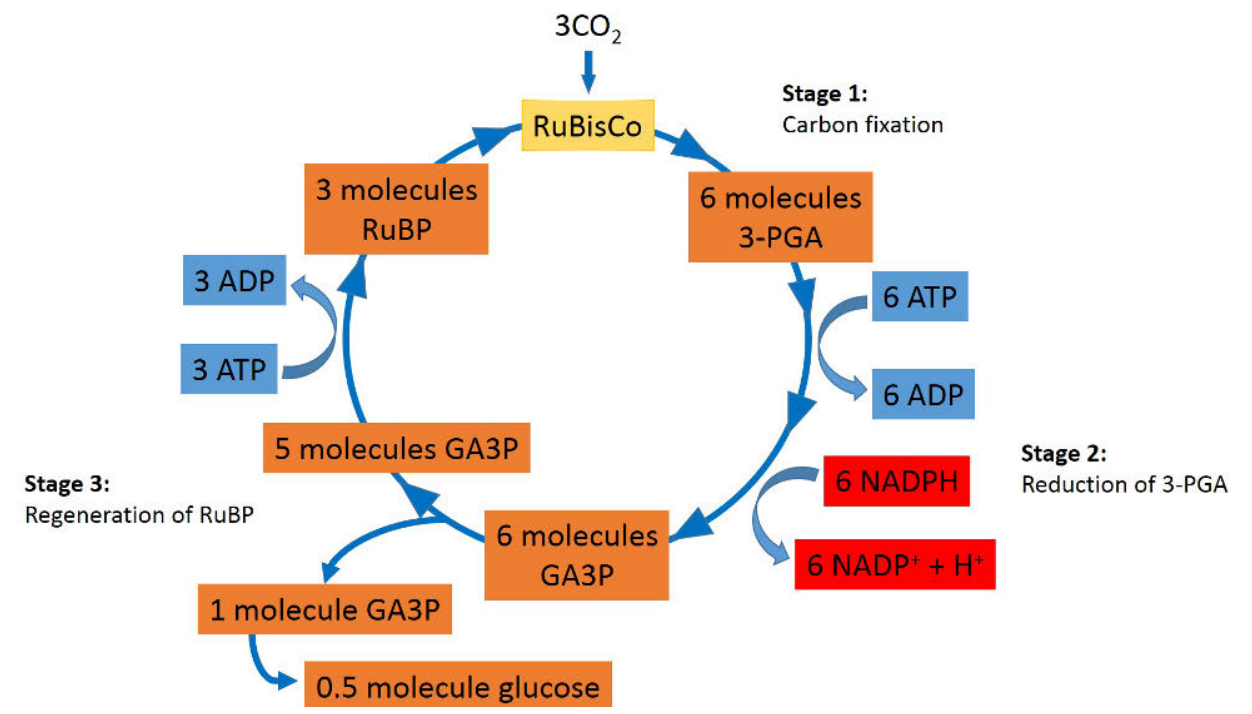

Figure 5. Reactions of the Calvin- Benson cycle occurring in three distinguished phases. RuBisCoRibulose-1,5-bisphosphate carboxylase/oxygenase; 3-PGA- 3-Phosphoglyceric acid; GA3P- Glyceraldehyde 3-phosphate; RuBP- ribulose bisphosphate. 
The Calvin-Benson cycle takes place in the chloroplast stroma in microalgae and in the cytoplasm of cyanobacteria. The cycle goes through three stages: carbon fixation, reduction and regeneration (Fig. 5). During carbon fixation, $\mathrm{CO}_{2}$ is bound to ribulose bisphosphate (RuBP) resulting in 2 molecules 3-phosphoglycerate (3-PGA). This stage is catalysed by RuBP carboxylase or RuBisCo. In the reduction stage, the NADPH and ATP produced during light reactions of photosynthesis are used for the reduction of 3-PGA to glyceraldehyde 3-phosphate (GA3P). GA3P is used as a precursor for the synthesis of glucose and other carbohydrates and utilized in the regeneration stage that recovers RuBP for the next round of the cycle with the help of ATP.

\subsection{Nutrient requirements of photoautotrophic microbes}

\subsubsection{Macronutrients}

\subsubsection{Carbon $(\mathrm{C})$}

Carbon is the most abundant element in any living organism. Microalgae and cyanobacteria grown autotrophically use inorganic carbon $\left(\mathrm{C}_{\mathrm{i}}\right.$, including $\mathrm{CO}_{2}, \mathrm{HCO}_{3}{ }^{-}$ and $\left.\mathrm{CO}_{3}{ }^{2-}\right)$ as main carbon source. In aquatic conditions, due to physiologically relevant $\mathrm{pH}$ values, $\mathrm{C}_{\mathrm{i}}$ is mainly present as $\mathrm{HCO}_{3}{ }^{-}($Colman et al. 2002). For carbon fixation to work efficiently in aquatic conditions, $\mathrm{CO}_{2}$ has to be present in high concentrations at the RuBisCo active site. Therefore, microalgae and cyanobacteria have developed carbon concentrating mechanisms (CCMs) that accumulate a high intercellular concentration of $\mathrm{CO}_{2}$. CCMs differ among microalgae and cyanobacteria. However, $\mathrm{CCMs}$ share three main characteristics: active transport via transporter molecules of $\mathrm{CO}_{2}$ and $\mathrm{HCO}_{3}{ }^{-}$across the plasma membrane; assistance from different extracellular and intracellular carbonic anhydrases (CAs); special cellular compartment where RuBisCo is located.

The alkaline $\mathrm{pH}$ of microalgal and cyanobacterial cytoplasm as well as the chloroplast stroma of microalgae in the light favours $\mathrm{HCO}_{3}{ }^{-}$as the dominant $\mathrm{C}_{\mathrm{i}}$ species. $\mathrm{CO}_{2}$ uptake is done with the help of different classes of $\mathrm{CA}$ associated transporters, catalysing the reversible conversion between $\mathrm{CO}_{2}$ and $\mathrm{HCO}_{3}{ }^{-}$. In Chlamydomonas besides the plasma membrane, also the chloroplast envelope membrane contains transporters and CAs. Since RuBisCo cannot fix $\mathrm{C}_{\mathrm{i}}$ in the form of $\mathrm{HCO}_{3}-\mathrm{HCO}_{3}$ must be converted to $\mathrm{CO}_{2}$. This is catalysed by CAs. In microalgae, $\mathrm{HCO}_{3}{ }^{-}$is converted to $\mathrm{CO}_{2}$ in the thylakoid lumen via lumenal CA. RuBisCo in microalgae is located in a specialized micro-compartment called pyrenoid. How 
exactly $\mathrm{CO}_{2}$ from the lumen is transferred to the pyrenoid is unclear. In some cases, thylakoid tubules have been shown to enter the pyrenoid, suggesting a possible way of transfer of the lumenal $\mathrm{CO}_{2}$ to RuBisCo (Wang et al. 2015). In cyanobacteria, RuBisCo is located in carboxysomes, situated in the cytosol. Besides RuBisCo, a cyanobacterial carboxysome contains $\mathrm{CA}$ that catalyses the conversion of $\mathrm{HCO}_{3}{ }^{-}$to $\mathrm{CO}_{2}$, available for RuBisCo.

\subsubsection{Nitrogen $(\mathrm{N})$}

Nitrogen comes as a fourth most abundant element of biomass, after $\mathrm{C}, \mathrm{O}$ and $\mathrm{H}$. Autotrophic microalgae and cyanobacteria can utilize inorganic nitrogen species, most common of which are $\mathrm{NH}_{4}{ }^{+}, \mathrm{NH}_{3}$ and $\mathrm{NO}_{3}{ }^{-}$. Ammonium diffuses through porine channels in the plasma membrane (Falkowski 1975; Boussiba and Gibson 1991; Perez-Garcia et al. 2011b), and the actual diffusion through the AMT or Rh channels probably occurs in the form of $\mathrm{NH}_{3}$ (Kim et al. 2005; Baday et al. 2015). $\mathrm{NH}_{3}$ can also diffuse through the plasma membrane. Nitrate is actively transported across the membrane via nitrate specific membrane transporters (Flynn 1991; Lara et al. 1993). Once inside the cell, nitrate is converted to ammonium. This two-step, enzyme catalysed process involves two enzymes - nitrate reductase (NR) and nitrite reductase (NiR). Intracellular ammonium is incorporated into cell biomass via the glutamine/glutamate pathway (Gln/Glu) that can be summarized with Equations 2 and 3:

$$
\begin{gathered}
\mathrm{NH}_{4}^{+}+\mathrm{Glu} \rightarrow \mathrm{Gln} \\
\mathrm{Gln}+2-\mathrm{OG} \rightarrow 2 \mathrm{Glu}
\end{gathered}
$$

where 2-OG is 2-oxoglutarate

Nitrogen and carbon assimilation in microalgae and cyanobacteria are in close relation, since nitrogen uptake is controlled by metabolites from the carbon fixing Calvin- Benson cycle. It has been proposed by Flynn (1991) that Gln, 2-oxoglutarate (2-OG) and the resulting Gln/2-OG ratio. A low intracellular concentration of ammonium lowers the Gln/2-OG ratio that triggers several metabolic responses, observed in algal cells under nitrogen deprived conditions (Flynn 1991). Under low Gln/2-OG ratio, decrease in photosynthetic rate and activation of enzymes responsible for the assimilation of different nitrogen sources, such as nitrogen, ammonium, urea and amino acids, have been reported (Hipkin and Syrett 1977). On the other hand, insufficient $\mathrm{C}_{\mathrm{i}}$, with regard to the intracellular ammonium concentration, will result in high cellular Gln/2-OG ratio, causing inactivation of the different nitrogen transporters and assimilatory enzymes (Flynn 1991). However, in high ammonium concentrations at alkaline conditions, ammonia is the dominant species. Insufficient $C_{i}$ will result in increase of the intracellular ammonium 
concentration, since the cells cannot control ammonia diffusion. This will create unfavourable conditions for the cells, since high ammonium concentrations inside the cell have been proven damaging for PS II, inhibiting photosynthetic growth (Drath et al. 2008).

\subsubsection{Phosphorus (P)}

Phosphorus is an essential element in algal and cyanobacterial biomass. Phosphorus in solution, depending on $\mathrm{pH}$, can exist as phosphoric acid $\left(\mathrm{H}_{3} \mathrm{PO}_{4}\right)$, dihydrogen phosphate ion $\left(\mathrm{H}_{2} \mathrm{PO}_{4}^{-}\right)$, hydrogen phosphate ion $\left(\mathrm{HPO}_{4}{ }^{2-}\right)$ and phosphate ion $\left(\mathrm{PO}_{4}^{3-}\right.$ ) (Wagh 2016). For autotrophic suspended culture of microalgae and cyanobacteria, the most relevant form of inorganic $\mathrm{P}$ is $\mathrm{HPO}_{4}{ }^{2-}$, since it is the dominant species between $\mathrm{pH} 7.2$ and 12.37 .

Nitrogen uptake is in direct relation with bioavailable phosphorus in the culture medium. Redfield (1934) after researching marine phytoplankton has observed that $\mathrm{N}$ and $\mathrm{P}$ composition of the oceans, on the average, is similar to the $\mathrm{N}: \mathrm{P}$ molar ratio of marine phytoplankton. This ratio is known today as Redfield ratio, where N:P is 16:1. However, microalgal and cyanobacterial cells have species-specific N:P ratios differing from the average. In some cases that difference can be used as a selective pressure. By changing the $\mathrm{N}: \mathrm{P}$ ratio of the culture medium, one could promote the growth of one microalgal or cyanobacterial species over another. It has also been shown that increasing the $\mathrm{P}$ content of culture medium can enable, to a certain extent, higher nitrogen uptake.

Both low and high affinity phosphate transporters have been found in a few microalgal and cyanobacterial species. Low affinity transporters are induced in high phosphate conditions and result in slower uptake rate. High affinity transporters are triggered in low phosphate conditions and increase the rate of phosphate uptake. Besides being building blocks for proteins, lipids and nucleic acids, phosphate plays roles in cell signalling and stress responses.

\subsubsection{Sulphur (S)}

Autotrophic cultures of microalgae and cyanobacteria utilize inorganic sulphur in the form of sulphate $\left(\mathrm{SO}_{4}{ }^{2-}\right)$. However, both groups are capable of cleaving sulphur from organic molecules, such as sulphate esters via extracellular arylsulfatases. Furthermore, it has been shown for Synechococcus 6301 and Anabaena variabilis that they can absorb sulfur containing cysteine, methionine and glutathione (Schmidt 1988). Sulphate is transported inside the cells via active transport (Pollock et al. 2005). Inside the cell, sulphate is firstly reduced to sulphite $\left(\mathrm{SO}_{3}{ }^{2-}\right)$ and then to sulphide $\left(\mathrm{S}^{2-}\right)$ through several reactions involving ATP sulfurylase, APS reductase 
and sulphite reductase (Saito 2000; Ratti and Giordano 2008). Finally, sulphide reacts with serine to form cysteine which is the first stable sulphur organic form in sulphate metabolism (Ratti and Giordano 2008). Cysteine is a precursor for methionine and other sulphur containing organic molecules. Sulphur containing compounds play vital roles in acclimation to different stress conditions such as osmotic stress, toxic metals and oxidation.

\subsubsection{Metal micronutrients involved in photosynthesis}

Micronutrients with metal nature are essential for all living organisms and also parts of the photosynthesis machinery. The following chapter will give a brief summary on metal micronutrients involved in photosynthesis. Therefore, molybdenum and cobalt will not be discussed, since they do not have direct relation with photosynthesis. The emphasis is on micronutrients that often limit the growth of photosynthetic organisms, and therefore magnesium and calcium are not discussed, despite of their high importance.

Iron $(\mathrm{Fe})$ is an essential micronutrient for all living organisms. Iron is engaged as a co-factor in many haem and non-haem photosynthetic proteins such as Fe-S proteins, involved in redox processes (Hänsch and Mendel 2009).

During growth in iron depleted conditions, cyanobacterial cells undergo changes in the organisation of the photosynthetic machinery. Amount of PS I complex decreases, suggesting that PS I is more dependent on iron availability than PS II. Amount of phycobilisomes is reduced as well, possibly because the proteins involved in their synthesis are iron containing proteins (Barber et al. 2006). In microalgae, iron deficiency has been shown to affect the overall photosynthetic activity and supress cell growth (López-Millán et al. 2000; Andaluz et al. 2006; Terauchi et al. 2010; Paper II). On the other hand, supplementing growth medium with iron up to $10^{-5} \mathrm{~mol} \mathrm{l}^{-1}$, significantly improved growth rate, cell densities and lipid accumulation of microalgae from Chlorella genus (Liu et al. 2008; Wan et al. 2014).

Copper $(\mathrm{Cu})$ plays role in electron transfer from cytochrome $f$ of the cytochrome $\mathrm{b}_{6} f$ complex to $\mathrm{P} 700+$, as part of the active site of plastocyanin. This makes it crucial to the normal operation of the photosynthetic process in microalgae. However, excess $\mathrm{Cu}$ can be extremely toxic. Toxicity levels of $\mathrm{Cu}$ may vary among microalgae and cyanobacterial species. It has been shown that microalgae cultivated in elevated $\mathrm{Cu}$ concentrations show enhanced production of glutathione, proline and thiols. Furthermore, under the same conditions, higher activity of superoxide dismutase (SOD) has been observed. It has been suggested that these metabolites might be involved in defence toward toxic concentrations of $\mathrm{Cu}$ (Rijstenbil et al. 1994; Tripathi and Gaur 2004). 
Manganese (Mn), bound to PS II, is involved in the water splitting reaction (Barber 2003). Zinc (Zn) containing superoxide dismutase converts the superoxide radical to $\mathrm{H}_{2} \mathrm{O}_{2}$. Zinc is also involved in $\mathrm{CO}_{2}$ assimilation, as a co-factor of carbonic anhydrase, and lack of zinc disturbs photosynthesis in plants (Jelakovic et al. 2003).

\subsection{Biotechnological application of microalgae and cyanobacteria}

Microalgae and cyanobacteria are diverse groups with various metabolisms, and their biotechnological potential has been proven by extensive research for food, feed and healthcare applications. Their biomass is a great source for several biochemical compounds such as starch, pigments, fatty acids, ethanol, glycerol, biotoxins and others. Microalgae and cyanobacteria have been promising candidates for bioenergy production and wastewater treatment.

Products derived from microalgal and cyanobacterial biomass can be classified as edible and non-edible, or high and low-value products. Even though cyanobacteria have been used as food since ancient times in Mexico and Chad, we have just 60 years of commercial production experience (Masojídek and Prášil 2010; Chu 2012; Borowitzka 2013). The pioneer species cultured on a commercial scale was green alga Chlorella in 1950 - 1960, followed by cyanobacterium Arthrospira in 1970 (Masojídek and Prášil 2010; Wijffels et al. 2013). China, Israel, Australia, USA and India have established industrial scale production for high-value products from microalgae and cyanobacteria. The main products are food supplements and additives such as eicosapentaenoic acid (EPA) and docosahexaenoic acid (DHA) (omega-3-fatty acids), beta-carotene, astaxanthin and beta-glucan (Pulz and Gross 2004; Spolaore et al. 2006).

With the approaching energy crisis, climate change and environmental concerns, great efforts are being laid toward bioenergy production from microalgae and cyanobacteria. The concepts of production of biodiesel and bioethanol have been technologically proven but it has been challenging to establish economically feasible algal/cyanobacterial based bioenergy processes. Nevertheless, researchers are still working on improvement and optimization of bio-based energy production in order to increase productivity and to lower the investment and operational costs of an industrial scale process.

Microalgae and cyanobacteria may also utilize pollutants as nutrients. Combining biomass production with wastewater treatment could help towards economically feasible bioenergy production. Furthermore, significant steps toward sustainable industry could be achieved via genetic modifications. 
An ideal hypothetical scenario is presented in Figure 6, showing the production of high and low value compounds from microalgae or cyanobacteria combined with wastewater treatment process.

\section{Wastewater}

Microalgae / Cyanobacteria

\section{Discharge quality water Low value products High value products}

Figure 6. A combined process for wastewater treatment and biomass production, showing hypothetical biotechnological application of microalgae and cyanobacteria.

\subsection{PBRs for suspended growth}

\subsubsection{Open systems}

Open systems have surfaces exposed to the environment. A typical example of an open PBR is a high rate algal pond (HRAP). Those were the first PBRs to be used on a large scale (Ugwu et al. 2008). They are technologically simple to construct and operate, which gives them an advantage when considering investment and operational costs. However, due to being exposed to the environment, process control is challenging. Contamination from other photoautotrophic microorganism, bacteria and zooplankton is highly possible, hence maintaining an axenic culture is difficult. Therefore, open systems can be used in specific scenarios, with fast growing cyanobacteria or extremophile species (Hayes et al. 2018). HRAP systems are known for poor mixing of the suspended culture, which results in uneven light distribution among the photoautotrophic cells (Ugwu et al. 2008). This causes nonoptimal growth conditions, leading to low cell densities and low volumetric productivities. Low biomass concentrations (cell densities) in open ponds are one more reason for increased chance of contamination (Deruyck et al. 2019). HRAP systems can be constructed only horizontally, which results in a large land requirement. 


\subsubsection{Closed PBRs}

Closed PBRs evade the drawbacks related with HRAPs (Borowitzka 1999). Closed systems are isolated from the environment and have to be constructed from transparent material like glass or acrylic. Complete isolation allows for precise process control. Specific operational parameters can be set, giving optimal conditions for the organism of interest. This allows microalgal and cyanobacterial cells that cannot be cultured in open systems to be easily grown in closed PBRs. Maintaining an axenic culture on an industrial scale is difficult and expensive but in a closed system, it can be easy to keep the species of interest as dominant. Closed systems are characterized with better mixing than HRAPs and with lower chance of contamination. With all the advantages stated above over the HRAP, closed PBRs are characterized with better light distribution, higher cell densities and higher volumetric productivities (Wang et al. 2012). However, open ponds are more commonly used on an industrial scale, due to their lower investment cost compared to closed systems (Wang et al. 2012; Hayes et al. 2018). Examples of closed PBRs used as a production system are tubular and flat panel PBRs. Excellent summary table, comparing open ponds and closed PBRs, has been presented by Jämsä (2019).

\subsection{Genetically modified photoautotrophs}

Already in 1996, an excessive research done in USA (Algae Species Programme) has concluded that in order to obtain price competitive biofuels from microalgae, genetic modification would be necessary (Sheehan et al. 1998). Recent developments in molecular-genetic techniques and technologies have shown promising progress in strain modification. The desired improvements necessary for the use of microalgae and cyanobacteria in economically feasible industrial and aquaculture processes has been described by Wijffels et al. (2013) and can be listed as follows:

1. Enhancement of cell's performance and photosynthetic efficiency under different environmental conditions (light and temperature fluctuations) caused by seasonal changes.

2. Increased productivity of the metabolite of interest as well as introduction of novel metabolic pathways.

3. Minimizing environmental risk when using genetically modified microalgae and cyanobacteria for industrial scale processes.

Control challenges in outdoor cultivation of microalgae and cyanobacteria are related to rapid changes in light intensity and temperature (Grobbelaar 2008). Temperature control in upstream processing of microalgae is crucial in order to 
establish optimal growth conditions (Béchet et al. 2010). Thermophilic cyanobacteria that can grow in high temperatures (Miyamoto et al. 1979) but most microalgal and cyanobacterial species with industrial applications have a temperature optimum between 20 and $30^{\circ} \mathrm{C}$ (Béchet et al. 2010). Identification of the genes responsible for high-temperature tolerance can enable the creation of heat tolerant strains that can produce valuable compounds. A recent study by Su et al. (2017) revealed that overexpression of stress tolerance proteins HspA and osmotin in the cyanobacterium Synechococcus elongatus enables cultivation of the mutant in high salt, high light and high temperature conditions in a closed outdoor PBR. Acclimation of cyanobacteria to stress conditions is regulated via group $2 \sigma$ factors of the RNA polymerase (RNAP) (Nikkinen et al. 2011; Rantamäki and Tyystjärvi 2013; Antal et al. 2016; Hakkila et al. 2019). Those $\sigma$ factors regulate the expression of genes responsible for certain stress acclimations (Koskinen et al. 2016). Group 2 $\sigma$ factors of the cyanobacterium Synechocystis sp. PCC 6803 consists SigB, SigC, SigD and SigE (Imamura et al. 2003). Through extensive studies performed with knockout mutants of PCC 6803, where triple inactivation strains (triple mutants), lacking 3 out of 4 group $\sigma$ factors 2 as well as strain lacking all (quadruple mutant), the roles of each member of the group $2 \sigma$ factors has been determined and can be seen summarized in Table 1 of Paper III. Those results show the potential of manipulating the expression levels of group $2 \sigma$ factors to produce a robust strain for biotechnological applications (Stensjö et al. 2018). Furthermore, further investigation of Synechocystis $\sigma$ mutants could potentially give a solution to the problems related with large-scale application of genetically modified microalgae and cyanobacteria and the environmental hazard risk that they bring. Cyanobacterial mutants could be designed as sigma knockout mutants, lacking certain sigma factors. Such mutants could be tuned to be less competitive in the environment, minimizing the risk of environmental contamination with GMOs, while being capable of tolerating fluctuating temperatures and light intensities.

Reduction in antenna size is beneficial in algal cultivation and could minimize energy loss caused by heat and fluorescence. Furthermore, small antenna could promote biomass accumulation due to more light available for the microalgae inside the reactor volume (Beckmann et al. 2009; Ort and Melis 2011).

Improving Rubisco carboxylation activity would result in increased $\mathrm{CO}_{2}$ fixation and biomass productivity. In Chlamydomonas reinhardtii, (Genkov et al. 2010) has successfully expressed a hybrid Rubisco enzyme consisting of a plant small subunit (from spinach, Arabidopsis, sunflower) and an algal large subunit. Even though the hybrid enzyme showed higher $\mathrm{CO}_{2} / \mathrm{O}_{2}$ specificity, typical for plants, it did not show changes in the overall carboxylation activity when compared with Rubisco from Chlamydomonas wild type (wt). However, research in those areas are encouraging 
in our pursuit of algal and cyanobacterial strains with faster growth, denser cultures and higher PBR productivities.

Studies on algal and cyanobacterial metabolites have often focused on lipid productivity in microalgae, due to potential applications in biofuel and food production. The preferred fraction of lipids for industrial applications is triacylglycerols (TAGs). Some microalgae accumulate triacylglycerols when exposed to nitrogen limited conditions (Pruvost et al. 2011; Bondioli et al. 2012; Breuer et al. 2012). However, under such conditions, cell growth is negatively influenced, resulting in low biomass productivity and low overall lipid productivity. Understanding the mechanisms behind lipid accumulation might enable its improvement without arresting cell growth (Wijffels and Barbosa 2010).

Several successful attempts have been made for ethanol, sucrose and isoprene production via recombinant cyanobacterial cells and metabolic pathway engineering (Deng and Coleman 1999; Lindberg et al. 2010; Ducat et al. 2012).

Another way to enable economically feasible production of value compounds from microalgae and cyanobacteria is to stimulate extracellular secretion of the desired metabolite. This would significantly decrease downstream processing cost. A genetically manipulated process for extracellular recombinant protein secretion has been designed for the green alga Chlamydomonas reinhardtii. Lauersen et al. (2013) managed to utilize the native secretion signal for CA of Chlamydomonas reinhardtii to secrete a recombinant protein in the culture medium (Lauersen et al. 2013).

\subsection{Photoautotrophs in wastewater treatment}

The idea of microalgae-based wastewater treatment was first proposed by Oswald et al. 1957 after investigating oxygen supply in oxidation ponds. Nowadays microalgae and cyanobacteria are considered promising for nutrient recovery in wastewater treatment. Multiple studies have proved the potential of microalgae and cyanobacteria for nitrogen and phosphorus removal from a variety of wastewater streams (González et al. 1997; Wilkie and Mulbry 2002; Ruiz-Marin et al. 2010; Chinnasamy et al. 2010; Wang et al. 2010; Riaño et al. 2012; Hernández et al. 2013; Sutherland et al. 2014; Michels et al. 2014; Hernández et al. 2016; Jämsä et al. 2017; Paper II). In USA and Canada two companies, Bio-Recovery System, Inc. and BV Sorbex, Inc. have developed immobilized microalga products that can achieve 99\% heavy metal removal (Molinuevo-Salces et al. 2019). Furthermore, microalgae and cyanobacteria produce $\mathrm{O}_{2}$ as a by-product of photosynthesis. In activated sludge process, up to $50 \%$ of the electricity consumed by an entire wastewater treatment plant is used to supply oxygen for the heterotrophic bacteria (Stoica et al. 2009). On the other hand, heterotrophic bacteria release $\mathrm{CO}_{2}$. Studies performed with mixed 
cultures of microalgae and heterotrophic bacteria have shown promising results in COD reduction of wastewaters with high organic content (Hernández et al. 2013, 2016). A combined microalgal-bacterial system reduces the carbon footprint of wastewater treatment.

Arguably, the main benefit of using microalgae in wastewater treatment is their versatile biotechnological application. The opportunity to combine wastewater treatment with production of low and high value compounds could significantly help to achieve an economically feasible process (Mulbry et al. 2008; Gouveia 2011).

The features mentioned above enable the possible application of microalgae and cyanobacteria in the secondary or tertiary stage of a wastewater treatment. However, there are several bottlenecks. Optimal light conditions should be applied. Day-night cycles and seasonal light availability have major impacts over the design and operation of such a wastewater treatment process; artificial light will probably not be economically feasible. Furthermore, the high turbidity and dark colour of wastewaters reduce light available for photosynthesis. Therefore, pre-treatment methods should be adopted such as sedimentation, coagulation/flocculation or filtration (Molinuevo-Salces et al. 2019; Roselet et al. 2019). Those methods will increase the investment and operational cost. PBR design is heavily influenced by light utilization, which presents a challenge for large-scale photoautotroph-based wastewater treatment. HRAPs, so far, seem to be more appropriate for wastewater treatment, since they are cheap to construct and up-scale.

Another bottleneck is the presence of certain inorganic elements in specific ratios. Optimal C:N:P ratio in wastewater is necessary for efficient nutrient uptake (Michels et al. 2014; Molinuevo-Salces et al. 2019). Furthermore, low availability of certain micronutrients, such as iron, copper, zinc and manganese can cause growth arrest (Posadas et al. 2013; Markou et al. 2014; Paper II). 


\section{AIMS OF THE STUDY}

Microalgae uptake and utilize nutrients efficiently, suggesting that they might be excellent alternatives for wastewater treatment (Selvaratnam et al. 2015). Furthermore, the use of wastewaters as growth media for microalgae would allow low-operational-cost industry that specifically aims at production of algal biomass and valuable algal compounds (Kligerman and Bouwer 2015). Due to the interest in microalgae, PBR systems have become popular among researchers and wastewater treatment companies.

In this thesis, the aim was to investigate the potential of microalgae and cyanobacteria in wastewater purification by utilizing actual wastewaters generated from several conventional industrial and waste management processes. Furthermore, we have designed and constructed an up-scale photobioreactor as more realistic approach to the evaluation of possible challenges that might occur on an industrialscale. We have also made an effort to look into the potential application of genetically modified cyanobacteria in wastewater treatment. To summarize, this thesis aims at the following:

1. To investigate the possibility of high value compounds production from microalgae grown in wastewaters.

2. To design and create an algal- based wastewater treatment process with pilot scale tubular PBR.

3. To investigate the potential of genetically modified cyanobacterial cells in wastewater treatment applications.

The relation between the content of this thesis with the scientific papers presented with it are shown via Venn diagram in Figure 7. 


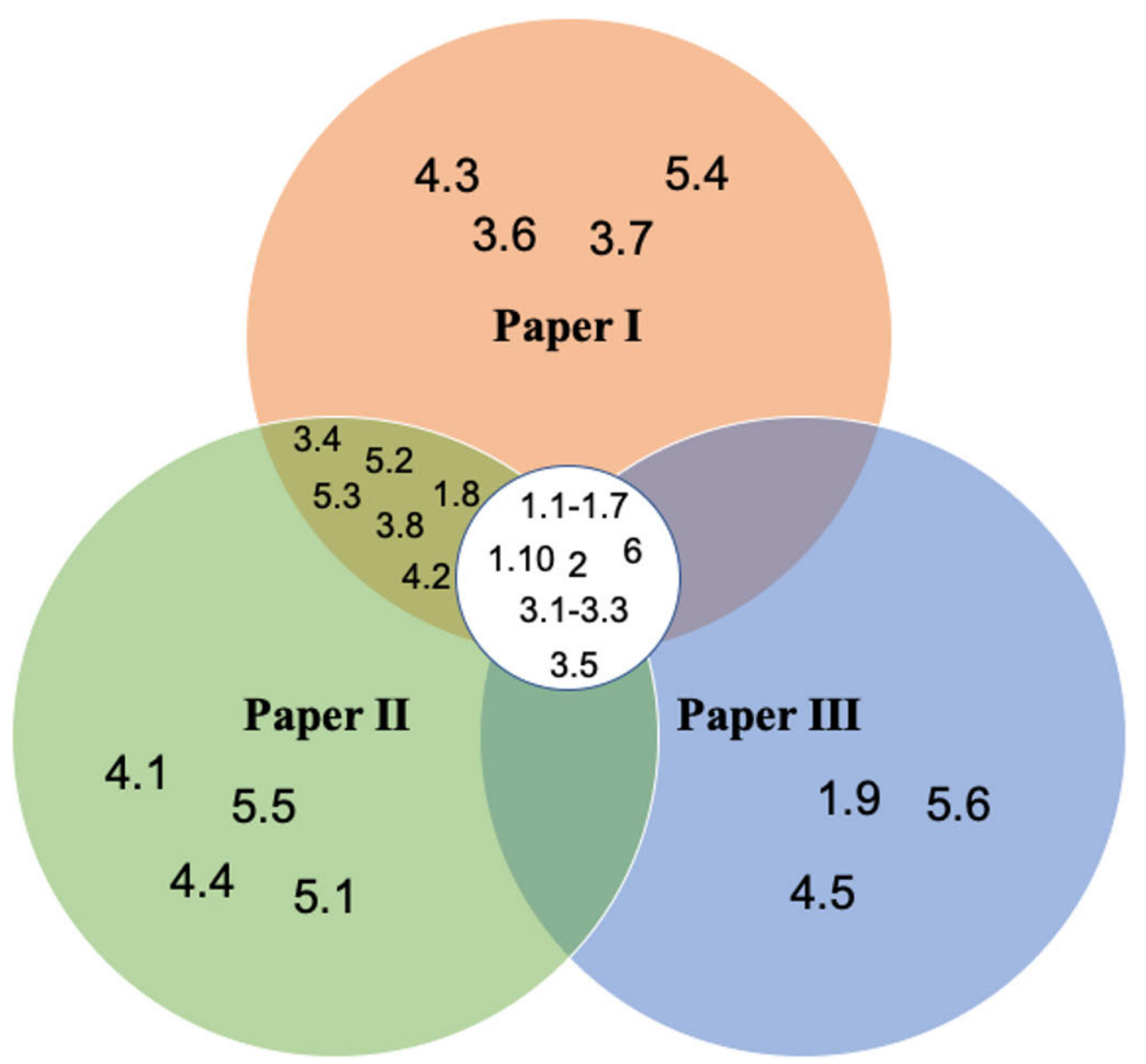

Figure 7. Venn diagram showing the relationship between the chapters and subchapters (Arabic numbers) of this thesis book with the scientific publications (Paper I, II and III) presented with it. 


\section{METHODOLOGY}

\subsection{Wastewaters}

During the course of these studies, we used several types of wastewater provided by our industrial partners - UPM-Kymmene Oyj and Helsingin Seudun Ympäristöpalvelut (HSY) (Table 2)

Table 2. Origin and pre-treatments of waste waters. PAC- powdered activated carbon; GACgranulated activated carbon.

\begin{tabular}{|c|c|c|c|c|}
\hline Name & Wastewater stream & Provider & Pre-treatment & Paper \\
\hline DER & Digest effluent & UPM & $\begin{array}{l}\text { flocculation }+ \text { PAC filtration } \\
+0.22 \mu \mathrm{m} \text { cup filter }\end{array}$ & 1 \\
\hline WWTPE & $\begin{array}{l}\text { wastewater treatment plant } \\
\text { effluent }\end{array}$ & UPM & 0.22 um filtration & I \\
\hline KA2 & landfill leachate & HSY & $\begin{array}{l}\text { GAC filtration } \\
+0.1 \text { PVDF filtration }\end{array}$ & II \\
\hline KA2 & landfill leachate & HSY & $\begin{array}{l}\text { PAC filtration } \\
+0.22 \mu \mathrm{m} \text { cup filter }\end{array}$ & III \\
\hline Biowasher & $\begin{array}{l}\text { leachate from aerobic } \\
\text { reactor for solid wastes }\end{array}$ & HSY & $\begin{array}{l}\text { PAC filtration } \\
+0.22 \mu \mathrm{m} \text { cup filter }\end{array}$ & Thesis \\
\hline TAL1 & mix of wastewaters streams & HSY & $\begin{array}{l}\text { PAC filtration } \\
+0.22 \mu \mathrm{m} \text { cup filter }\end{array}$ & Thesis \\
\hline
\end{tabular}

The excess activated sludge, collected from a wastewater treatment plant servicing a mixture of process wastewaters from a paper/pulp factory and municipal wastewaters in Rauma, Finland was anaerobically digested in laboratory scale bioreactors as described in Paper I. To remove solids, the raw digester effluent (DER) was first treated with SuperFloc C-581 flocculant, then the supernatant was further treated with powdered activated carbon (PAC) and filtrated through a mesh filter. Finally, the purified form of the digester effluent (DE) was prepared by filter sterilizing DER with a $0.22 \mu \mathrm{m}$ bottle top cup filter and stored at $4{ }^{\circ} \mathrm{C}$ until use. Nutrient and heavy metal compositions of DER are shown in Tables 1 and 2 of Paper I, respectively. The analysis was done by Labtium Oy (Espoo, Finland) with 
inductively coupled mass spectrometry. Nitrate and ammonium were determined with ion-selective electrodes (Thermo Fischer Scientific, Waltham, MA, USA). As DER is very rich in ammonium and magnesium, DE was typically diluted with either distilled water or with wastewater treatment plant effluent (WWTPE) prior to use. WWPTE was collected from the same wastewater treatment plant as the excess activated sludge used for DER production, filter sterilized and stored at $4{ }^{\circ} \mathrm{C}$ until use.

KA2 from HSY is groundwater contaminated with leachate seeping through the bottom structures of an anaerobic landfill. In large scale experiments (Paper II), turbid yellowish-orange KA2 was first filtered through a granular activated carbon unit by pumping KA2 through a $20 \mathrm{~L}$ canister filled halfway with granular activated carbon in up-flow manner, and thereafter through a $0.1-\mu \mathrm{m}$ drinking water polyvinylidene difluoride (PVDF) membrane filter. In small scale purification (Paper III), KA2 solids were removed with PAC and the liquid was sterilized with a $0.22 \mu \mathrm{m}$ filter.

Biowasher is leachate from an aerobic reactor for solid waste whereas TAL1 is a mixture of KA2, Biowasher and all other wastewater streams that are generated on a solid waste management site of HSY. Biowasher and TAL1 were pre-treated with PAC and filter sterilized (Table 2). Ammonium, nitrate, phosphate and sulphate were determined spectrophotometrically using Spectroquant test kits 100683, 114773, 114848, 101812, respectively (Merck Millipore, Merck, Germany). The measurement protocols were adapted to Genesys 10S UV-VIS (Thermo Fisher Scientific, US) spectrophotometer and $10 \mathrm{~mm}$ cuvettes. Calibration curves were obtained for each test kit (Paper II, Figs. S2, S3, S4 and S5). BOD and COD analyses were performed by Ramboll Oy (Lahti, Finland) and standard methods were used as described in Subchapter 1.2.2.2.

Table 3 summarizes the wastewater-based growth media and photoautotrophs used in this study. DE was either diluted with distilled water or with WWTPE, using either $10 \%$ or $25 \%$ of DE (Table 3). For a continuous alga-based wastewater treatment process with Ettlia oleoabundans, KA2 was modified by adding extra phosphate during the initial batch mode to a final concentration of $25 \mathrm{mg} \mathrm{L}^{-1}$ and further in the turbidostat phase to $34 \mathrm{mg} \mathrm{L}^{-1}$. In addition, extra sulphate and micronutrients were added to correspond to those in the BG-11 growth medium (Paper II). 
Table 3. Wastewater streams, wastewater optimization strategies and microorganisms.

\begin{tabular}{lcc}
\hline Growth media & Organism used & Paper \\
\hline DE $10 \%+$ WWTPE $90 \%$ & N. oculata & I \\
DE $25 \%+$ WWTPE $75 \%$ & N. oculata & I \\
DE $10 \%+$ DW $90 \%$ & N. oculata & Thesis \\
DE $25 \%+$ DW $75 \%$ & N. oculata & Thesis \\
KA2 & E. oleoabundans & II, Thesis \\
KA2 $+\mathrm{PO}_{4}{ }^{3-}+\mathrm{SO}_{4}{ }^{2-}+$ heavy metals & E. oleoabundans & II \\
TAL1 & E. oleoabundans & Thesis \\
Biowasher & E. oleoabundans & Thesis \\
KA2 & Synechocystis sp. PCC6803 & III \\
KA2 +20 mM HEPES pH 7.5 & Synechocystis sp. PCC6803 & III \\
KA2 + $\mathrm{PO}_{4}{ }^{3-}$ & Synechocystis sp. PCC6803 & III \\
\hline
\end{tabular}

\subsection{Strains and growth conditions}

Table 4 compares the physiological and morphological features of the three species used in the studies. Well-known model species were chosen for the studies, and optimal growth conditions for each species were applied during pre-culturing.

\subsubsection{Nannochloropsis oculata}

The Nannochloropsis oculata strain UTEX LB 2164 was grown in artificial seawater medium (ASW) or in diluted digester effluent DE under continuous illumination at the photosynthetic photon flux density (PPFD) of $25 \mu \mathrm{mol} \mathrm{m} \mathrm{m}^{-2}$ at $20^{\circ} \mathrm{C}$ in ambient air (Paper I). First, the growth of $N$. oculata was tested in batch cultures grown in Erlenmeyer bottles using DE media prepared via dilution either with distilled water (DE $10 \%+$ DW $90 \%$ or DE $25 \%+$ DW $75 \%$ ) or with wastewater treatment plant effluent (DE 10\% + WWTPE 90\% or DE $25 \%+$ WWTPE $75 \%$ ). For biomass and EPA production experiments, $N$. oculata was grown in a DE medium (DE $25 \%+$ WWTPE $75 \%$ ) in the FMT-150 flat panel PBR (Photon Systems Instruments, Brno, Czech Republic) as a 400-ml batch culture (Paper I). During the first $24 \mathrm{~h}$, PPFD was $50 \mu \mathrm{mol} \mathrm{m} \mathrm{m}^{-2}$, then $100 \mu \mathrm{mol} \mathrm{m}^{-2} \mathrm{~s}^{-1}$ for $24 \mathrm{~h}$, and thereafter $200 \mu \mathrm{mol} \mathrm{m}^{-2} \mathrm{~s}^{-1}$. Mixing was provided via bubbling with air or $0.3 \% \mathrm{CO}_{2}$ as described in Paper II. 
Table 4. Comparison between N. oculata, E. oleoabundans and Synechocystis sp. PCC6803, based on basic physiological and morphological features.

\begin{tabular}{|c|c|c|c|}
\hline & $\begin{array}{l}\text { Nannochloropsis } \\
\text { oculata }\end{array}$ & $\begin{array}{c}\text { Ettlia } \\
\text { oleoabundans }\end{array}$ & $\begin{array}{l}\text { Synechocystis sp. } \\
\text { PCC6803 }\end{array}$ \\
\hline Phylogeny & $\begin{array}{c}\text { Eukaryota, } \\
\text { Eustigmatophyceae }\end{array}$ & Eukaryota, Chlorophyceae & $\begin{array}{c}\text { Bacteria, } \\
\text { Cyanophyceae }\end{array}$ \\
\hline Habitat & $\begin{array}{l}\text { brackish waters } \\
\text { (Droop 1955) }\end{array}$ & $\begin{array}{c}\text { arid soils } \\
\text { (Chantanachat and Bold } \\
\text { 1962) }\end{array}$ & $\begin{array}{c}\text { freshwaters } \\
\text { (Rippka et al. 1979) }\end{array}$ \\
\hline $\begin{array}{l}\text { Carbon } \\
\text { assimilation }\end{array}$ & $\begin{array}{c}\text { phototrophic, } \\
\text { mixotrophic } \\
\text { (Razak et al. 2015) }\end{array}$ & $\begin{array}{l}\text { phototrophic, mixotrophic } \\
\text { and heterotrophic } \\
\text { (Baldisserotto et al. 2016; } \\
\text { Morales-Sánchez et al. } \\
\text { 2013) }\end{array}$ & $\begin{array}{c}\text { phototrophic, } \\
\text { mixotrophic, light- } \\
\text { activated heterotrophic } \\
\text { (Anderson and } \\
\text { Mclntosh 1991) }\end{array}$ \\
\hline $\begin{array}{l}\text { Location of } \\
\text { Rubisco }\end{array}$ & $\begin{array}{l}\text { pyrenoid-like structure } \\
\text { (Suda et al. 2002) }\end{array}$ & $\begin{array}{c}\text { pyrenoid } \\
\text { (Giovanardi et al. 2013) }\end{array}$ & $\begin{array}{l}\text { carboxysomes } \\
\text { (Hackenberg et al. } \\
\text { 2012) }\end{array}$ \\
\hline Photosynthesis & oxigenic & oxigenic & oxygenic \\
\hline $\begin{array}{l}\text { Antenna } \\
\text { pigments }\end{array}$ & $\begin{array}{l}\text { chlorophyl a, } \\
\text { carotenoids, } \\
\text { violaxanthin } \\
\text { (Adl et al. 2005) }\end{array}$ & $\begin{array}{l}\text { chlorophyl } a \text { and } b \text {, } \\
\text { carotenoids } \\
\text { (Giovanardi et al. 2013) }\end{array}$ & $\begin{array}{c}\text { chlorophyl a, } \\
\text { phycocyanobilins, } \\
\text { carotenoids } \\
\text { (Vavilin et al. 2003) }\end{array}$ \\
\hline Cell size & $\begin{array}{l}\quad 2-4 \mu \mathrm{m} \\
\text { (Conveti et al. 2009) }\end{array}$ & $\begin{array}{c}5-12 \mu \mathrm{m} \\
\text { (Loera-Quezada et al. 2011) }\end{array}$ & $\begin{array}{l}\sim 2 \mu \mathrm{m} \\
\text { (Zavrel et al. 2019) }\end{array}$ \\
\hline Cell wall & $\begin{array}{c}\text { Cellulose } \\
\text { (Jeong et al. 2017) }\end{array}$ & $\begin{array}{c}\text { Non-cellulose } \\
\text { (Rashidi and Trindade 2018) }\end{array}$ & $\begin{array}{l}\text { Gram negative } \\
\text { (Huang et al. 2004) }\end{array}$ \\
\hline Reproduction & $\begin{array}{l}\text { asexual } \\
\text { cell division } \\
\text { (Droop 1955) }\end{array}$ & $\begin{array}{c}\text { asexual } \\
\text { autospores } \\
\text { (Garibay-Hernández et al. } \\
2017)\end{array}$ & $\begin{array}{c}\text { asexual } \\
\text { cell division } \\
\text { (Rippka et al. 1979) }\end{array}$ \\
\hline Growth mode & unicellular & unicellular & unicellular \\
\hline $\begin{array}{l}\text { Optimal Growth } \\
\text { temperature }\end{array}$ & $\begin{array}{c}20-25^{\circ} \mathrm{C} \\
\text { (Conventi et al. 2009) }\end{array}$ & $\begin{array}{c}25-30{ }^{\circ} \mathrm{C} \\
\text { (Wang and Lan 2011) }\end{array}$ & $\begin{array}{c}30-35^{\circ} \mathrm{C} \\
\text { (Zavrel et al. 2015) }\end{array}$ \\
\hline Growth medium & saline & freshwater and saline & freshwater \\
\hline $\begin{array}{l}\text { Biotechnologycal } \\
\text { relevance }\end{array}$ & $\begin{array}{c}\text { EPA } \\
\text { (Omega 3- fatty acid) }\end{array}$ & $\begin{array}{l}\text { high neutral lipid content } \\
\text { (biodiesel production) }\end{array}$ & $\begin{array}{c}\text { model organism } \\
\text { genetic transformations }\end{array}$ \\
\hline
\end{tabular}

\subsubsection{Ettlia oleoabundans}

Ettlia oleoabundans (Komárek 1989) UTEX 1185, referred to with the widely used but recently deprecated name Neochloris oleoabundans in Paper II, was maintained as a liquid culture in BG-11 growth medium (Rippka et al. 1979) under continuous light, PPFD $30 \mu \mathrm{mol} \mathrm{m}{ }^{-2} \mathrm{~s}^{-1}$ at $20^{\circ} \mathrm{C}$, in ambient air (Paper II). The growth of Ettlia oleoabundans in KA2, TAL1 and Biowasher wastewaters was first tested with 
Erlenmyer flask experiments. For large scale experiments, KA2 wastewater was selected, and Ettlia oleoabundans was grown in a home-made 45 L PBR in batch and turbidostat mode (Paper II). In some experiments, the KA2 wastewater was supplemented with extra nutrients and for a control, cells were also grown in BG-11 medium (Paper II).

\subsubsection{Synechocystis sp. PCC6803}

The glucose-tolerant strain of Synechocystis sp. PCC6803 (Williams, 1988) was used as a control strain (CS) in Paper III. Construction of the $\sigma$ factor inactivation strains $\Delta$ sigBCD, $\Delta$ sigBCE, $\Delta$ sigBDE $\Delta$ sigCDE (Pollari et al. 2011) and $\Delta$ sigBCDE (Koskinen et al. 2016) have been described earlier. The strains were maintained on BG-11 medium plates supplemented with $20 \mathrm{mM}$ HEPES $\mathrm{pH}$ 7.5. The plates for triple mutants were supplemented with chloramphenicol $\left(10 \mu \mathrm{g} \mathrm{ml}^{-1}\right)$, kanamycin (20 $\left.\mu \mathrm{g} \mathrm{ml}^{-1}\right)$, spectinomycin $\left(10 \mu \mathrm{g} \mathrm{ml}^{-1}\right)$ and streptomycin $\left(20 \mu \mathrm{g} \mathrm{ml}^{-1}\right)$ and those for the quadruple mutant also with nourseothricin $\left(10 \mu \mathrm{g} \mathrm{ml}^{-1}\right)$. Plates were grown in standard growth conditions under continuous light, PPFD of $40 \mu \mathrm{mol} \mathrm{m} \mathrm{m}^{-2} \mathrm{~s}^{-1}$, at 32 ${ }^{\circ} \mathrm{C}$ in ambient air (Paper III).

For liquid cultures, cells were grown as $30 \mathrm{ml}$ cultures in 100-ml Erlenmyer flasks without antibiotic supplements. Cell were grown in standard growth conditions using either BG-11 medium, BG-11 medium supplemented with $20 \mathrm{mM}$ HEPES, pH 7.5, low phosphate BG-11 medium with 20 mM HEPES, pH 7.5 or KA2 wastewater medium with or without addition of $20 \mathrm{mM}$ HEPES, $\mathrm{pH} 7.5$, or with extra phosphate as indicated (Paper III). In some experiments, as indicated, the growth chamber air was enriched with $3 \% \mathrm{CO}_{2}$ (Paper III).

\subsection{Growth measurements}

Growth curves of Nannochloropsis oculata were measured at $\mathrm{OD}_{720}$ by the optical sensor provided with the FMT150 flat panel PBR (Paper I). Measurements were taken every 30 minutes. Based on those measurements, maximum specific growth rates $\left(\mu_{\max }\right)$ were calculated from the exponential part of the growth curve.

Growth of Ettlia oleoabundans was monitored with a self-made optical sensor, measuring scattering of $880 \mathrm{~nm}$ light. This sensor was used to apply turbidostat operation in order to maintain constant biomass concentration during continuous mode. The $\mathrm{mV}$ signal from the photodiode was converted via custom software to $\mathrm{OD}_{880}$ using the Lambert-Beer equation (Equation 5):

$$
O D=\log _{10} \frac{I_{0}}{I},
$$


where $\mathrm{I}_{0}$ is the signal measured before inoculation and $\mathrm{I}$ is the signal measured during algal growth.

During the up-scale experiments, $\mathrm{OD}_{880}$ was measured every $10 \mathrm{~s}$.

Growth of Synechocystis sp. was followed by measuring OD ${ }_{730}$ every $24 \mathrm{~h}$ (Paper III). If $\mathrm{OD}_{730}$ exceeded 0.4 , the cell culture sample was diluted before the measurement.

\subsection{Biomass Dry Weight Analysis}

In Paper I, $10 \mathrm{~mL}$ of the $N$. oculata culture at the end of growth experiment was filtered through a glass microfiber filter, dried for $3 \mathrm{~h}$ at $105{ }^{\circ} \mathrm{C}$, and the dry mass measured with an analytical balance. In Paper II, dry weight of algal biomass was measured daily from a $5 \mathrm{ml}$ sample. The sample was withdrawn from the PBR, filtered with a glass fibre filter and dried overnight at $96{ }^{\circ} \mathrm{C}$ before weighing.

\subsection{Nutrient content and removal efficiency}

Elemental wastewater analysis of DER was performed by Labtium Oy (Espoo, Finland) (Paper I). In addition, we measured nitrate and ammonium concentrations as those varied between DER batches and also depended on DER storage time. Ammonium and nitrate contents of the DE medium were analysed with ion-selective electrodes (Thermo Fischer Scientific, Waltham, MA, USA) as described earlier (Ojanen et al. 2015).

The removal of $\mathrm{NH}_{4}{ }^{+}, \mathrm{NO}_{3}{ }^{-}, \mathrm{PO}_{4}{ }^{3-}$ and $\mathrm{SO}_{4}{ }^{2-}$ from the growth medium was followed by measuring their concentrations using SpectroQuant ${ }^{\circledR}$ Nitrate, Ammonium, Phosphate and Sulfate tests (Papers II and III). We prepared and used our own calibration curves for each method (Paper II), using standard solutions of $\mathrm{NH}_{4} \mathrm{Cl}, \mathrm{NaNO}_{3}, \mathrm{KH}_{2} \mathrm{PO}_{4}$ and $\mathrm{K}_{2} \mathrm{SO}_{4}$. Samples exceeding the dynamic range of the particular method were diluted accordingly. Nutrient measurements were performed on a daily base. Prior to nutrient measurements, biomass was removed from the sample via filtration through a $0.2 \mu \mathrm{m}$ filter.

$\mathrm{NH}_{4}{ }^{+}$and $\mathrm{PO}_{4}{ }^{3-}$ removal efficiencies for the stable wastewater treatment phase of the final experiment described in Paper II were calculated by Equation 6:

$$
N R E=\frac{\text { Concentration(influent })- \text { Concentr ation }(\text { effluent })}{\text { Concentration(influent })} \times 100
$$

where NRE is the nutrient removal efficiency (\%). 


\subsection{Lipid analysis}

An extensive lipid analysis was performed during this work and the detailed procedure is described in Paper I. At the end of each growth experiment (after 7 days), $N$. oculata cells were harvested via centrifugation. The harvest was subjected to lipid extraction. The extracted lipids were separated to cholesteryl esters (CEs), triacylglycerols (TAGs), glycolipids (GLs) and phospholipids (PLs). The fatty acids of each lipid class were converted to methyl esters with $\mathrm{BF}_{3}$-methanol treatment (Metcalfe et al. 1966, with minor modifications), and the fatty acid profile of each lipid class was the determined with gas chromatography. Standards were used for cholesteryl esters, triacylglycerols and phospholipids fractions, whereas the glycolipid fraction was identified on the basis of its green colour and high EPA content. Fatty acid methyl esters were identified with standards.

\subsection{Chlorophyll $a$ and carotenoids}

Chlorophylls and carotenoids of $N$. oculata were extracted with methanol (99.9\%) and determined spectrophotometrically according to Ritchie (2006) and Strickland and Parsons (1972), respectively (Paper I).

\subsection{Photosynthesis measurements}

Pulse amplitude modulation fluorometry was used to measure the relative quantum yield of photosynthetic electron transfer and the relative electron transfer rate (ETR), non-photochemical quenching (NPQ) and the coefficient of photochemical quenching $(\mathrm{qP})$. The relative quantum yield of photosynthetic electron transfer and ETR were measured from $1 \mathrm{ml}$ sample illuminated with actinic PPFD ranging from 0 to $3000 \mu \mathrm{mol} \mathrm{m}^{-2} \mathrm{~s}^{-1}$. The sample was illuminated at each PPFD for 30 seconds before firing a saturating pulse, PPFD $5000 \mu \mathrm{mol} \mathrm{m}^{-2} \mathrm{~s}^{-1}$. Relative ETR was obtained from equation 7 :

$$
E T R=P P F D \times\left(F M^{\prime}-F S\right) / F M^{\prime}
$$

where PPFD is the actinic PPFD, $F M^{\prime}$ ' is fluorescence intensity measured during a saturating pulse of light, and $F S$ is fluorescence intensity before the pulse.

Relative quantum yield of photosynthetic electron transfer $(\alpha)$ and maximum ETR (ETR max $_{\text {ax }}$ ) were obtained as the best fit of the dependence of ETR on PPFD to equation 8 :

$$
\left.\operatorname{ETR}(P P F D)=E T R_{\text {max }} \times \tanh (\alpha \times P P F D) / E T R_{\max }\right)
$$

Maximum $\left(\mathrm{F}_{\mathrm{M}}\right)$ and minimum $\left(\mathrm{F}_{0}\right)$ fluorescence were measured after 5 min dark incubation from $N$. oculata and after 10 min from E. oleoabundans. NPQ and qP 
were obtained from samples illuminated for $5 \mathrm{~min}$ with PPFD $1000 \mu \mathrm{mol} \mathrm{m} \mathrm{m}^{-2} \mathrm{~s}^{-1}$. After the measurement, the sample was darkened for $15 \mathrm{~min}$ and NPQ and qP were measured again. NPQ and qP were calculated using Equations 9, 10 and 11:

$$
\begin{gathered}
N P Q=\left(F_{M}-F_{M}^{\prime}\right) / F_{M}^{\prime} \\
\boldsymbol{q P}=\left(\boldsymbol{F}_{\boldsymbol{M}}^{\prime}-\boldsymbol{F}_{\boldsymbol{t}}\right) /\left(\boldsymbol{F}_{\boldsymbol{M}}^{\prime}-\boldsymbol{F}_{\mathbf{0}}^{\prime}\right) \\
F_{0}^{\prime}=\frac{F_{0}}{\frac{F_{M^{-} F_{0}}}{F_{M}}+\frac{F_{0}}{F_{M}^{\prime}}}
\end{gathered}
$$

where $\mathrm{F}_{\mathrm{M}}$ and $\mathrm{F}_{0}$ are the maximum and minimum fluorescence, respectively, from a dark acclimated sample, $\mathrm{F}_{\mathrm{M}}{ }^{\prime}$ is the maximum fluorescence during illumination, $\mathrm{F}_{0}{ }^{\prime}$ is the minimum fluorescence from an illuminated sample, calculated using Eq. 11, and $\mathrm{F}_{\mathrm{t}}$ is fluorescence during illumination, measured before a saturating pulse.

\subsection{Statistical analysis}

In Paper I the cell number, dry weight measurements, EPA content, total fatty acids (TFA), lipid fractions, fatty acids profile, as well as major fatty acids in the lipid fractions, and pigments content were determent from four independent experiments. The standard deviation was calculated with STDV function of Microsoft Excel.

In paper II DW measurements and were obtained from three technical replicates collected on a daily base. Measurements of $\mathrm{NH}_{4}{ }^{+}, \mathrm{NO}_{3}{ }^{-}, \mathrm{PO}_{4}{ }^{3-}$ and $\mathrm{SO}_{4}{ }^{2-}$ from the wastewater and from the photobioreactor samples, were collected from three technical replicates on a daily base. The standard deviation was calculated as in Paper I.

Wastewater treatment process with the up-scale photobioreactor was performed for 5 times HRT counted from day 13 of the experiment, ensuring steady state conditions.

All Synechocystis sp. growth experiments were performed with three biological replicates and three technical samples from each biological replicate were subjected to analysis. Standard deviation was calculated as in Paper I and II.

Student's t-test was used to compare the statistical significance of differences between sample sets. 


\section{OVERVIEW OF RESULTS}

\subsection{Construction of a pilot scale tubular PBR}

Significant part of this thesis work has been devoted to the design and construction of a pilot-scale tubular PBR. Detailed schematics of the self-made up-scale tubular PBR is shown in Paper II, Figure 1. The reactor was designed and constructed as a vertical airlift tubular PBR, where circulation of the suspension was done with an air pump. The tubular PBR is equipped with seven real-time sensors. Two self- made optical sensors, OD880 and OD680, measure biomass growth as turbidity, and relative chlorophyll content of the culture, respectively. The OD sensors consist of a LED source ( $880 \mathrm{~nm}$ and $680 \mathrm{~nm}$ respectively) and a corresponding photodiode (Paper II). The LED source and the photodiode of each sensor are placed in custom designed stainless-steel part, that is incorporated in-line the photobiorectr's tube. The LED and the photodiode are positioned against each other at $15 \mathrm{~mm}$ distance. The photodiode voltage signal output can be regulated via resistor R1 (Paper II, Fig. S1), which enables the sensors' sensitivity to be adjusted according to the desired operational biomass density. The OD measurements are result of extinction of light either mostly by absorption (OD680) or solely by light scattering (OD880). Two oxygen sensors $\left(\mathrm{O}_{2 \text { in }}\right.$ and $\left.\mathrm{O}_{2 \text { out }}\right)$ measure $\mathrm{O}_{2}$ concentrations (mbar) before and after degassing. A temperature sensor measures temperature inside the $\mathrm{PBR}$ and a $\mathrm{pH}$ sensor was installed for $\mathrm{pH}$ control via on demand sparging of $99 \% \mathrm{CO}_{2}$. The flow rate is measured with flow sensor (Paper II). Technical details and manufacturers of the sensors can be found in Paper II.

The tubular PBR's volume could be adjusted according to preferences and experimental planning. During the course of my work either $80 \mathrm{~L}$ (Fig. 8A) or $45 \mathrm{~L}$ (Fig. 8B) construction was used. 


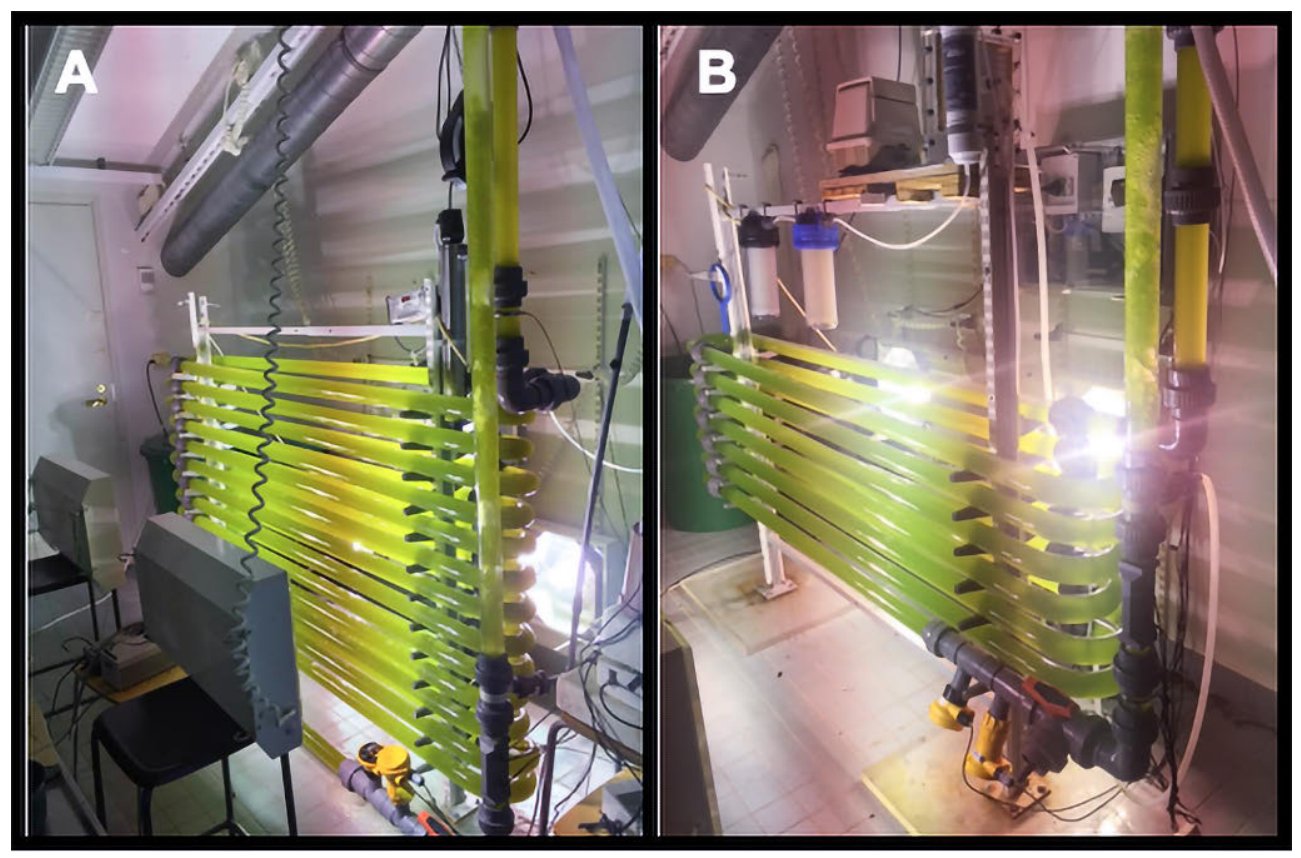

Figure 8. Pilot scale tubular PBR. A $80 \mathrm{~L}$ reactor set up. B $45 \mathrm{~L}$ reactor set up.

A test run for the $80 \mathrm{~L}$ tubular PRB was performed using $N$. oculata cells and ASW medium. A $3 \mathrm{~L}$ inoculum was grown in a $5 \mathrm{~L}$ flask at $25^{\circ} \mathrm{C}$, PPFD $150 \mu \mathrm{mol} \mathrm{m}^{-2} \mathrm{~s}^{-1}$, $1 \% \mathrm{CO}_{2}$ in ASW medium. The PRB was first run in batch culture mode for 5 days and thereafter switched to the turbidostat mode. Figure 9 shows real time data recorded by the six in line sensors, as well as offline dry weight measurements during the run. The batch mode period allowed cells to acclimate to the conditions in the reactor and reach high cell density. Also, during batch mode, the $\mathrm{OD}_{880}$ measurements were calibrated with off-line dry weight measurements for each reactor experiment. Reactor volume was kept constant with an overflow point in the degasser. The overflow (harvest) was collected in a 200 L harvest tank. Growth rates of the microalgae grown in the system were determined by automated gravimetrical measurement of the harvest tank every $10 \mathrm{~min}$. The specific growth rate achieved during the turbidostat phase of this test experiment was 1.24 day $^{-1}$. 


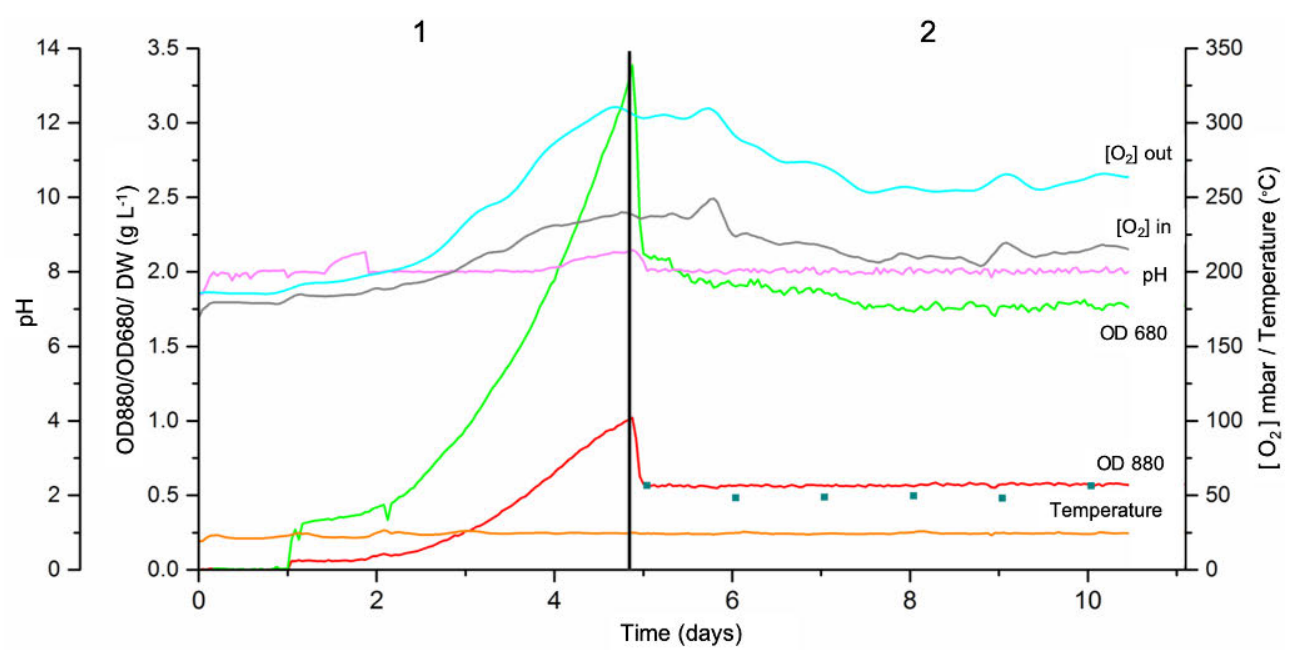

Figure 9. Test experiment with a $80 \mathrm{~L}$ tubular PBR, N. oculata and ASW medium. (1) Batch phase of the experiment; (2) Turbidostat phase of the experiment. Measurements shown from six in-line real-time sensors: $(-)\left[\mathrm{O}_{2}\right]$ out- oxygen concentration after degassing; $(-)$ $\left[\mathrm{O}_{2}\right]$ in- oxygen concentration before degassing; $(-) \mathrm{pH} ;(-)$ OD 680 - optical density at $680 \mathrm{~nm} ;(-)$ OD 880 - optical density at $880 \mathrm{~nm} ;(-)$ temperature. Squares show the results of off-line dry weight measurements.

This test experiment showed that the PBR constructed for the purpose of my work did not show any growth limiting features that could disturb the evaluation of algal growth in wastewaters. Furthermore, the dry weight measurements confirmed that our home-made OD880 sensor can be used for setting up a constant biomass concentration, enabling continuous operation of the process.

\subsection{Pre-treating and testing wastewaters as growth media for microalgae}

\subsubsection{Removing solids from wastewaters}

All the wastewaters (DER, WWTPE, KA2, TAL1 and Biowasher) investigated in this work were received in their raw form. All were coloured and required pretreatment before use as growth media. 


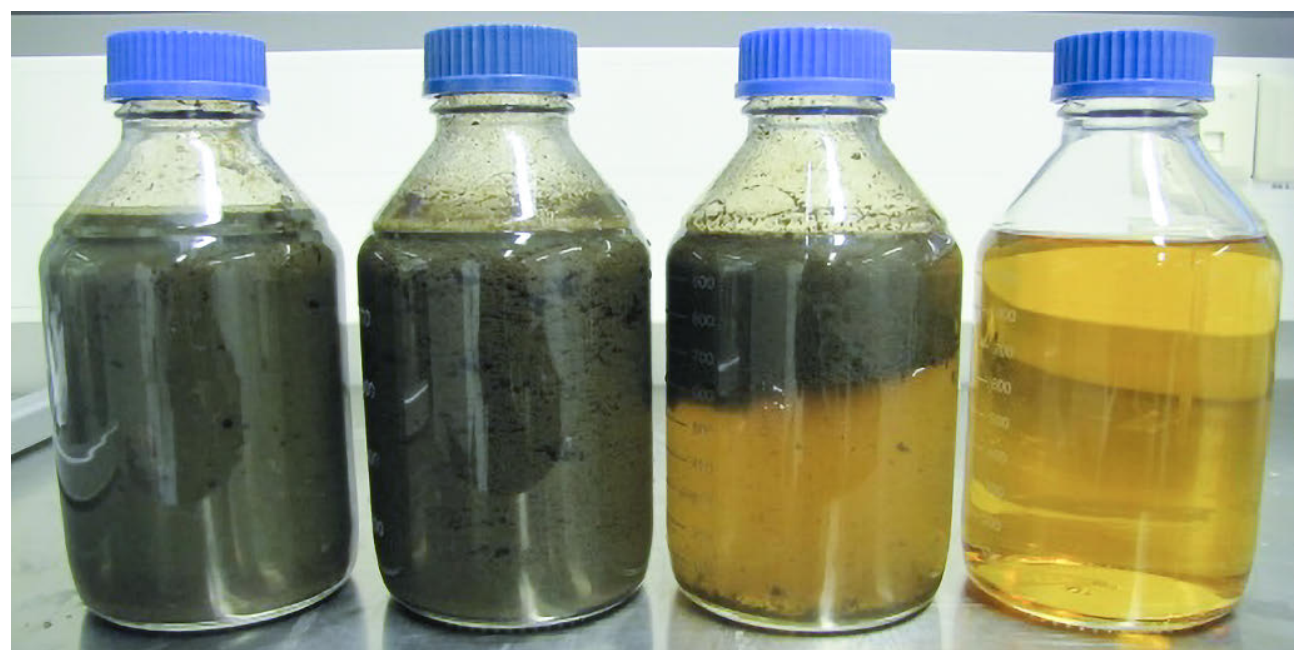

Figure 10. Four stages of coagulation/flocculation pre-treatment. From left to right: DER; DER and coagulant/flocculant; separation of the sludge and the liquid phase (after 10 minutes of addition of coagulant/flocculant); DER after removal of the solid phase.

DER (Paper I), had a high total solids content, consisting mainly of bacterial biomass sludge and undissolved particles (Fig. 10). Coagulation/flocculation was used to separate the sludge from the liquid, but the process could not completely remove colour, and the wastewater appeared dark yellow (Fig. 10). Therefore, DER was treated with PAC, which produced completely transparent wastewater (Fig. 11) that was used as part of a growth medium (Paper I).

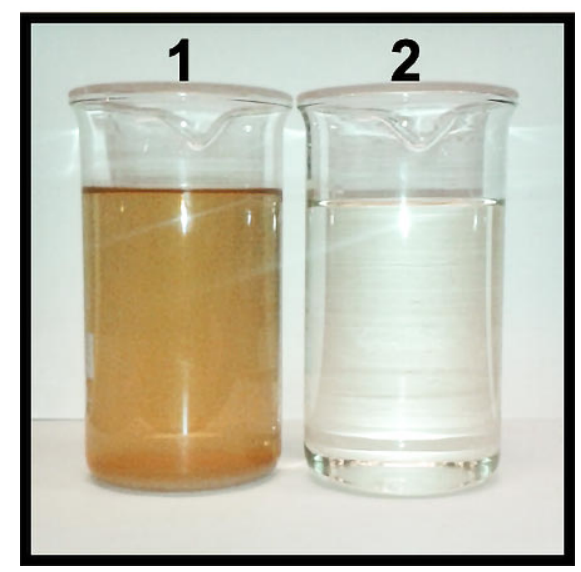

Figure 11. DER after coagulation/flocculation (1) and DE obtained after treatment with powdered activated carbon (2). 
For the tubular PBR experiments, bigger volumes of wastewater were needed. Therefore, a home-made granulated activated carbon filter (GAC) was designed (Fig. 12). A canister was filled to $2 / 3$ of its volume with granulated activated carbon, specially prepared for wastewater treatment purposes. The wastewater was pumped from the bottom, passed through an activated carbon bed and left the filter from the top via overflow.

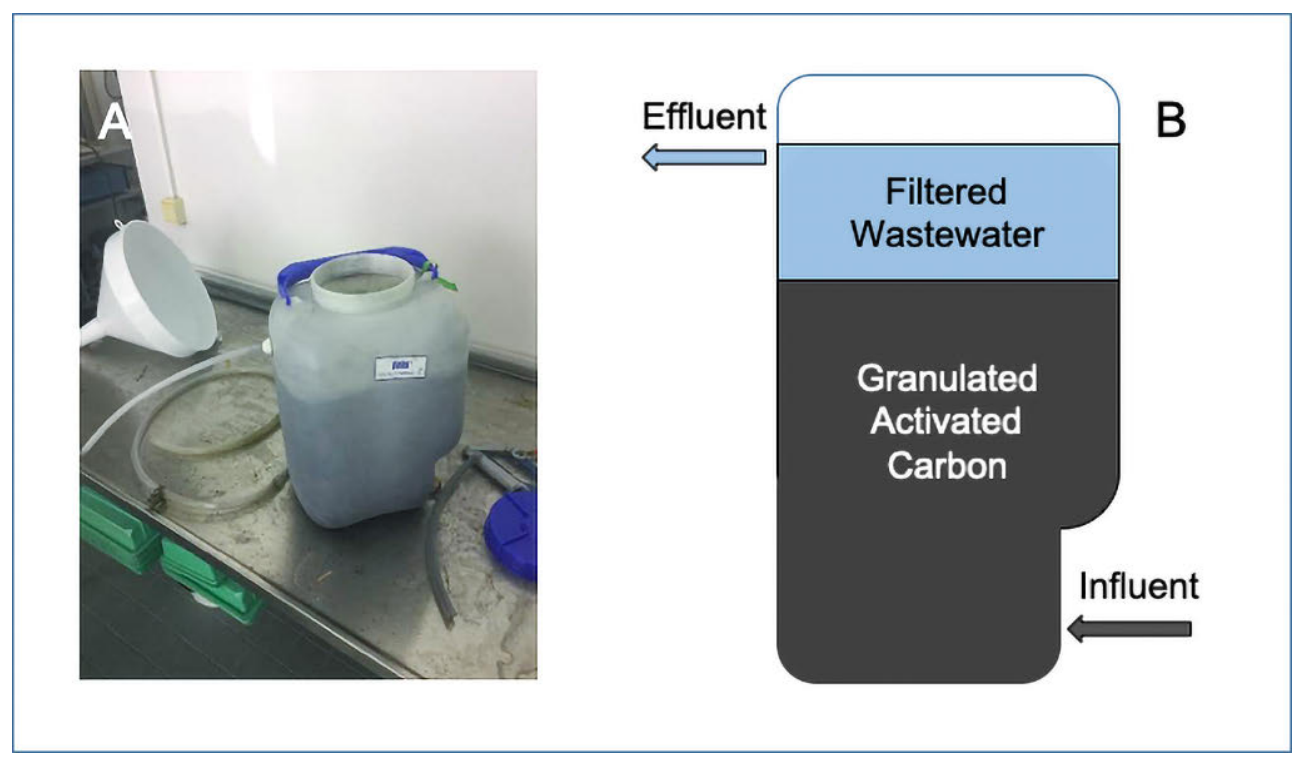

Figure 12. A: Home-made GAC filter; B: schematic representation of GAC up-flow filter operation.

The GAC filter was used without a coagulation/flocculation step for "TAL1", "KA2" and "Biowasher" wastewaters as they had a low total solids content (Fig. 13). The rates used to efficiently pre-treat wastewaters were $50-100 \mathrm{ml} \mathrm{min}^{-1}$, depending on the turbidity and colour intensity of the wastewater. Figure 13 shows the effect of the GAC filter pre-treatment for "TAL1", "KA2" and "Biowasher". 


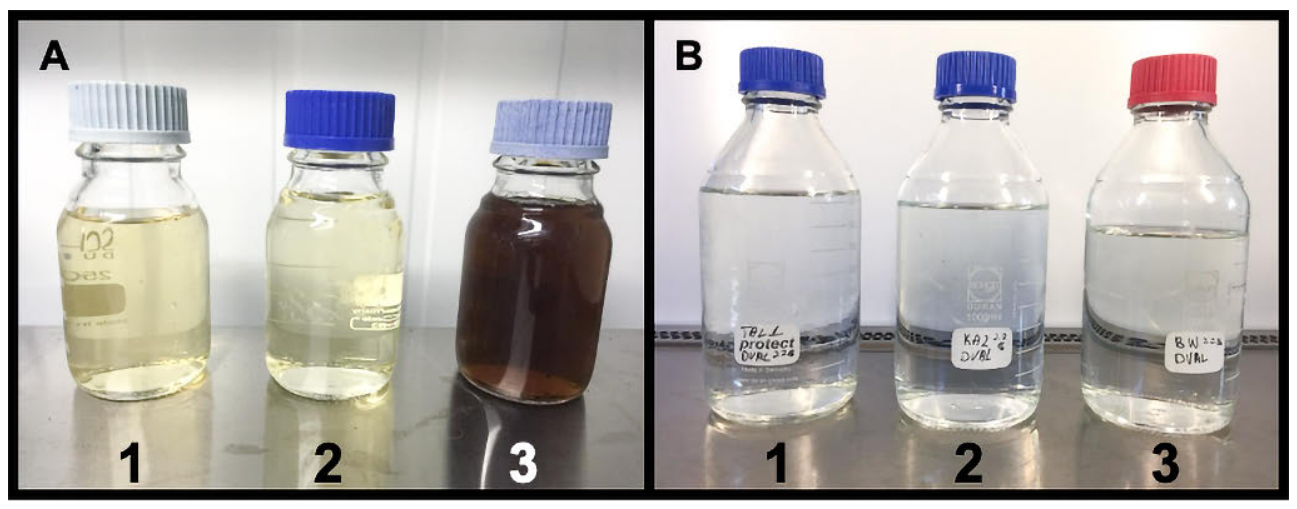

Figure 13. Three different wastewater streams treated with GAC filter. 1 TAL1; 2 KA2; 3 Biowasher. A wastewaters before treatment with a GAC filter; $B$ the respective wastewater samples after treatment with the GAC filter.

\subsubsection{Ammonium contents of different wastewaters and their ability to sustain algal growth}

The concentrations of main nutrients varied between the different wastewaters, and especially ammonium concentrations varied, even between batches of the same wastewater (Table 5). All tested wastewaters contained nitrogen mainly as ammonium while nitrate concentrations were low.

Table 5. Ammonium concentrations of different batches of wastewaters.

\begin{tabular}{lccc}
\hline \multirow{2}{*}{ Wastewater } & & \multicolumn{3}{c}{$\mathrm{NH}_{4}{ }^{+}$} & $\mathrm{mM}$ \\
\hline \multirow{2}{*}{ DER } & Batch 1 & 1300 & 72.1 \\
& Batch 2 & 380 & 21.1 \\
& Batch 3 & 200 & 11.1 \\
\hline \multirow{4}{*}{ KA2 } & Batch 1 & 40 & 2.2 \\
& Batch 2 & 60 & 3.3 \\
& Batch 3 & 105 & 5.8 \\
& Batch 4 & 120 & 6.7 \\
\multirow{2}{*}{ TAL1 } & Batch 1 & 60 & 3.3 \\
& Batch 2 & 70 & 3.9 \\
\multirow{2}{*}{ Biowasher } & Batch 3 & 120 & 6.7 \\
& Batch 1 & 600 & 33.3 \\
& Batch 2 & 800 & 44.3 \\
\hline
\end{tabular}

Prior to PBR experiments, the wastewaters were always tested in small scale batch cultures in Erlenmyer flasks. The first attempts to grow $N$. oculata in DE were performed with a wastewater batch with the $\mathrm{NH}_{4}{ }^{+}$concentration of $1.3 \mathrm{~g} \mathrm{~L}^{-1} . N$. 
oculata did not grow in $100 \% \mathrm{DE}$. If $\mathrm{DE}$ was diluted with distilled water, cells did not grow in $25 \%$ DE, but grew well in $10 \%$ DE (Fig. 14). However, when DE was diluted with wastewater treatment plant effluent (WWTPE), $N$. oculata cells grew fast in $25 \%$ DE (Paper I, Fig. 1). Therefore, the EPA production experiments in the flat panel PBR were performed in wastewater mix (DE medium) of $25 \% \mathrm{DE}$ and 75 $\%$ WWTPE.

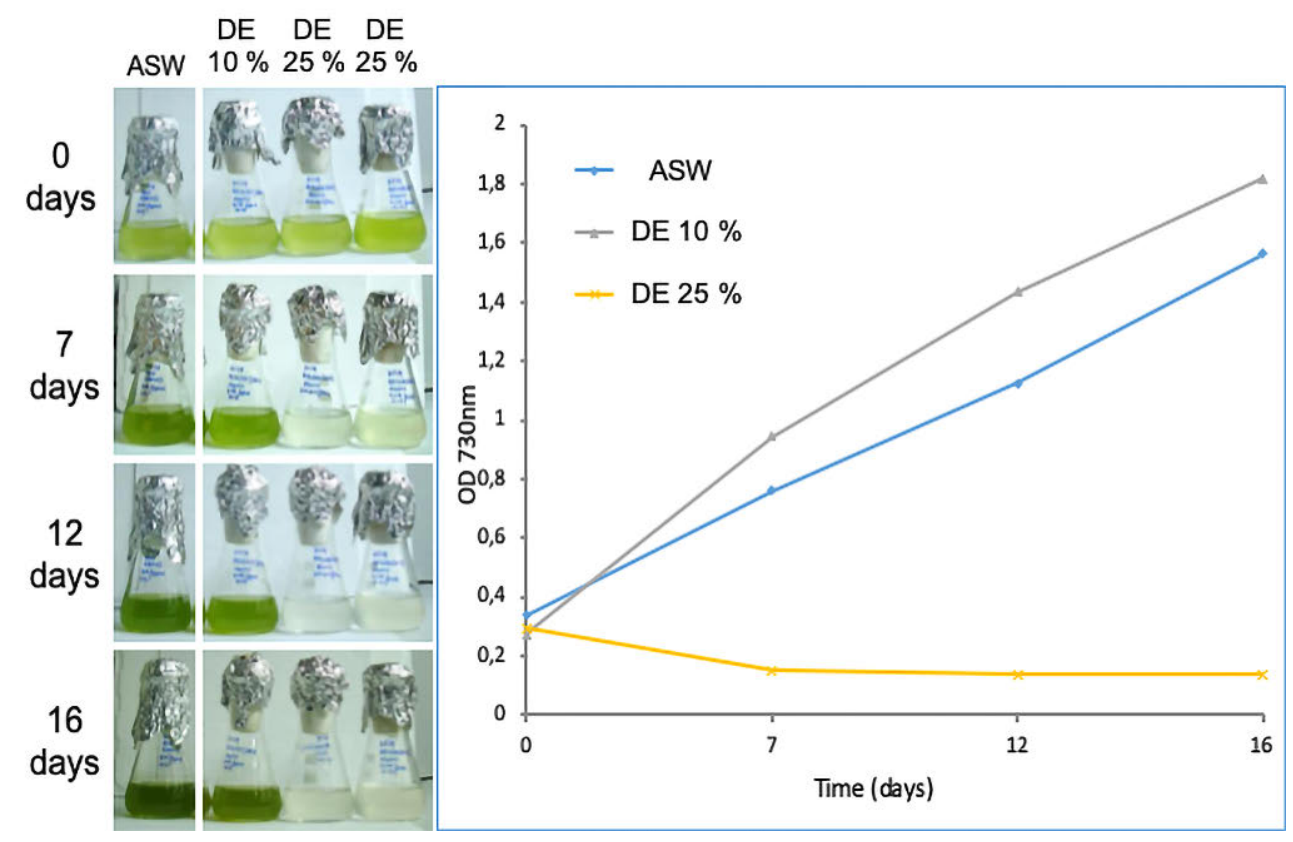

Figure 14. N. oculata grown in flasks with different ratios of DE and distilled water- $10 \% \mathrm{DE}+90$ $\%$ DW; $25 \%$ DE + $75 \%$ DW (duplicate). ASW was used as reference growth medium.

Suitability of E. oleoabundans for wastewater remediation was tested with three different wastewater streams provided by HSY. E. oleoabundans failed to grow in the high ammonium containing "Biowasher" wastewater (Fig. 15). Just in three days cells bleached out, showing no signs of growth. Based on this experiment, only TAL1 and KA2 were submitted for further investigation with the pilot-scale PBR. 


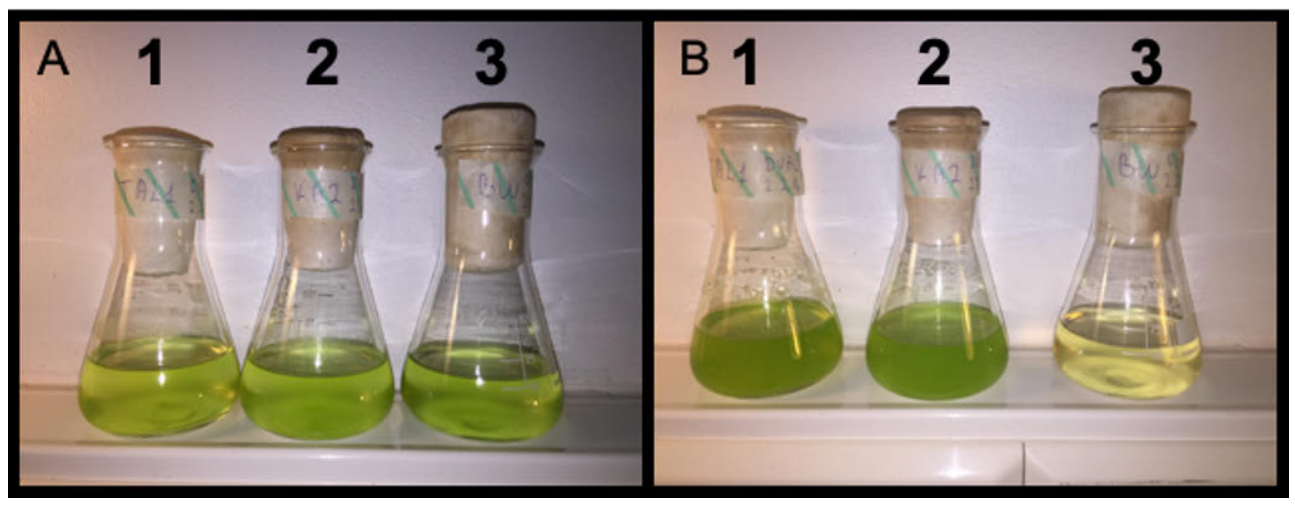

Figure 15. Flask batch growth of $E$. oleoabundans in three different wastewater streams. (1) TAL1; (2) KA2; (3) Biowasher. A E. oleoabundans cultures on day 0; B E. oleoabundans cultures after 3 days of growth.

\subsection{Biomass and EPA production of Nannochloropsis oculata in digester effluent based media}

N. oculata was grown in a flat panel bioreactor in ASW or in DE medium at $21^{\circ} \mathrm{C}$ in continuous illumination, PPFD $200 \mu \mathrm{mol} \mathrm{m}^{-2} \mathrm{~s}^{-1}$. (Paper I, Fig. 2). ASW was buffered with $25 \mathrm{mM}$ Tricine to $\mathrm{pH} 8.1$ whereas the DE medium was not buffered and had $\mathrm{pH}$ of 9.2. The cultures were sparged with air, except for short periods of sparging with $\mathrm{CO}_{2}$ to balance increased $\mathrm{pH}$ (for details, see Paper I). For the ASW experiment this happened first at $72 \mathrm{~h}$ (Paper I, Fig. 2A) and for the DE medium experiment at $100 \mathrm{~h}$ (Paper I, Fig. 2B). A second increase of $\mathrm{pH}$ for both experiments occurred after $130 \mathrm{~h}$, and this time the $\mathrm{pH}$ correction was done with $2 \% \mathrm{CO}_{2}$, applying an EPA accumulation enhancement procedure proposed by Hoshida et al. 2005.

Maximum specific growth rates $\left(\mu_{\max }\right)$ of $N$. oculata were 0.365 day $^{-1}$ and 0.405 day $^{-1}$ in ASW and DE medium, respectively (Paper I). Although the maximum specific growth rate of the microalgae was similar in the ASW and DE medium, there were several distinct differences. Growth of $N$. oculata in ASW medium did not stop at the end of the experiment $(160 \mathrm{~h})$, whereas in DE medium, $N$. oculata cells reached a stationary phase already at $130 \mathrm{~h}$, and due to degradation of chlorophyll, cells showed yellowish-green appearance at the end of the experiment (Paper I, Fig. 3). The chlorophyll content of N. oculata was lower in DE medium that in ASW, whereas the carotenoid content was similar in both media (Fig. 16), resulting in a lower chlorophyll $a$ to carotenoid ratio of 5.4 for the cells grown in the DE medium than in the ASW medium, where the ratio was 6.2. 


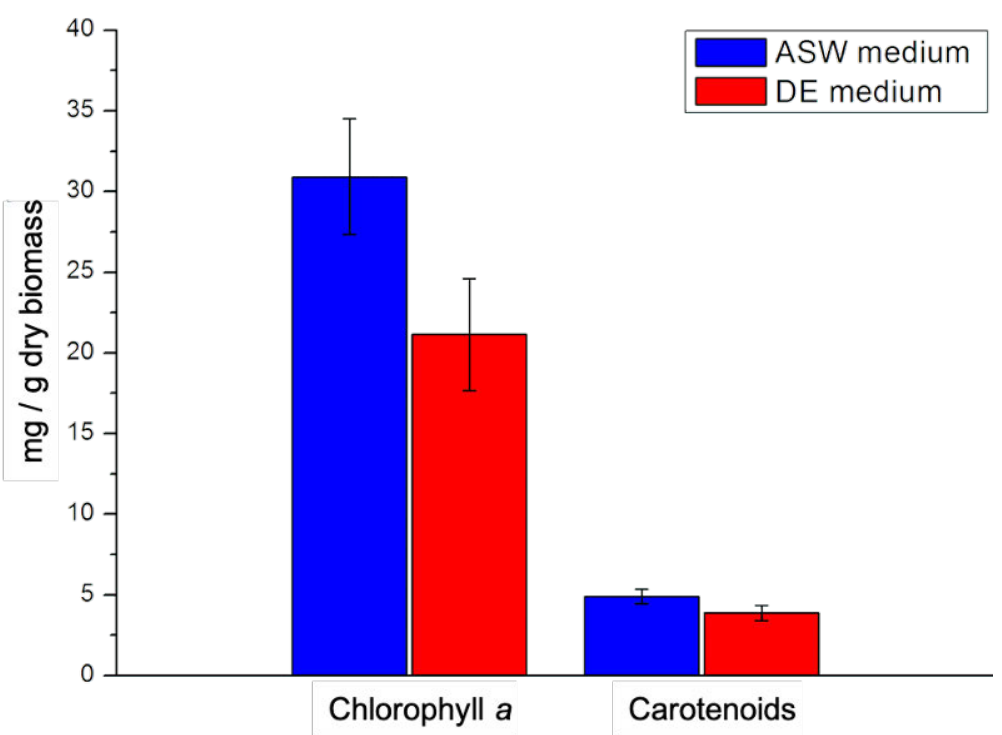

Figure 16. Chlorophyll a and carotenoid contents of $N$. oculata grown in ASW (blue) and DE medium (red) after 7 days of growth in flat panel PBR. Each bar represents an average of four independent experiments and the error bars show SD.

To follow the photosynthetic properties of cells grown in ASW or in DE medium, PS II quantum yield and electron transfer rate, non-photochemical quenching (NPQ) and photochemical quenching (qP) were measured from $N$. oculata samples after 3 , 5,6 and 7 days of growth. The electron transfer rates, and quantum yields were similar in ASW and in the DE medium grown cells (Paper I, Fig. S1). High-lightinduced NPQ and closure of PS II reaction centres occurred similarly whether the cells were grown in ASW or in DE medium, and the dark relaxation of NPQ and reopening of PS II centres were similar for cells grown in ASW and for cells grown in the DE medium (Paper I, Fig. S1). Overall, the results revealed that the growth medium (ASW or DE medium) did not have any significant effect on photosynthesis parameters.

Our goal was to use wastewater-grown $N$. oculata to produce EPA. EPA (20:5n3 ) was found to be the most abundant fatty acids in N. oculata. Cells grown in the ASW medium were able to accumulate $37.2 \%$ EPA of their total fatty acid content whereas the EPA content of cells grown in DE medium was $29.2 \%$ of total fatty acids (Paper I). However, the EPA content of $N$. oculata cells grown in the DE medium for 7 days was slightly higher than that of cells grown in ASW. However, it has to be taken into account that the total fatty acid content of cells grown in DE medium was twice as high as that of ASW grown cells (Fig. 17). 


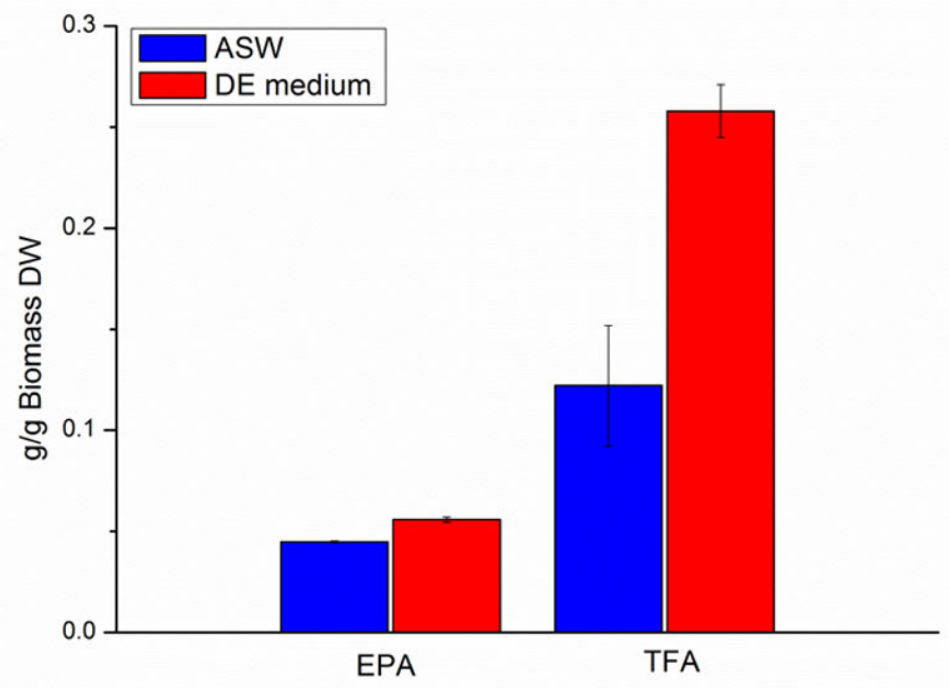

Figure 17. EPA and total fatty acids (TFA) content as gram per gram of dry weight biomass of $N$. oculata cultures grown in ASW (blue) and in DE medium (red) for 7 days in a flat panel PBR. Each bar represents an average of four independent experiments and the error bars show SD.

Growth medium affected the relative amounts of cholesterylesters, galactolipids, phospholipids and triacylglycerols (Paper I, Table 5). EPA in N. oculata when grown in ASW medium, was primarily associated with the membrane lipid classes (phospholipids and galactolipids) (Fig. 18).

When cells were grown in the DE medium, the triacylglycerol fraction was larger and the phospholipid fraction was smaller than in control cells (Paper I, Table 5). Furthermore, the fatty acid profiles of the lipid classes depended on growth medium (Paper I, Fig. 6). In particular, the DE medium appears to have induced formation of EPA-containing triacylglycerides (Fig. 18). Due to the relatively high EPA content of the triacylglyceride fraction, the overall EPA content of the culture was slightly higher in the DE medium than in the control medium (Fig.17). 


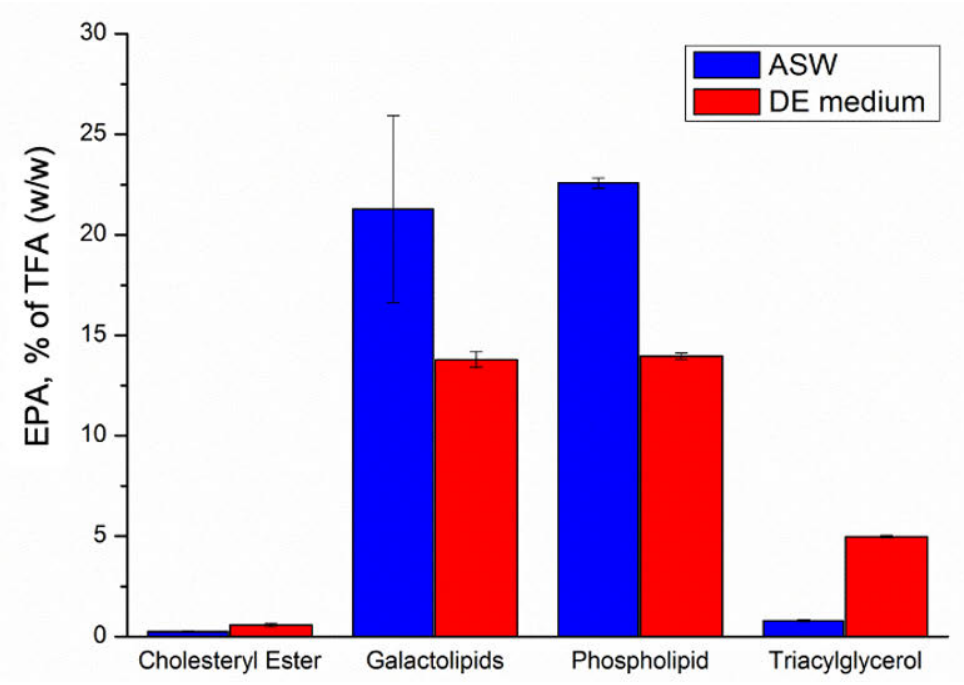

Figure 18. EPA (\% of TFA) as part of TFA belonging to each lipid fraction of $N$. oculata grown in ASW (blue) and in DE medium (red) for 7 days in flat panel PBR. Each bar represents an average of four independent experiments and the error bars show SD.

\subsection{Wastewater treatment with E. oleoabundans in a pilot scale tubular PBR}

\subsubsection{Optimizing wastewater pre-treatment for up-scale experiments}

The second goal of my thesis was to test if E. oleoabundans could be used to remove nitrogen and phosphorus from wastewater. In the first large-scale experiment, growth of E. oleoabundans slowed down early before the shadowing effect could be assumed to have an impact. Since KA2, Batch 2 (Table 2) used in this experiment was low in ammonium, $10 \mathrm{~L}$ of ammonium rich TAL1 Batch 3 was used to replace $10 \mathrm{~L}$ of cell culture on days 4, 5, 6 and 7. Some recovery of growth was observed, and continuous mode was set on day 9 (Fig. 19). Productivity of the system was only 0.1 day $^{-1}$ in the beginning of the turbidostat mode indicating that something was limiting the growth. After 3 days of turbidostat, the growth rate did not recover and the system was brought back to batch growth, switching off the dilution. However, growth did not recover (Fig. 19) At that point a sample from the reactor was taken and analysed under microscope. 


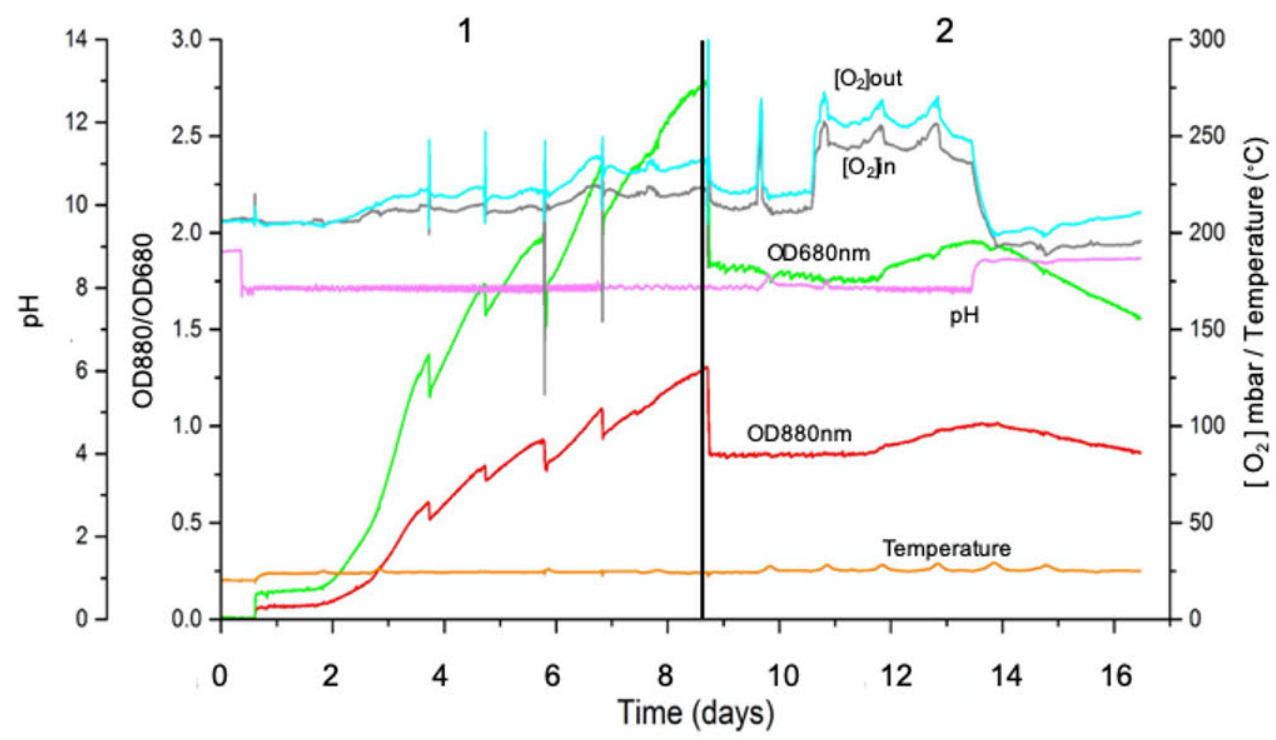

Figure 19. Experimental run with E. oleoabundans and KA2/TAL1 in $45 \mathrm{~L} P B R$. (1) Batch mode + semi- batch mode. The experiment started with KA2 as a batch and around day 4, semibatch mode was started with repeated additions of TAL1 (downward shifts in OD880); (2) Turbidostat mode with TAL1. The data are from six in-line real-time sensors: $(-)$ $\left[\mathrm{O}_{2}\right]$ out - oxygen concentration after degassing; $(-)\left[\mathrm{O}_{2}\right]$ in - oxygen concentration before degassing; $(-) \mathrm{pH}$; $(-)$ OD680 - optical density at $680 \mathrm{~nm}$; $(-)$ OD880 - optical density at $880 \mathrm{~nm} ;(-)$ Temperature.

The microscope observation revealed that the wastewater was contaminated with a predator that was able to penetrate the cell wall of E. oleoabundans, bursting the cell open. Obviously, the UV treatment of the wastewater was not enough to kill predators. Therefore, a decision for selecting a new approach was taken. The reactor was equipped with three mechanical filters (Fig. 20). The first one, $1 \mu \mathrm{m}$ mesh filter, removed bigger particles and that was followed by $0.5 \mu \mathrm{m}$ ceramic filter and $0.1 \mu \mathrm{m}$ PVDF membrane filter. The $0.5 \mu \mathrm{m}$ filter was included to protect the expensive and important $0.1 \mu \mathrm{m}$ filter. 


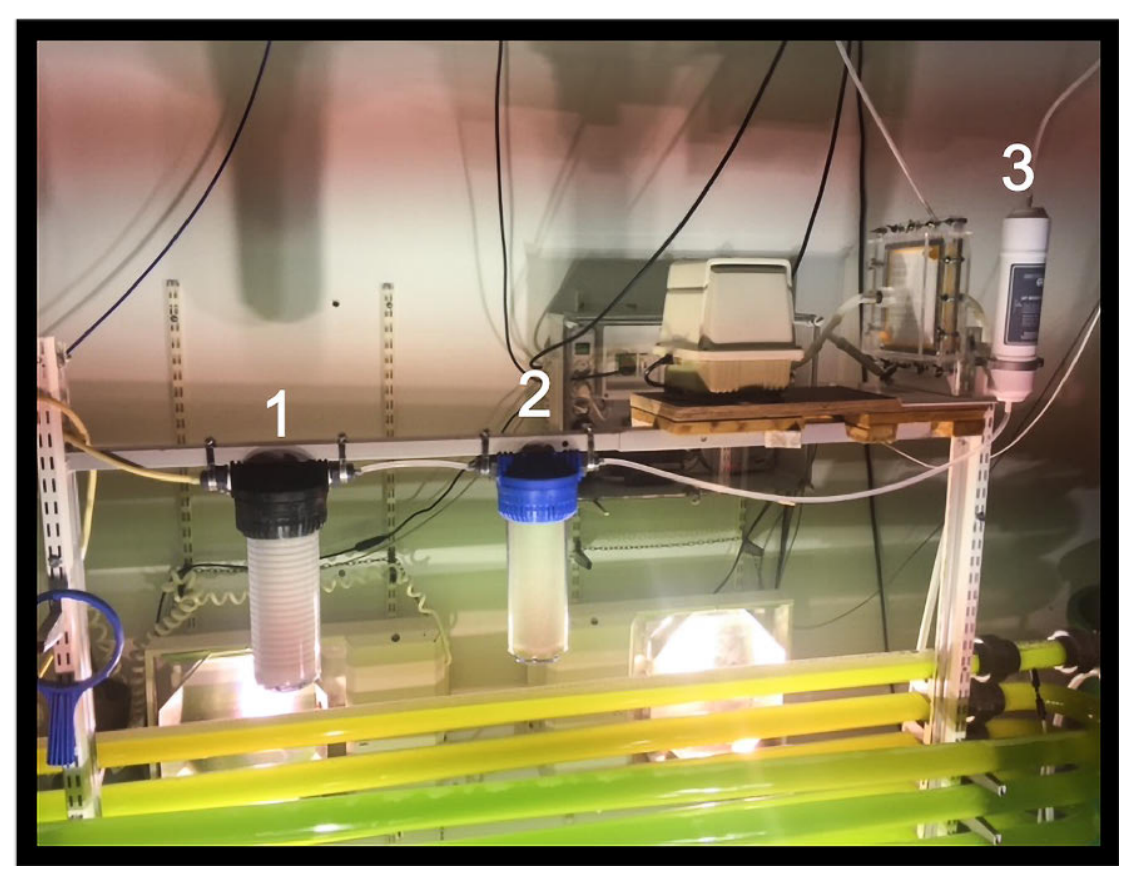

Figure 20. (1) $5 \mu \mathrm{m}$ mesh filter, (2) $0.5 \mu \mathrm{m}$ ceramic filter, (3) $0.1 \mu \mathrm{m}$ PVDF filter as inline pre-treatment strategy. Flow direction from (1) to (3).

To test for potential side effects of the new filter sterilization system, for example nutrients collection, a test experiment was run by growing $E$. oleoabundans in $45 \mathrm{~L}$ of BG-11 medium in the PBR. After a successful batch mode period (Fig. 21), the system was set in turbidostat mode. After 24 hours in turbidostat mode, the growth rate first decreased from 0.8 day $^{-1}$ to 0.5 day $^{-1}$ and finally down to 0.12 day $^{-1}$ (Fig. 21). At that point, the system was set back to batch mode operation, but growth rate did not improve and in the end of the experiment, and all biomass was lost (Fig. 21). This was due to formation of algal cell flocs, which started sticking to the surface of the reactor tubes. At that point, microscopic analysis was performed, and the results confirmed that no predator agents were present. In order to remove the biofouling on the inner reactor surface, a self-made pom-pom was inserted inside the system (Fig. 21). The spikes of OD 880 sensor, seen in Figure 21 result from the pom-pom sticking between the OD880 sensor components. Therefore, the pom-pom was removed for the rest of the experiment. In the following phase, $10 \mathrm{~L}$ of the cell culture was replaced with fresh BG-11 medium. This resulted in immediate recovery of growth. This was received as an effect of the pom-pom ball which managed to clean the inner reactor surfaces and suspend the attached biomass back to the suspension. The reactor was brought back to turbidostat operation mode. However, growth rate 
deceased in few days after that, and it was found that both $1 \mu \mathrm{m}$ and $0.5 \mu \mathrm{m}$ filters had collected biomass within their transparent casings.

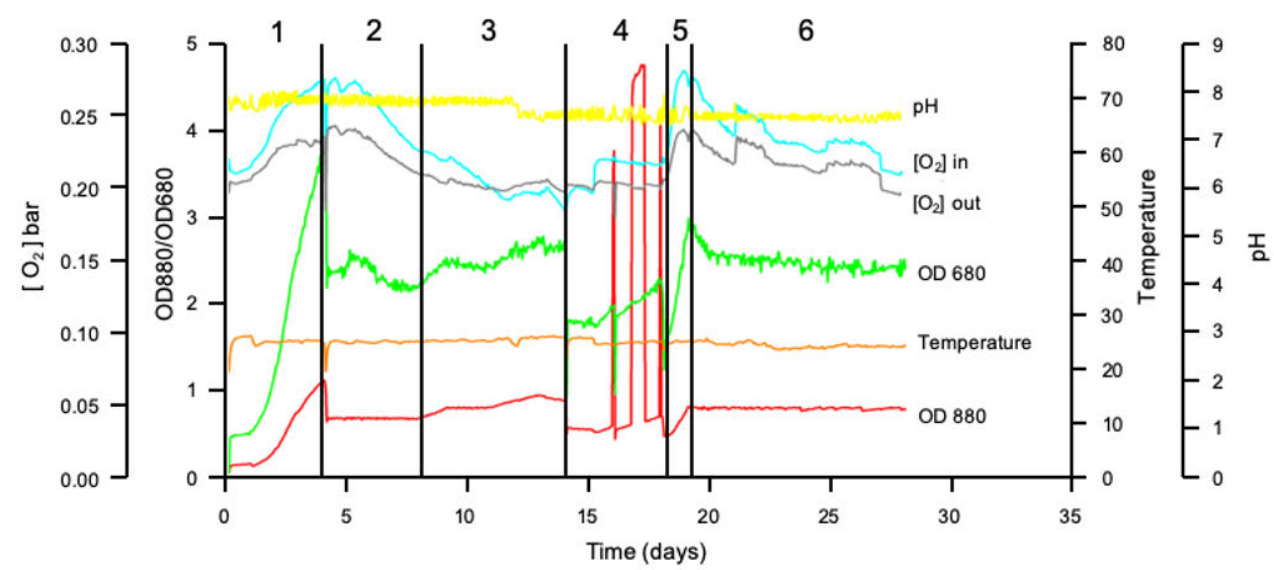

Figure 21. Experiment with E. oleoabundans, BG-11 in 45 L PBR. (1) Successful batch phase, (2) unsuccessful turbidostat phase, (3) unsuccessful batch phase, (4) unsuccessful batch phase with pom-pom, (5) batch phase after addition of 10 L BG-11 medium, (6) unsuccessful turbidostat phase. The data are from six in-line real-time sensors: $(-)\left[\mathrm{O}_{2}\right]$ out- oxygen concentration after degassing; $(-)\left[\mathrm{O}_{2}\right]$ in- oxygen concentration before degassing; ( ) pH; (-) OD680 - optical density at $680 \mathrm{~nm} ;(-)$ OD880 - optical density at $880 \mathrm{~nm} ;(-)$ temperature.

The surfaces of the filters inside the casings were getting greener during turbidostat mode, indicating photosynthetic growth. Samples were collected after each filter and from the BG-11 medium supply tank. The sample after the $0.5 \mu \mathrm{m}$ filter showed 60 $\%$ decrease in phosphate content compared with the sample collected from the BG11 supply tank. Furthermore, additional $20 \%$ loss of phosphate was measured after the $0.1 \mu \mathrm{m}$ filter. Thus, photosynthetic cells accumulating on filters collected $80 \%$ of total phosphate of BG-11 before the growth medium reached the bioreactor. To prevent accumulation of photosynthetic organisms in filters, the whole batch of the wastewater was pre-filtered through $1 \mu \mathrm{m}$ and $0.5 \mu \mathrm{m}$ filters and only the $0.1 \mu \mathrm{m}$ PVDF filter was used in-line during turbidostat mode.

\subsubsection{Wastewater optimization for stable algal growth}

For the first experiment, E. oleoabundans inoculum was prepared in BG-11 medium. After inoculation of the tubular PBR (45 L, KA2), a long lag phase (2.5 days) was observed, but thereafter algal cells acclimated and grew well for 5.5 days. On day 8 , turbidostat operation was started at $0.5 \mathrm{~g} \mathrm{~L}^{-1}$ biomass concentration. Shortly after the shift to the turbidostat phase, productivity significantly decreased, indicating a 
growth limitation in the process (Paper II, Fig. 3). The growth limitation was investigated by addition of nutrient components based on BG-11 composition. For that purpose, the reactor was set back to batch mode and the nutrients were added one by one in the following order to final concentrations of $23 \mathrm{mM} \mathrm{K}_{2} \mathrm{HPO}_{4} ; 0.24$ $\mathrm{mM} \mathrm{CaCl} 2 ; 0.3 \mathrm{mM} \mathrm{MgSO}{ }_{4}$; BG-11 trace metal mix $\left(46 \mu \mathrm{M} \mathrm{H}_{3} \mathrm{BO}_{3} ; 9 \mu \mathrm{M} \mathrm{MnCl}_{2}\right.$; $0.77 \mu \mathrm{M} \mathrm{ZnSO}_{4} ; 1.6 \mu \mathrm{M} \mathrm{Na}_{2} \mathrm{MoO}_{4} ; 0.3 \mu \mathrm{M} \mathrm{CuSO}_{4} ; 0.17 \mu \mathrm{M} \mathrm{Co}\left(\mathrm{NO}_{3}\right)_{2}$ and finally $21 \mu \mathrm{M}$ ferric ammonium citrate (Paper II, Fig. 3). Between nutrient additions, a 24 $\mathrm{h}$ period was left to allow each nutrient to cause a growth effect. Growth recovery was observed after addition of $\mathrm{Fe}$ as ferric ammonium citrate (Paper II, Fig. 3).

For the second trial, E. oleoabundans inoculum was grown in KA2 wastewater supplemented with $21 \mu \mathrm{M}$ ferric ammonium citrate. This time no significant lag phase was observed after inoculation and the microalgae grew well in the wastewater (Paper II, Fig. 4). However, four days after the start of the batch phase, growth limitation was observed indicating that KA2 was still limiting growth. Since iron had already been added, we decided to investigate if deprivation of other metals limited growth. Therefore BG-11 "trace metal mix" (same concentrations as in the previous experiment) was introduced directly in the PBR. Growth recovered (Paper II, Fig. 4 ), indicating that low concentration or absence of a trace metal was the reason of algal growth arrest in KA2 wastewater.

\subsubsection{Achieving a stable wastewater treatment process}

In Paper II, in the final experiment, all algal growth limitations present with KA2 wastewater were addressed by introducing appropriate pre-treatment strategy and optimizing the wastewater with additional nutrients (Paper II, Fig. 5).

This experiment started as usual with a batch phase, followed by a turbidostat phase (Paper II, Fig. 5). Macronutrient concentrations in the growth medium were followed during the batch phase (Paper II, Fig. 6), and these measurements suggested the need of extra phosphate. Phosphate was re-adjusted for the turbidostat phase to $33.95 \mathrm{mg} \mathrm{L}^{-1}(0.357 \mathrm{mM})$ (Paper II, Table 2). Shortly after the start of the turbidostat phase (24 h), a decrease in $\mathrm{O}_{2}$ production (Paper II, Fig. 5), drop in PBR productivity as well as a low $F_{V} / F_{M}$ value of 0.334 were observed. However, growth was successfully recovered by addition of trace metal mix solution directly into the PBR, indicating possible chelating of metals occurring in the wastewater supply tank. From that point on the experiment continued without any disturbances for 7 days, until all KA2 wastewater dedicated for the experiment had been finished. Daily samples from the reactor during that period showed a stable $\mathrm{F}_{\mathrm{V}} / \mathrm{F}_{\mathrm{M}}$ value of 0.76 . In summary, appropriate treatment of the KA2 wastewater includes pre-treatment with GAC and 0.1 PVDF membrane filter, addition of iron and "trace metal mix" and 
adjustment of $\mathrm{PO}_{4}{ }^{3-}$ and $\mathrm{SO}_{4}{ }^{2-}$ concentrations of the feeding wastewater (Paper II, Table 2). Table 6 summarizes the stable KA2 wastewater treatment process.

Table 6. KA2 wastewater treatment process parameters achieved with $E$. oleoabundans.

\begin{tabular}{ll}
\hline Parameter & Value \\
\hline Biomass concentration (Avg.) & $0.47 \mathrm{~g} \mathrm{~L}^{-1}$ \\
Growth rate (Avg.) & 0.73 day $^{-1}$ \\
Volumetric productivity (Avg.) & $0.34 \mathrm{~g} \mathrm{~L}^{-1}$ day $^{-1}$ \\
$\mathrm{NH}_{4}{ }^{+}$removal efficiency & $75 \%$ \\
$\mathrm{PO}_{4}{ }^{3-}$ removal efficiency & $99.60 \%$ \\
\hline
\end{tabular}

\subsection{Potential of Synechocystis sp. PCC 6803 and its regulatory sigma factor mutants for wastewater purification}

Series of batch-based flasks experiments were conducted in order to investigate how efficiently cyanobacteria can remediate wastewaters, especially remove phosphate, nitrate or ammonium. A rapidly growing Synechocystis sp. PCC 6803 cell culture removed almost all phosphate and $50 \%$ of nitrate from the nutrient rich BG-11 growth medium within four days (Paper III, Fig. 1). Similarly, Synechocystis cells removed nutrients efficiently from KA2 wastewater, as in only three days, almost all ammonium and phosphate were collected (Paper III, Fig. 2). However, the cells continued growing for a few more days (Paper III, Fig. 3), showing the nutrient storage capabilities of Synechocystis sp. PCC 6803 cells.

In addition to the control strain of Synechocystis sp. PCC 6803, we also tested sigma factor mutants ( $\triangle$ sigBCD, $\Delta$ sigBCE, $\Delta$ sigBDE, $\Delta$ sigCDE and $\Delta$ sigBCDE) for their growth abilities in KA2 (Paper III, Fig. 3). The aim of the experiment was to reveal if the KA2 wastewater induces oxidative stress to Synechocystis cells, as $\triangle$ sigBCDE is known to be highly vulnerable to any kind of oxidative stress (Hakkila et al. 2019) whereas the $\triangle \operatorname{sigBCE}$ and $\triangle \operatorname{sigCDE}$ strains have shown superior growth compared to the control strain in chemically induced oxidative stress (Hakkila et al. 2019).

For the first 4 days, all mutant strains showed similar growth in the wastewater as the control strain (Paper III, Fig. 3a). It was clear that for all strains, long term exposure to KA2 causes premature seizure of growth, when compared to CS grown in BG-11 (Paper III, Fig. 3a). Strain $\triangle$ sigBCDE, switched to stationary growth 
already after six days in KA2, and bleaching of pigments was especially noticeable on the $13^{\text {th }}$ day of growth (Paper III, Fig. 3). The pale yellow-orange colour indicated that the old $\triangle$ sigBCDE culture (Paper III, Fig. 3) had degraded almost all chlorophyll $a$ and phycocyanobilin. $\triangle$ sigBCD and $\triangle$ sigBCE switched to stationary growth phase already after the $8^{\text {th }}$ day of growth. The $\triangle$ sigBCE strain did not show any visible loss of pigments, whereas $\triangle$ sigBCD cells appeared bleached during the stationary phase (Paper III, Fig. 3). $\Delta \operatorname{sigBDE}$ (contains only $\mathrm{SigC}$ ) and $\Delta \operatorname{sigCDE}$ (contains only SigB) grew almost as well as the control strain (Paper III, Fig. 3).

We hypothesized that the low phosphorus content of the KA2 wastewater (circa half of that in the BG-11 medium) might explain growth differences between the strains, as in a previously study (Hakkila et al. 2018) phosphate transporters genes were highly upregulated in the $\triangle \mathrm{sigBCD}$ strain even when cells were grown in normal phosphate-replete BG-11 medium. To check this hypothesis, we investigated the ability of Synechocystis strains to grow in BG-11-5\%P medium that contains only $8.75 \mu \mathrm{M}$ phosphate (Paper III, Fig. 4). For the first 2 days all Synechocystis strains grew well in BG-11-5 \%P medium. After that, $\triangle$ sigBCD and $\triangle$ sigBCE grew only slowly (Paper III, Fig. 4). All other strains grew almost as well as the control strain, including the $\triangle$ sigBCDE mutant strain. This showed that for $\triangle$ sigBCD and $\triangle$ sigBCE strains, low phosphate concentration might be the reason for early growth arrest in KA2 wastewater. For the rest of the strains, the low phosphate in KA2 might not be not explain the early growth arrest. Therefore, we submitted $\triangle$ sigBCD and $\triangle$ sigBCE strains to further investigation in order to find the relationship between phosphate concentration and their growth abilities. We conducted batch growth experiments with KA2, where we added additional phosphate, adjusting the final phosphate concentration of wastewater to be the same as in the BG-11 medium. However, this addition did not improve the growth of $\triangle$ sigBCD or $\triangle$ sigBCE strains, and actually $\triangle$ sigBCD cells had a long lag phase before they started to grow indicating that low phosphate is not the main reason for the early growth arrest of $\triangle$ sigBCD or $\triangle$ sigBCE.

Unlike the BG-11 growth medium, the KA2 wastewater was not buffered for the growth experiments. We next investigated how a constant $\mathrm{pH}$ of 7.5 would affect nutrient uptake, as growth of cyanobacteria without buffering rapidly increases the $\mathrm{pH}$ of the growth medium. Growth and nutrient uptake of CS, $\triangle$ sigBCD and $\triangle$ sigBCE cells were studied in KA2 wastewater supplemented with phosphate and buffered with $20 \mathrm{mM}$ HEPES to $\mathrm{pH}$ 7.5. No differences were detected in ammonium removal between CS, $\triangle$ sigBCD and $\Delta$ sigBCE cells (Paper III, Fig. 5c). However, the removal of ammonium from KA2 after buffering (Paper III, Fig. 5c) was slower than without buffering (Paper III, Fig. 2) indicating that without buffering, volatile ammonia formed and escaped. $\triangle$ sigBCD cells grew more slowly than CS cells even 
after buffering KA2 medium and $\triangle$ sigBCD cells collected phosphate more slowly from buffered KA2 than the other strains (Paper III, Fig. 5c).

Adjustment of $\mathrm{pH}$ changed the behaviour of the $\triangle$ sigBCE strain. The $\triangle$ sigBCE strain first grew like CS in buffered KA2 and growth was even better than that of the $\mathrm{CS}$ in the end of the experiment (Paper III, Fig. 5c). Rapid growth of $\triangle$ sigBCE cells in the end of the experiment was accompanied with more rapid removal of phosphate than in the control strain (Paper III, Fig. 5c). As $\Delta$ sigBCE strain not only collected phosphate slightly more efficiently than the other stains, but it also grew better than the other strains in bright light (Paper III, Fig. 6), it might be a more robust strain for wastewater treatments than the control strain if $\mathrm{pH}$ adjustment is included in the process to prevent formation of toxic ammonia. 


\section{DISCUSSION}

\subsection{Up-scale PBR as an experimental set up for wastewater treatment}

In order to investigate the potential of a given algal species for wastewater remediation, the PBR used in the experimental set up should not present any growth limitations caused by its design and operation or materials used for the construction. A good PBR helps testing as wastewater treatment systems, as the only possible growth limitations will come from the wastewater itself. The test run shown in Figure 9 shows that the system built here has excellent characteristics.

The marine alga $N$. oculata was used for the test run because a salt water medium such as ASW is optimal for the alga but acts as a natural preservative, decreasing the chance for contamination (von Alvensleben et al. 2013). This setting would therefore reveal growth limiting factors inherent to the reactor design and operation. Batch phase operation already showed that the system can support the growth of $N$. oculata without any severe limitations, as the biomass grew to a high density just in 4 days, indicated by the OD880 sensor growth curve. Furthermore, the batch phase of the experiment was efficiently used as a calibration stage by comparing the OD880 sensor reading to dry biomass concentration. Calibrating the OD880 sensor is important for the turbidostat mode operation, as setting a constant $\mathrm{OD}_{880}$ value enables constant biomass concentration in the PBR, achieved by on demand dilution of the reactor contents when $\mathrm{OD}_{880}$ measurement exceeds a set value. Continuous dilution and harvest through an overflow of the tubular PBR define continuous bioreactor operation. It was also important to test the reactor's on demand $\mathrm{pH}$ control with $99 \% \mathrm{CO}_{2}$. As will be discussed later, maintaining a constant $\mathrm{pH}$ when using ammonium rich wastewater is crucial for optimal algal growth. It has been previously shown that $N$. oculata shows higher growth rates when the culture was sparged with $2 \% \mathrm{CO}_{2}$ enriched air. However, higher concentrations of $\mathrm{CO}_{2}$ at $5 \%$, $10 \%$ and $15 \%$ proved to be growth inhibiting for N. oculata (Chiu et al. 2009). On demand sparging with $\mathrm{CO}_{2}$ based on $\mathrm{pH}$ is a safe and efficient way to supply necessary inorganic carbon for photosynthetic growth, without an inhibitory effect. As seen in Figure 9, $\mathrm{pH}$ was kept stable at 7. 8 using this approach during the turbidostat phase. Furthermore, on demand $\mathrm{CO}_{2}$ addition enables a high specific 
growth rate, on the average 1.24 day $^{-1}$, for $N$. oculata during the turbidostat phase. A slightly higher specific growth of 1.49 day $^{-1}$ was achieved in small scale (2L) batch experiments with $N$. oculata sparged with $1 \% \mathrm{CO}_{2}$ enriched air (Rasdi and Qin 2015).

\subsection{Importance of wastewater pre-treatment}

Wastewater turbidity is an unfavourable factor in the design of algal based wastewater treatment. Removing undissolved solids and colloidal particles from the wastewater vastly improves the performance of a process based on autotrophic microalgae. Low turbidity ensures good light penetration into the reactor, and more light will be available for photosynthetic growth, which also drives fast uptake of inorganic nutrients by microalgae or cyanobacteria. High turbidity is also related to dissolved organic pollutants, and the presence of biodegradable organic compounds promotes growth of heterotrophic bacteria that can easily overtake the algal culture. Wastewaters coming from an anaerobic process have a low concentration of biodegradable pollutants but may contain dense anaerobic sludges as seen in Figure 10. DER, coming from the pilot-scale anaerobic digestors, had a high sludge content and was treated via chemical coagulation/flocculation (Fig. 10). A combination of chemical coagulation and flocculation is a well adopted process in wastewater treatment engineering, with decades of applications (Metcalf \& Eddy et al. 2004, Chapter 6). Therefore, applying it in an algal based wastewater treatment would not be a big design challenge.

There are other possible processes such as electrocoagulation, granulated activated charcoal, sand filtration or membrane filtration for removal of solids from wastewater. In my studies, activated granular charcoal was the pre-treatment strategy for the KA2, TAL1 and "Biowasher" wastewaters, as well as an additional pretreatment step for DER after coagulation/flocculation. All those wastewaters were yellowish, and a home-made PAC and GAC filter (Fig. 12) were used for their complete discoloration (Fig. 11 and Fig. 13). This method is well established for waters with high turbidity (Metcalf \& Eddy et al. 2004; Hatt et al. 2013). Furthermore, GAC has little or no effect on inorganic nutrients such as ammonium, phosphate and nitrate (Metcalf \& Eddy et al. 2004, Table 11-2). However, during the experimental work described in Paper II, GAC may have had an impact on the heavy metal content of the wastewater. Goher et al. (2015) have shown that GAC can reduce the content of iron and manganese by $99.02 \%$ and $79.05 \%$ respectively. Unfortunately, we cannot show how much of the heavy metal content of KA2 were affected by GAC, as we did not have the facilities to perform detailed micronutrient analysis. However, adsorption by GAC would change the metal composition of the wastewater, and possibly even deprive microalgae of essential micronutrients. 
In Paper I we speculated that one of the reasons why $N$. oculata cannot grow in non-diluted DE wastewater, besides high ammonium content, is the presence of manganese above limits tolerable by the alga. Optimizing the GAC pre-treatment could completely solve this problem, as GAC can efficiently remove manganese. Thus, in particular cases where heavy metal ion concentrations are high enough to become toxic for microalgae (Arunakumara and Zhang 2008), GAC filtration might be an option that can adsorb growth inhibiting heavy metal ions.

Turbidity can alternatively be removed by using a series of filters. A set of filters including a $5 \mu \mathrm{m}$ mash filter, $0.5 \mu \mathrm{m}$ ceramic filter and $0.1 \mu \mathrm{m}$ membrane filter could completely substitute coagulation/flocculation and GAC filtration. Membrane filtration has shown great potential in the removal of natural organic matter in drinking water treatment (Metsämuuronen et al. 2014). During the experimental work for Paper II, on many occasions bacterial growth started in the wastewater supply tank for the PBR. When wastewater was kept at room temperature, just in 24 hours, visible bio sludge had been accumulated on the walls of the supply tank. Besides heterotrophic bacteria, we have observed cyanobacteria and microalgae native for the wastewaters growing in the transparent supply silicone tubing. Without the $0.1 \mu \mathrm{m}$ PVDF filtration, those bacteria could easily contaminate the algal culture in the PBR and take over the process. In the experimental set up, we used filters designed for domestic drinking water applications (Fig. 20). These filters are easy to clog and difficult to maintain. The absence of self-cleaning or manual cleaning options of those disposable filters brought the biggest disadvantage in the set-up of the pre-treatment. The filtered bacterial and algal biomass coming with the wastewaters accumulated on the filter surface as described in Chapter 4.4.1. This biofouling resulted in substantial decrease of phosphate by $80 \%$. The algal culture in the reactor was deprived of phosphorus and therefore did not grow (Fig. 21). This would lead to a lower than expected wastewater treatment capacity. An appropriate industry-based membrane filter would apply daily back flush cleaning cycles that would remove the attached biomass.

To avoid the above challenges, pre-treatment consisting of a GAC filter and a $0.1 \mu \mathrm{m}$ membrane filter was designed. Furthermore, during a PBR run, wastewater analysis was performed from the supply tank and after the $0.1 \mu \mathrm{m}$ membrane filter. If significant difference was detected, a sanitation procedure with sodium hypochlorite was performed. The membrane was unplugged from the reactor influent supply line and $10 \mathrm{~L}, 1 \%$ sodium hypochlorite was pumped through the filter. After that the filter was washed with $30 \mathrm{~L}$ of tap water and installed back to the PBR.

Applying a pre-treatment step for algal based wastewater treatment would increase investment and operational costs. In the studies described here, I used coagulant/flocculant and GAC methods as best suited for the research, as they are commercially available and relatively simple to implement. As any engineering 
process, availability of the methods as well as financial capabilities will determine the most cost-effective solution. However, coagulation and GAC filtration are widely used in conventional wastewater treatment and in many cases used prior to an activated sludge step for organic content reduction to promote the efficiency of the biological process. Thus, use of these pre-treatment methods in microalga-based wastewater treatment might not be so different when comparing with conventional biological treatment. However, if one's main objective is to benefit from the microalgal biomass as a product with a good market value, using wastewaters might not be the optimal choice and one should consider a mineral growth medium from clean water and salts, avoiding the investment and operational costs related to wastewater pre-treatment. On the other hand, ultra and microfiltration are more economical to apply than coagulation and flocculation. We have managed to show that a membrane filter could function as a sole pre-treatment step, when wastewaters with low TS content are treated. Furthermore, introducing membrane filtration is critical, in my opinion, as in general algal-based processes strongly benefit from sterilization of not only wastewaters, but also mineral growth medium.

\subsection{Wastewater optimization for a stable alga- based wastewater treatment process}

\subsubsection{Fluctuations in wastewaters composition}

Wastewaters come from different sources, which directly impacts the qualities and characteristics of the wastewaters. Furthermore, as shown in Table 2, one and the same wastewater source can produce different wastewaters, based on pollutant concentrations and composition. Many of the processes generating wastewaters can fluctuate based on materials used for the process, process parameters and seasonal changes (Leitão et al. 2006; Chang et al. 2008; Niwa et al. 2016).

DER was obtained as an effluent from semi-batch pilot-scale anaerobic reactors. The ammonium composition of anaerobic reactor effluent can vary due to temperature fluctuations (El-Mashad et al. 2004). However, in the case of DER, the effluent was obtained from a laboratory set up, where the reactors were kept at constant room temperature, ensuring optimal temperature conditions. Therefore, we can speculate that the mean reason for ammonium fluctuation in DER was that the organic loading rates varied between batches.

KA2 is generated from an anaerobic landfill. Newly loaded landfills produce leachate that has high BOD values and low concentrations of inorganic pollutants. In our case the leachate has been obtained from an old landfill where complete mineralization of the organic matter has occurred, hence the low BOD values measured from the wastewater (Renou et al. 2008). As mentioned previously, 
anaerobic processes are more likely influenced by the seasonal changes due to temperature fluctuations. Environmental factors impact the metabolic performance of the anaerobic bacteria. Furthermore, drought or heavy rain can increase pollutants concentrations or dilute the leachate, respectively.

Another factor influencing the variation in the ammonium concentration of the wastewaters used in this study is the fact that they were collected and shipped to us. In some cases, wastewaters had to be stored for weeks. Although we stored them at $4{ }^{\circ} \mathrm{C}$, there still could be bacterial metabolic activity. In such case, in a tightly closed storage vessel, the anaerobic bacteria, naturally present in the wastewater, would continue degrading the organic pollutants present in the water.

However, our experience has shown, that the major factor involved in variation of the wastewater ammonium content was the naturally alkaline $\mathrm{pH}$ of the wastewaters. In alkaline conditions, part of the soluble ammonium converts to its gaseous ammonia $\left(\mathrm{NH}_{3}\right)$ that escapes. After one year of storage at $4{ }^{\circ} \mathrm{C}$, all ammonium was lost from DER. These experiences suggest that wastewater research projects should be performed at the wastewater generation site, avoiding transportation and storage.

Fluctuations of the nutrient content require strict monitoring of the wastewater composition. Adjustment can then correct for absence or shortage of an inorganic nutrient. This is how we solved the low P and S content of KA2 in Paper II. Adjusting the levels of those two nutrients led to optimal nutrient concentrations for $0.5 \mathrm{mg} \mathrm{L}^{-1}$ of biomass and resulted in fast growth and a low hydraulic retention time of the process.

\subsubsection{Ammonium toxicity}

Fluctuation of pollutant composition can inhibit the growth of microalgae if a concentration exceeds specific tolerance threshold. A high ammonium concentration could be toxic for microalgae (Figs. 14 and 15). Ammonium $\left(\mathrm{NH}_{4}{ }^{+}\right)$in aqueous solution, exists in a $\mathrm{pH}$ dependent equilibrium with ammonia $\left(\mathrm{NH}_{3}\right)$. Källqvist and Svenson (2003) showed that ammonia is 100 times more toxic than ammonium for the marine green microalga Nephroselmis pyriformis. However, inside an algal cell, all inorganic nitrogen is reduced to ammonium. The higher toxicity of ammonia can be explained by the fact that ammonium is transported through the cell membrane via specific channels (Rees et al. 1980; Flynn and Syrett 1986) whereas ammonia $\left(\mathrm{NH}_{3}\right)$ can also diffuse through the membrane and cells have no mechanism to control it. High intracellular concentration of ammonium leads to a high glutamine/2-oxoglutarate ratio, which can inactivate the ammonium transporter (Flynn 1991). 
In suspensions with high ammonium concentrations (such as the wastewaters in Paper I), photosynthetic activity leads to a $\mathrm{pH}$ increase which favours conversion of ammonium to ammonia. Ammonia would diffuse freely through the cell membrane and cause build-up of a high intracellular ammonium content, which can cause cell damaging events. The $\mathrm{pH}$ dependent conversion between ammonium and ammonia on acidic and basic sides of biological membranes and the diffusion of ammonia through the membrane are routine laboratory practices for discharging $\mathrm{pH}$ gradients. Ammonium toxicity inhibits both mitochondrial respiration (Vines and Wedding 1960) and photophosphorylation (Flynn 1991). An elevated level of intracellular ammonium can also cause oxidative stress, inactivating enzymes and promoting lipid peroxidation (Nimptsch and Pflugmacher 2007). Therefore, wastewaters with high ammonium content must be treated with microalgae in a $\mathrm{pH}$-controlled process, as otherwise the ammonium toxicity effect will be enhanced. Another way to cope with high ammonium wastewater concentration might be to increase the amount of inorganic carbon. Since 2-oxoglutarate, as described in the introduction, is an essential molecule in ammonium incorporation via the glutamate synthaseglutamine-oxoglutarate aminotransferase (GS-GOGAT) pathway, $\mathrm{CO}_{2}$ fixation plays an important role in algal nitrogen metabolism. It has been shown that by adjusting the carbon to nitrogen ratio $(\mathrm{C} / \mathrm{N})$, ammonium assimilation by microalgae can be enhanced (Perez-Garcia et al. 2011a). Microalgae can tolerate a higher ammonium concentration and show faster ammonium absorption when grown in high $\mathrm{CO}_{2}$ conditions (Collos 1989; Lynch et al. 2015).

Due to the above considerations, $\mathrm{pH}$ control via on demand sparging with $\mathrm{CO}_{2}$, as shown in Paper II, Figure 1, is beneficial for alga based wastewater treatment.

\subsubsection{Importance of continuous growth experiments for determining nutrient deprivation}

Success of batch growth may not be a trustable indication about of the ability of microalgae to be used for wastewater treatment. The results of Paper II show that if an optimal growth medium, such as BG-11, is used for the preparation of the inoculum, only the continuous phase of the experiment will reliably reveal nutrient limitations. Therefore, in order to investigate properly the growth of microalgae in a wastewater, one should either prepare the inoculum in the same wastewater or use continuous growth. In addition to potentially revealing nutrient limitations of the wastewater already during the batch phase, the use of wastewater as growth medium for the inoculum would give the additional advantage of acclimating the algal culture to the wastewater. Figure 4 of Paper II shows an example of this procedure, as the inoculum of E. oleoabundans was prepared in KA2. In contrast to earlier experiments, the microalgae did not show prolonged lag (Paper II, Fig.3). 
Experiments with KA2 shown in Figures 3 and 4 of Paper II clearly show that wastewaters can be low on essential micronutrients. It remains to be found out whether these wastewaters naturally lacked heavy metal ions, or whether our choice of pre-treatment resulted in heavy metal deficiency.

The slow growth and slow increase in chlorophyll content, indicated by $\mathrm{OD}_{880}$ and $\mathrm{OD}_{680}$ in Paper II, Fig. 3, suggest that iron might be present in the wastewater or came with the inoculum. However, its final concentration in the PBR was low. However, full negative effect upon the growth of the microalgae was observed only when the experiment was set to turbidostat mode. The continuous additions of wastewater did not introduce additional iron to the PBR to support the turbidostat growth phase. During the second up-scale experiment (Paper II, Fig. 4), limitation by another heavy metal component was revealed. The $\mathrm{F}_{\mathrm{V}} / \mathrm{F}_{\mathrm{M}}$ value of the algal suspension was very low and recovered after addition of the BG-11 trace metal mix, indicating that photosynthesis was among the cellular processes that were inhibited by the nutrient deficiency. This, however, does not allow specifying which one of the trace elements limited E. oleoabundans growth. Deficiency of metals needed in photosynthesis might cause lowering of $\mathrm{F}_{\mathrm{V}} / \mathrm{F}_{\mathrm{M}}$. In addition, the continuous repair of the photoinhibitory damage of Photosystem II is known to be inhibited by nutrient deficiency (Melis et al. 2000; Volgusheva et al. 2015).

\subsection{Cultivation of Nannochloropsis oculata in wastewater for EPA production}

In Paper I, the marine microalgae $N$. oculata was successfully grown in a mixture of $25 \%$ digest effluent and $75 \%$ wastewater treatment plant effluent (Paper II, Fig. 1). The results also show that the DE medium can be used when we want to achieve an $N$. oculata culture with high EPA content and a high oil content (Fig. 17).

The wastewater-based growth medium (DE medium) proved to be not limiting for the growth of $N$. oculata. Furthermore, microalgae grown in the DE medium showed similar maximum specific growth rates when compared with ASW growth (Paper I, Fig.2). It has been previously shown Nannochloropsis sp. can grow in wastewaters mixed with seawater and tolerate low salt content (Jiang et al. 2011; Biondi et al. 2013). N. oculata has been isolated from supralittoral rock ponds, and it has been shown to naturally exist in habitats with water salinity as low as $0.4 \%$ (Droop 1955, Table 1). This could explain N. oculata's ability for sustained growth in the freshwater based DE medium with no additional salt (Paper I, Fig. 2B).

In the ASW medium, the major form of inorganic nitrogen is nitrate, whereas in $\mathrm{DE}$ it is ammonium. It has been shown that Nannochloropsis salina can utilize both $\mathrm{NO}_{3}{ }^{-}$and $\mathrm{NH}_{4}{ }^{+}$but strongly prefers $\mathrm{NO}_{3}{ }^{-}$(Campos et al. 2014). However, an unnamed strain of Nannochloropsis sp. prefers ammonium over nitrate (Hii et al. 
2011), indicating that the preference varies within the genus. We show that, once ammonium has been adjusted, via dilution, below a toxic concentration, $N$. oculata can utilize it for biomass synthesis (Paper I, Table 1).

The phosphorus content of the DE medium was approximately one fourth of that of the ASW medium. In Paper I we speculated, based on data shown by Mayers et al. (2014) for Nannochloropsis sp., that in our experiments the high N:P ratio would not cause serious effect on growth in batch mode. However, the results of Paper II show that batch growth can hide nutrient limitation.

Sulphur in the ASW medium is present as sulphate. The water analysis of the digest effluent did not show any sulphate present in the wastewater. However, the analysis revealed the presence of elemental sulphur (Paper I, Table 1). Due to the batch operation of the experiments, it is hard to predict whether the form of sulphur present in the DE medium was bioavailable.

A stationary state was reached faster in the DE medium than in the ASW medium (Paper I, Fig. 2), strengthening the idea that the DE medium might be nutrientlimited. In order to examine this further, a turbidostat-type production system should be used.

Aluminium and manganese concentrations of undiluted DE exceeded the toxicity threshold for Nannochloropsis sp. (Paper I, Fig. 2). Aluminium in alkaline conditions, like in the DE medium, has reduced toxicity because it is mainly present as insoluble oxides (Rwehumbiza et al. 2012). Manganese, as discussed previously, can be efficiently removed via activated charcoal which was used as the pretreatment strategy for DER. However high removal efficiency for Mn up to $79 \%$ via activated charcoal can be achieved only in well optimized conditions (Goher et al. 2015). Therefore, it is unlikely that our pre-treatment step by itself was enough to lower the Mn content of DER below the toxicity level. Nevertheless, in our growth experiments we have used four times diluted DE (25\%), which brings the final Mn concentration in DE medium below toxicity level (Paper I, Table 2).

The similarity in biomass productivity in both the DE and ASW media was reflected by the photosynthesis parameters. Chlorophyll $a$ fluorescence did not show any significant differences between $N$. oculata cultures grown in the ASW or the DE medium (Paper I, Table 2). These results show that, even if cell division slowed down toward the end of the batch growth experiment (Paper I, Fig. 2), photosynthesis continued at high rate in cells grown in the DE medium.

Even though the freshwater nature of the DE medium or the nutrient concentrations and bioavailability did not have an impact over the growth rate and overall biomass productivity of batch grown $N$. oculata, those factors might have played roles in the difference observed in the lipid contents between the cultures grown in the DE and ASW media. Our results show 6.5 times higher neutral lipid content in the culture grown in the DE medium than in that cultivated in the ASW 
medium. Furthermore, the TAG fraction was almost 3 times as large in cells grown in the DE medium, compared to those grown in the ASW medium (Fig. 18), although biomass productivity did not differ substantially between the media. This resulted in a slightly higher EPA content per litre of culture for the cultures grown in the DE medium (Paper I, Table 2). Usually accumulation of neutral lipids is associated with nitrogen-depleted conditions, high light and or variation during diurnal light phases (Roessler 1990; Sukenik and Carmeli 1990; Lukeš et al. 2017). Furthermore, the total amounts of fatty acids belonging to different lipid classes and the fatty acid compositions of the lipid classes in Nannochloropsis species are controlled by stress factors and other environmental conditions (Sukenik et al. 1989; Sukenik 1991; Hu et al. 2008).

In our experiments with $N$. oculata in the DE medium, the algal culture reached steady state earlier than the culture grown in the ASW medium (Paper I, Fig. 2); the growth arrest was probably caused by lack of nutrients. The biomass collected for lipid analysis from the DE medium after a $40 \mathrm{~h}$ retention time (Paper I, Fig. 2) consisted of less cells and had a higher oil content than the biomass cultured in the ASW medium (Paper I, Table 2). Furthermore, low chlorophyll $a$ content and low chlorophyll to carotenoid ratio were observed for $N$. oculata grown in the DE medium (Paper I, Fig. 3). A similar observation has been earlier reported for $N$. salina grown in nitrogen depleted conditions (Adams and Bugbee 2014). The fact that the DE medium is essentially fresh water (Paper I, Table 1) may also contribute to the stress caused by the nutrient depletion.

\subsection{Wastewater treatment with Ettlia oleoabundans in a pilot scale tubular PBR}

Paper II shows the steps necessary for establishing a reliable and stable wastewater treatment process with the green microalgae E. oleoabundans and KA2. After addressing all growth limitations caused by the wastewater, such as turbidity, biological contamination and nutrient deficiencies, a successful process was established (Paper II, Fig. 5). We have managed to achieve $75 \%$ and $99.6 \%$ removal efficiency for $\mathrm{NH}_{4}{ }^{+}$and $\mathrm{PO}_{4}{ }^{3-}$ respectively (Paper II, Fig. 7) with the average biomass concentration of $0.47 \mathrm{~g} \mathrm{~L}^{-1}$ and average growth rate of $0.73 \mathrm{day}^{-1}$. This experiment showed that macronutrients, especially $\mathrm{N}, \mathrm{P}$ and $\mathrm{S}$ must be in optimal concentrations in order to achieve well balanced and fast process. The results show that even though $\mathrm{N}: \mathrm{P}$ ratios close to the Redfield N:P molar ratio of 16 (Redfield 1934) are optimal for establishing optimal E. oleoabundans growth, the lower N:P ratio of 11.5 can promote higher inorganic nitrogen uptake by E. oleoabundans. The same dependency has been previously shown for Tetraselmis suecica by Michels et al. (2014). 
The batch phase of the experiment was proven useful in realizing possible nutrient limitations. Even though we have adjusted $\mathrm{PO}_{4}{ }^{3-}$ and $\mathrm{SO}_{4}{ }^{2-}$ prior to the experiment, during the batch phase it was noted that E. oleoabundans used more phosphate than we predicted (Paper II, Fig. 6). This led to a need to increase the phosphate concentration during the experiment in order to optimize the turbidostat phase. The batch phase of the experiment revealed another interesting observation. Even though it is considered that E. oleoabundans grows better in nitrate containing medium than in an ammonium containing medium ( $\mathrm{Li}$ et al. 2008), the observation that the nitrate, introduced by the inoculum, was absorbed only after the ammonium was depleted, confirms that ammonium is involved in inactivation of nitrate transporters (Paper II, Fig. 6) (Morris and Syrett 1963; Losada et al. 1970; Cresswell and Syrett 1979). This experiment also shows that chlorophyll $a$ fluorescence measurements are fast methods for investigating stress that limits algal growth and process performance.

\subsection{Synechocystis sp. 6803 mutants grown in wastewater}

Paper III confirms previous observations from other researchers that Synechocystis sp. PCC 6803 and other cyanobacterial species offer a potential solution for nitrogen and phosphorus removal from wastewaters (Rojsitthisak et al. 2017; Campos-Rudin M and Silva-Benavides AM 2018; Jayesh H. Kabariya and Vimal M. Ramani 2018). The results show that even though KA2 wastewater does not cause any immediate oxidative stress, as the stress sensitive mutant strain $\triangle$ sigBCDE grew for few days in KA2 (Paper III, Fig. 3), adjusting the $\mathrm{pH}$ of ammonium containing wastewater is important in order to minimize the stress effects. Moreover, in unbuffered wastewater in which photosynthetic growth causes increase in $\mathrm{pH}$, ammonium is likely to become rapidly depleted because it is lost as gaseous $\mathrm{NH}_{3}$ (Paper III, Fig. 2). When we used buffered KA2 wastewater (pH 7.5), Synechocystis sp. PCC 6803 showed a longer retention time for ammonium and phosphate, indicating better nutrient utilization (Paper III, Fig. 5c).

Even though the CS strain grown in KA2 remained healthy green, showing none of the well-known symptoms of stress induced by nitrogen depletion (Antal et al. 2016; Ruan et al. 2018), it reaches stationary phase in KA2 earlier than in BG-11 medium (Paper III, Fig. 3). Therefore, we investigated if phosphate was a growth limiting factor for Synechocystis cells in the KA2 wastewater, by growing Synechocystis in low phosphate BG-11 (BG-11-5\%P). Synechocystis sp. PCC 6803 strains grew well for four days, indicating that phosphate is unlikely to be a limiting factor for the CS in KA2 (Paper III, Fig. 4). On the other hand, $\triangle$ sigBCD showed early growth arrest in BG-11-5\%P. Furthermore, this strain absorbed phosphate 
more slowly than the other strains (Paper III, Fig. 5c). We speculate that this is due to defects in phosphate absorption, as suggested by the finding that genes encoding phosphate transporters are highly expressed in this even under standard growth conditions (Paper III, Supplemental Table S1). However, increasing the phosphate concentration in the wastewater did not improve growth of $\triangle$ sigBCD in KA2 (Paper III, Fig. 5a). Nevertheless, our finding that the long lag phase disappeared, when $\triangle$ sigBCD was grown in buffered KA2 instead of an unbuffered wastewater (Paper III, Figs. 5a and 5c). This finding suggests that ammonia formed in the unbuffered KA2 has a toxic effect on the strains. Since $\Delta$ sigBCD lacks the two main stress responsive $\sigma$ factors $\operatorname{SigB}$ and $\operatorname{SigD}$ (Hakkila et al. 2019), it is possible that this causes the strain to be more sensitive to ammonia.

The other mutant strain $\triangle$ sigBCE, missing one of the two main oxidative stress responsive $\sigma$ factors ( $\mathrm{SigB}$ ), showed improved growth in KA2 wastewater adjusted to $\mathrm{pH}$ 7.5. Furthermore, $\triangle$ sigBCE cells showed higher nutrient removal efficiency and cell density than the control strain (Paper III, Fig. 5c). The $\Delta$ sigBCE strain also grows better than the control strain in high light (Paper III, Fig. 6), singlet oxygen or $\mathrm{H}_{2} \mathrm{O}_{2}$ stresses (Hakkila et al. 2019). In this strain, $\mathrm{SigD}$ is the only group 2 sigma factor, and the data may therefore suggest that overexpression of SigD factor in cyanobacteria might be potentially interesting for wastewater treatment where tolerance of high light and reactive oxygen species is beneficial. 


\section{6 \\ CONCLUSION AND FUTURE PERSPECTIVES}

In my PhD studies I investigated the potential of using microalgae and cyanobacteria as a biological method in wastewater treatment.

The results of Paper I show that it is possible to produce high value compounds from algal biomass grown in wastewater. However, continuous production of EPA containing $N$. oculata biomass grown in DE medium should be investigated. In that way nutrient limitation and their impact over the growth of $N$. oculata and its EPA content could be examined. Furthermore, it is hard to say how economically feasible the downstream processing will be in order to purify the EPA produced from wastewaters as well as the impact over the marketing potential of an edible product produced from biomass grown in wastewater. This should be investigated in additional studies.

In Paper II, a stable wastewater treatment process in a tubular PBR was established. This work has also revealed that implementing wastewater pre-treatment and determining possible limiting factors such as metal concentrations and the N:P ratio is crucial for an efficient and stable process. Nevertheless, an optimized process could reach close to $100 \%$ of recovery of macronutrients. This study stresses the importance of continuous growth of the algal/cyanobacterial culture in the wastewater. If this is not an option, at least the inoculum used in the final experiment should be prepared in the wastewater. Logical continuation of this work is further in-depth investigation of the importance of micronutrients in algal-based processes. This would enable better estimation of the potential of microalgae for heavy metal removal from polluted waters. This work also shows the importance of pre-treatment in wastewater treatment with algae. However, it hard to say what impact this will have over the investment and operational costs. This presents an excellent opportunity for a review paper, looking into different pre-treatment methods and their financial feasibility.

Paper III revealed the potential of sigma factor D in creating a more robust strain for future outdoor wastewater treatment applications. However, further investigation of how exactly the sigD gene can be applied is needed. Furthermore, since all the experiments were done on a batch scale, a continuous experiment would give more 
information regarding the possible application of Synechocystis's group 2 sigma factor mutants in wastewater treatment.

Ideally. all these 3 separate works should be united in the future under one experimental project - Wastewater treatment with genetically enhanced algal/cyanobacterial strain for the production of high value compounds in an outdoor photobioreactor.

At this point, eventhough promising, microalgae and cyanobacteria can not yet be included among the conventinal biological methods of wastewater treatment. However, further research exploring co-cultivation of several agal species and cocultivation of algae and nitrifying bacteria could potentially enable microalgae applications in wastewater treatment. 


\section{$7 \quad$ ACKNOWLEDGEMENTS}

The experiments described in this thesis work and publications have been performed in the laboratories of Molecular Plant Biology as well as the laboratory of Food Chemistry and Food Development at University of Turku. Funding by Academy of Finland (grants 259075, 265807 and 307335), European Regional Development Fund (BioRefTech project), Helsingin Seudun Ympäristöpalvelut, NordForsk (NordAqua project), Novo Nordisk Foundation, University of Turku Graduate School, and Maa- ja vesitekniikan tuki R.Y is thankfully acknowledged.

I am grateful for the support of my supervisors- Esa Tyystjärvi and Taina Tyystjärvi. Esa, Thank You for your patience with me and my work, for the constructive criticism throughout our publications and my thesis, pushing me to investigate further and thought me to be sincere, accurate and complete in science. Taina, Thank You, for stepping up in a crucial moment in my $\mathrm{PhD}$ studies, including me in your work. Thank you for sharing your knowledge and tremendous help throughout our publications and my thesis. Kiitos paljon!

All my gratitude to Academician Eva-Mari Aro, Prof. Eevi Rintamäki and Assoc. Prof. Yagut Allahverdiyeva-Rinne for having me and helping for what it turned out to be a long, long PhD study

Thank You, Taras Antal and Sujata Mishra, my co- supervisors for the help and all the tips and guidance during my $\mathrm{PhD}$ studies.

Many thanks go for all my co- authors, Anna Polishchuk, Sujata Mishra, Marko Tarvainen, Viljami Kinnunen, Taras Antal, Baoru Yang, Jukka Rintala, Hellen Silva Santos and Juha Kurkela. It goes without saying, this thesis work will not be possible without your help and professional work.

Aino Kainulainen, Christoph Careis and Roni Järvensivu from Helsinki Region Environmental Services Authority (HSY) are thanked for cooperation with the wastewaters.

Special thanks to Pasi Saarenmaa, Kurt Ståhle, Dr. Mika Keränen and all technicians from the workshop of University of Turku, for cooperation in the construction of the PBR and materializing all my design ideas. Tapio Ronkainen, thank you, not just for the valid advices and help for the up- scale PBR but also for teaching me practical knowledge as well as keeping the doors to your office always 
open for me. Thank you for all discussions regarding life and all advices given, all is well appreciated!

Many thanks go to Dr. Fiona Lynch for sharing her know how and Dr. Sema Sirin for her support and encouragement in a difficult moment.

Thank You, Heta Mattila, Pooneh Sotoudehnia, Vesa Havurinne, Juha Kurkela, Olli Virtanen, Sergey Korobrykh, Steffen Grebe, Duncan Fitzpatrick, Andrea Trotta and all the colleagues from Molecular Plant Biology Department for all the shared moments (beers), good talks and laughter.

Words are not enough to express my gratitude to my spouse Hellen Silva Santos. Not only she had helped me to complete seven years of work and have become a coauthor in one of the publications included in this thesis, but she has been the biggest support in the past six years in what turned out be extremely turbulent period in my professional and personal life. Thank you, my love, for being an essential part in all of it! Te amo muito!

A special place in these acknowledgments goes in memorial to my father Ivan Valev. He did not have the chance to see the completion of my studies. However, I am grateful not just for his parental guidance, but his contribution to my work. As an experience wastewater treatment engineer, he helped with his advices in the design of the pre- treatment methods used throughout my studies as well as strengthen my overall understanding regarding wastewater treatment engineering. Благодаря ти за всичко, тате! Ще ми липсваш!

Gratitude goes to my mother and my brother, Tania Valeva and Kaloyan Valev for the support and encouragement during all those years. Благодаря ти, мамо! Балгодарско, браточка!

A big Thank You to my Brazilian family. To my sister-in-law Helma Santos and my brother-in-law Emanoel Fonseca, thank you for being there in good and bad times. Obrigado minha mãe e meu pai (Dione e Edson), e meu cunhado Helisson pelo apoio! Deus vos abençoe!

Thanks to all my friends that I have gained through life, Christhopher Andel, Dimitar Runkov, Xu Weiyi, Gabriel Elmagian, Simeon Georogiev, Mario and Ina Sarabakovi, Nikolay Nenov and Ivan Tankovski. Your friendship has been more than helpful!

June 2020

Dimitar Valev 


\section{List of References}

91/271/EEC (1991) The Council of the European communities, Directive concerning urban waste water treatment (91/271/EEC).

Adams C, Bugbee B (2014) Nitrogen retention and partitioning at the initiation of lipid accumulation in nitrogen-deficient algae. J Phycol 50:356-365.

Adl SM, Simpson AGB, Farmer MA, Andersen RA, Anderson OR, Barta JR, Bowser SS, Brugerolle G, Fensome RA, Frederico S, James TY, Karpov S, Kugrens P, Krug J, Lane CE, Lewis LA, Lodge J, Lynn DH, Mann DG, McCourt RM, Mendoza L, Moestrup Ø, Mozley-Standridge SE, Nerad TA, Shearer CA, Smirnov AV, Spiegel FW, Taylor MFJR (2005) The new higher level classification of eukaryotes with emphasis on the taxonomy of protists. J. Eukaryot. Microbiol. 52(5): 399-451.

Andaluz S, López-Millán A-F, De las Rivas J, Aro E-M, Abadía J, Abadía A (2006) Proteomic profiles of thylakoid membranes and changes in response to iron deficiency. Photosynth Res 89:141-155.

Anderson SL, McIntosh L (1991) Light-activated heterotrophic growth of the cyanobacterium Synechocystis sp. strain PCC 6803: a blue-light-requiring process. Journal of Bacteriology, 173(9): 2761-2767.

Antal T, Kurkela J, Parikainen M, Kårlund A, Hakkila K, Tyystjärvi E E, Tyystjärvi T (2016) Roles of group 2 sigma factors in acclimation of the cyanobacterium Synechocystis sp. PCC 6803 to nitrogen deficiency. Plant Cell Physiol 57:1309-1318.

Ardern E, Lockett WT (1914) Experiments on the oxidation of sewage without the aid of filters. J Soc Chem Ind 33:523-539.

Arunakumara KKIU, Zhang X (2008) Heavy metal bioaccumulation and toxicity with special reference to microalgae. J Ocean Univ China 7:60-64.

Baday S, Orabi EA, Wang S, Lamoureux G, Bernèche S (2015) Mechanism of

$\mathrm{NH}_{4}{ }^{+}$recruitment and $\mathrm{NH}_{3}$ transport in Rh proteins. Structure 23:1550-1557.

Baldisserotto C, Popovich C, Giovanardi M, Sabia A, Ferroni L, Constenla D, Leonardi P, Pancaldi S (2016) Photosynthetic aspects and lipid profiles in the mixotrophic alga Neochloris oleoabundans as useful parameters for biodiesel production. Algal Res 16: 255-265.

Barber J (2003) Photosystem II: The engine of life. Q. Rev. Biophys. 36:71-89.

Barber J, Nield J, Duncan J, Bibby TS (2006) Accessory chlorophyll proteins in cyanobacterial Photosystem I. In: Golbeck JH (ed) Photosystem I: The Light-Driven Plastocyanin:Ferredoxin Oxidoreductase. Springer Netherlands, Dordrecht, pp 99-117.

Béchet Q, Shilton A, Fringer OB, Muñoz R, Guieysse B (2010) Mechanistic modeling of broth temperature in outdoor photobioreactors. Environ Sci Technol 44:2197-2203.

Beckmann J, Lehr F, Finazzi G, Hankamer B, Posten C, Wobbe L, Kruse O (2009) Improvement of light to biomass conversion by de-regulation of light-harvesting protein translation in Chlamydomonas reinhardtii. J Biotechnol 142:70-77.

Biondi N, Bassi N, Chini Zittelli G, De Faveri D, Giovannini A, Rodolfi L, Allevi C, Macrì C, Tredici MR (2013) Nannochloropsis sp. F\&M-M24: Oil production, effect of mixing on productivity and growth in an industrial wastewater. Environ Prog Sustain Energy 32:846-853. 
Bondioli P, Della Bella L, Rivolta G, Chini Zittelli G, Bassi N, Rodolfi L, Casini D, Prussi M, Chiaramonti D, Tredici MR (2012) Oil production by the marine microalgae Nannochloropsis sp. F\&M-M24 and Tetraselmis suecica F\&M-M33. Bioresour Technol 114:567-572.

Borowitzka M (2013) Energy from microalgae: A short history. In: Algae for Biofuels and Energy. pp $1-15$.

Borowitzka MA (1999) Commercial production of microalgae: ponds, tanks, and fermenters. In: Osinga R, Tramper J, Burgess JG, Wijffels RHBT-P in IM (eds) Marine Bioprocess Engineering. Elsevier, pp 313-321.

Boussiba S, Gibson J (1991) Ammonia translocation in cyanobacteria. FEMS Microbiol Rev 8:1-14.

Breuer G, Lamers PP, Martens DE, Draaisma RB, Wijffels RH (2012) The impact of nitrogen starvation on the dynamics of triacylglycerol accumulation in nine microalgae strains. Bioresour Technol 124:217-226.

Campos-Rudin M, Silva-Benavides AM (2018) Ammonium and phosphate removal using batch laboratory cultures by microalgae and cyanobacteria isolated from Costa Rica water bodies. Int $\mathrm{J}$ Trop Biol Conserv 66:83-91.

Campos H, Boeing WJ, Dungan BN, Schaub T (2014) Cultivating the marine microalga Nannochloropsis salina under various nitrogen sources: Effect on biovolume yields, lipid content and composition, and invasive organisms. Biomass and Bioenergy 66:301-307.

Chang C-Y, Chang J-S, Vigneswaran S, Kandasamy J (2008) Pharmaceutical wastewater treatment by membrane bioreactor process - a case study in southern Taiwan. Desalination 234:393-401.

Chantanachat S, Bold HC (1962) Phycological Studies II. Some Algae from Arid Soils. University of Texas, Austin, Texas.

Chinnasamy S, Bhatnagar A, Hunt RW, Das KC (2010) Microalgae cultivation in a wastewater dominated by carpet mill effluents for biofuel applications. Bioresour Technol 101:3097-3105.

Chiu S-Y, Kao C-Y, Tsai M-T, Ong S-C, Chen C-H, Lin C-S (2009) Lipid accumulation and $\mathrm{CO}_{2}$ utilization of Nannochloropsis oculata in response to $\mathrm{CO}_{2}$ aeration. Bioresour Technol 100:833838.

Chu W-L (2012) Biotechnological applications of microalgae. IeJSME 6:24-37.

Clegg RM, Sener M, Govindjee (2010) From Förster resonance energy transfer to coherent resonance energy transfer and back. In: Proc.SPIE.

Collos Y (1989) A linear model of external interactions during uptake of different forms of inorganic nitrogen by microalgae. J Plankton Res 11:521-533.

Colman B, Huertas IE, Bhatti S, Dason JS (2002) The diversity of inorganic carbon acquisition mechanisms in eukaryotic microalgae. Funct Plant Biol 29:261-270.

Converti A, Casazza AA, Ortiz EY, Perego P, Del Borghi M (2009) Effect of temperature and nitrogen concentration on the growth and lipid content of Nannochloropsis oculata and Chlorella vulgaris for biodiesel production. Chemical Engineering and Processing 48: 1146-1151.

Cresswell RC, Syrett PJ (1979) Ammonium inhibition of nitrate uptake by the diatom, Phaeodactylum tricornutum. Plant Sci Lett 14:321-325.

Deng M-D, Coleman JR (1999) Ethanol synthesis by genetic engineering in cyanobacteria. Appl Environ Microbiol 65:523-528.

Deruyck B, Thi Nguyen KH, Decaestecker E, Muylaert K (2019) Modeling the impact of rotifer contamination on microalgal production in open pond, photobioreactor and thin layer cultivation systems. Algal Res 38:101398.

Drath M, Kloft N, Batschauer A, Marin K, Novak J, Forchhammer K (2008) Ammonia triggers photodamage of photosystem II in the cyanobacteriumSynechocystis sp. strain PCC 6803. Plant Physiol 147:206-215.

Droop MR (1955) Some new supra-littoral Protista. Marine biology Ass. U.K. 34: 233-245.

Ducat DC, Avelar-Rivas JA, Way JC, Silver PA (2012) Rerouting carbon flux to enhance photosynthetic productivity. Appl Environ Microbiol 78:2660-2668. 
El-Mashad HM, Zeeman G, van Loon WKP, Bot GPA, Lettinga G (2004) Effect of temperature and temperature fluctuation on thermophilic anaerobic digestion of cattle manure. Bioresour Technol 95:191-201.

Falkowski PG (1975) Nitrate uptake in marine phytoplankton: (nitrate, chiloride)-activated adenosine triphosphatase from Skeletonema costatum (Bacillariophyceae). J Phycol 11:323-326.

Flynn KJ (1991) Algal carbon-nitrogen metabolism: a biochemical basis for modelling the interactions between nitrate and ammonium uptake. J Plankton Res 13:373-387.

Flynn KJ, Syrett PJ (1986) Characteristics of the uptake system for L-lysine and L-arginine in Phaeodactylum tricornutum. Mar Biol 90:151-158.

Garibay-Hernández A, Barkla BJ, Vera-Estrella R, Martinez A, Pantoja O (2017) Membrane proteomic insights into the physiology and taxonomy of an oleaginous green microalga. Plant Physiology_, 173: 390-416.

Genkov T, Meyer M, Griffiths H, Spreitzer RJ (2010) Functional hybrid rubisco enzymes with plant small subunits and algal large subunits: Engineered rbcS cDNA for expression in Chlamydomonas. J Biol Chem 285:19833-19841.

Giovanardi M, Ferroni L, Baldisserotto C, Tedeschi P, Maietti A, Pantaleoni L, Pancaldi S (2013) Morphophysiological analyses of Neochloris oleoabundans (Chlorophyta) grown mixotrophically in a carbon-rich waste product. Protoplasma 250: 161-174.

Goher ME, Hassan AM, Abdel-Moniem IA, Fahmy AH, Abdo MH, El-sayed SM (2015) Removal of aluminum, iron and manganese ions from industrial wastes using granular activated carbon and amberlite IR-120H. Egypt J Aquat Res 41:155-164.

González LE, Cañizares RO, Baena S (1997) Efficiency of ammonia and phosphorus removal from a Colombian agroindustrial wastewater by the microalgae Chlorella vulgaris and Scenedesmus dimorphus. Bioresour Technol 60:259-262.

Gouveia L (2011) Microalgae as a feedstock for biofuels. In: Gouveia L (ed) Microalgae as a feedstock for biofuels. Springer Berlin Heidelberg, Berlin, Heidelberg, pp 1-69.

Grobbelaar JU (2008) Factors governing algal growth in photobioreactors: the "open" versus "closed" debate. J Appl Phycol 21:489.

Hackenberg C, Huege J, Engelhardt A, Wittink F, Laue M, Matthijs HCP, Kopka J, Bauwe H, Hagemann M (2012) Low-carbon acclimation in carboxysome-less and photorespiratory mutants of the cyanobacterium Synechocystis sp. strain PCC 6803. Microbiology, 158: 398-413.

Hakkila K, Valev D, Antal T, Tyystjärvi E, Tyystjärvi T (2019) Group 2 sigma factors are central regulators of oxidative stress acclimation in cyanobacteria. Plant Cell Physiol 60:436-447.

Hänsch R, Mendel RR (2009) Physiological functions of mineral micronutrients (Cu, Zn, Mn, Fe, Ni, Mo, B, Cl). Curr. Opin. Plant Biol. 12:259-266.

Hatt JW, Germain E, Judd SJ (2013) Granular activated carbon for removal of organic matter and turbidity from secondary wastewater. Water Sci Technol 67:846-853.

Hayes M, Bastiaens L, Gouveia L, Gkelis S, Skomedal H, Skjanes K, Murray P García-Vaquero M, Hosoglu MI, Dodd J, Konstantinou D, Safarik I, Zittelli GC, Rimkus V, del Pino V, Muylaert K, Edwards C, Laake M, da Silva JGL, Pereira H, Abelho J (2018) Microalgal bioactive compounds including protein, peptides and pigments: applications, opportunities, and challenges during biorefinery processes. In: Hayes M (ed.) Novel proteins for food, pharmaceuticals and agriculture: sources, applications and advances: pp 239-255. John Wiley \& Sons, Ltd.

Hernández D, Riaño B, Coca M, García-González MC (2016) Microalgae cultivation in high rate algal ponds using slaughterhouse wastewater for biofuel applications. Chem Eng J 285:449-458.

Hernández D, Riaño B, Coca M, García-González MC (2013) Treatment of agro-industrial wastewater using microalgae-bacteria consortium combined with anaerobic digestion of the produced biomass. Bioresour Technol 135:598-603.

Hii Y, Soo CL, Chuah T-S, Mohd-Azmi A, Abol-Munafi AB (2011) Interactive effect of ammonia and nitrate on the nitrogen uptake by Nannochloropsis sp. J Sustain Sci Manag 6:60-68. 
Hipkin CR, Syrett PJ (1977) Some effects of nitrogen-starvation on nitrogen and carbohydrate metabolism in Ankistrodesmus braunii. Planta 133:209-214.

Hu Q, Sommerfeld M, Jarvis E, Ghirardi M, Posewitz M, Seibert M, Darzins A (2008) Microalgal triacylglycerols as feedstocks for biofuel production: perspectives and advances. Plant J 54:621639.

Imamura S, Yoshihara S, Nakano S, Shiozaki N, Yamada A, Tanaka K, Takahashi H, Asayama M, Shirai M (2003) Purification, characterization, and gene expression of all sigma factors of RNA polymerase in a cyanobacterium. J Mol Biol 325:857-872.

Jämsä M (2019) Improving the efficiencies of photoautotrophic biofuel production: from biomass to biocatalysts. Doctoral Thesis, University of Turku, http://urn.fi/URN:ISBN:978-951-297684-3.

Jämsä M, Lynch F, Santana-Sánchez A, Laaksonen P, Zaitsev G, Solovchenko A, Allahverdiyeva Y (2017) Nutrient removal and biodiesel feedstock potential of green alga UHCC00027 grown in municipal wastewater under Nordic conditions. Algal Res 26:65-73.

Jayesh H. Kabariya and Vimal M. Ramani (2018) Dairy wastewater treatment by cyanobacteria for removal of nutrients with extraction of high value combounds from biomass. Int J Curr Microbiol Appl Sci 7:1527-1538.

Jelakovic S, Kopriva S, Süss KH, Schulz GE (2003) Structure and catalytic mechanism of the cytosolic D-ribulose-5-phosphate 3-epimerase from rice. J Mol Biol 326:127-135.

Jeong SW, Nam SW, HwangBo K, Jeong WJ, Jeong B, Chang YK, Park Y (2017) Transcriptional regulation of cellulose biosynthesis during the early phase of nitrogen deprivation in Nannochloropsis salina. Scientific Reports 7, 5264.

Jiang L, Luo S, Fan X, Yang Z, Guo R (2011) Biomass and lipid production of marine microalgae using municipal wastewater and high concentration of $\mathrm{CO}_{2}$. Appl Energy 88:3336-3341.

Källqvist T, Svenson A (2003) Assessment of ammonia toxicity in tests with the microalga, Nephroselmis pyriformis, Chlorophyta. Water Res 37:477-484.

Kim K-S, Feild E, King N, et al (2005) Spontaneous mutations in the ammonium transport gene AMT4 of Chlamydomonas reinhardtii. Genetics 170:631-644.

Kligerman DC, Bouwer EJ (2015) Prospects for biodiesel production from algae-based wastewater treatment in Brazil: A review. Renew Sustain Energy Rev 52:1834-1846.

Komárek R (1989) Polynuclearity of vegetative cells in coccal green algae from the family Neochloridaceae. Arch für Protistenkd 137:255-273.

Koskinen S, Hakkila K, Gunnelius L, Kurkela J, Wada H, Tyystjärvi T (2016) In vivo recruitment analysis and a mutant strain without any group $2 \sigma$ factor reveal roles of different $\sigma$ factors in cyanobacteria. Mol Microbiol 99:43-54.

Kudela, R. M., Seeyave, S., \& Cochlan, W. P. (2010). The role of nutrients in regulation and promotion of harmful algal blooms in upwelling systems. Progress in Oceanography, 85(1-2), 122-135.

Lara C, Rodríguez R, Guerrero MG (1993) Nitrate transport in the cyanobacterium Anacystis nidulans. Physiol Plant 89:582-587.

Lauersen KJ, Berger H, Mussgnug JH, Kruse O (2013) Efficient recombinant protein production and secretion from nuclear transgenes in Chlamydomonas reinhardtii. J Biotechnol 167:101-110.

Leitão RC, van Haandel AC, Zeeman G, Lettinga G (2006) The effects of operational and environmental variations on anaerobic wastewater treatment systems: A review. Bioresour Technol 97:1105-1118.

Lettinga G, van Velsen AFM, Hobma SW, de Zeeuw W, Klapwijk A (1980) Use of the upflow sludge blanket (USB) reactor concept for biological wastewater treatment, especially for anaerobic treatment. Biotechnol Bioeng 22:699-734.

Li Y, Horsman M, Wang B, Wu N, Lan CQ (2008) Effects of nitrogen sources on cell growth and lipid accumulation of green alga Neochloris oleoabundans. Appl Microbiol Biotechnol 81:629-636.

Lindberg P, Park S, Melis A (2010) Engineering a platform for photosynthetic isoprene production in cyanobacteria, using Synechocystis as the model organism. Metab Eng 12:70-79. 
Liu ZY, Wang GC, Zhou BC (2008) Effect of iron on growth and lipid accumulation in Chlorella vulgaris. Bioresour Technol 99:4717-4722.

Loera-Quezada MM, Angeles G, Olguín EJ (2011) Effect of irradiance on the cell density, size and lipid accumulation of Neochloris oleoabundans. Rev. Latinoam. Biotecnol. Amb. Algal 2(2): 8192.

Lofrano G, Brown J (2010) Wastewater management through the ages: A history of mankind. Sci Total Environ 408:5254-5264.

López-Millán AF, Morales F, Andaluz S, Gogorcena Y, Abadía A, Rivas JDL, Abadía J (2000) Responses of sugar beet roots to iron deficiency. Changes in carbon assimilation and oxygen use. Plant Physiol 124:885-89.

Losada M, Paneque A, Aparicio PJ, Mvega J, Cárdenas J, Herrera J (1970) Inactivation and repression by ammonium of the nitrate reducing system in Chlorella. Biochem Biophys Res Commun 38:1009-1015.

Lukeš M, Giordano M, Prášil O (2017) The effect of environmental factors on fatty acid composition of Chromera velia (Chromeridae). J Appl Phycol 29:1791-1799.

Lynch F, Santana-Sánchez A, Jämsä M, Sivonen K, Aro E-M, Allahverdiyeva Y (2015) Screening native isolates of cyanobacteria and a green alga for integrated wastewater treatment, biomass accumulation and neutral lipid production. Algal Res 11:411-420.

Markou G, Vandamme D, Muylaert K (2014) Microalgal and cyanobacterial cultivation: The supply of nutrients. Water Res. 65:186-202.

Masojídek J, Prášil O (2010) The development of microalgal biotechnology in the Czech Republic. J Ind Microbiol Biotechnol 37:1307-1317.

Mayers JJ, Flynn KJ, Shields RJ (2014) Influence of the N: P supply ratio on biomass productivity and time-resolved changes in elemental and bulk biochemical composition of Nannochloropsis sp. Bioresour Technol 169:588-595.

Melis A, Zhang L, Forestier M, Ghirardi ML, Seibert (2000) Sustained photobiological hydrogen gas production upon reversible inactivation of oxygen evolution in the green alga Chlamydomonas reinhardtii. Plant Physiol 122:127-136.

Metcalf \& Eddy, Tchobanoglous G, Burton LF, Stensel HD (2004) Wastewater engineering : treatment and reuse. McGraw-Hill, Boston.

Metsämuuronen S, Sillanpää M, Bhatnagar A, Mänttäri M (2014) Natural Organic Matter Removal from Drinking Water by Membrane Technology. Sep Purif Rev 43:1-61.

Michels MHA, Vaskoska M, Vermuë MH, Wijffels RH (2014) Growth of Tetraselmis suecica in a tubular photobioreactor on wastewater from a fish farm. Water Res 65:290-296.

Miyamoto K, Hallenbeck PC, Benemann JR (1979) Nitrogen fixation by thermophilic blue-green algae (cyanobacteria): Temperature characteristics and potential use in biophotolysis. Appl Environ Microbiol 37:454-458.

Molinuevo-Salces B, Riaño B, Hernández D, García-González M (2019) Microalgae and wastewater treatment: Advantages and disadvantages. pp 505-534.

Morales-Sánchez D, Tinoco-Valencia R, Kyndt J, Martinez A (2013) Heterotrophic growth of Neochloris oleoabundans using glucose as a carbon source. Biotechnol Biofuels 6: 100.

Morris I, Syrett PJ (1963) The development of nitrate reductase in Chlorella and its repression by ammonium. Arch Mikrobiol 47:32-41.

Mulbry W, Kondrad S, Buyer J (2008) Treatment of dairy and swine manure effluents using freshwater algae: Fatty acid content and composition of algal biomass at different manure loading rates. $\mathrm{J}$ Appl Phycol 20:1079-1085.

Naik KS, Stenstrom MK (2012) Evidence of the influence of wastewater treatment on improved public health. Water Sci Technol 66:644-652.

Nikkinen H-L, Hakkila K, Gunnelius L, Huokko T, Pollari M, Tyystjärvi T (2011) The sigB factor regulates multiple salt acclimation responses of the cyanobacterium Synechocystis sp. PCC 6803. Plant Physiol 158:514-523. 
Nimptsch J, Pflugmacher S (2007) Ammonia triggers the promotion of oxidative stress in the aquatic macrophyte Myriophyllum mattogrossense. Chemosphere 66:708-714.

Niwa T, Hatamoto M, Yamashita T, Noguchi H, Takase O, Kekre KA, Ang WS, Tao G, Seah H, Yamaguchi T (2016) Demonstration of a full-scale plant using an UASB followed by a ceramic MBR for the reclamation of industrial wastewater. Bioresour Technol 218:1-8.

Ojanen S, Tyystjärvi E, Holmberg H, Ahtila P (2015) Porous membrane as a means of gas and nutrient exchange in a tubular photobioreactor. J Appl Phycol 27:1169-1175.

Ort DR, Melis A (2011) Optimizing antenna size to maximize photosynthetic efficiency. Plant Physiol 155:79-85.

Oswald WJ, Gotaas HB, Golueke CG, Kellen WR, Gloyna EF, Hermann ER (1957) Algae in waste treatment [with discussion]. Sewage Ind Waste 29:437-457.

Perez-Garcia O, Bashan Y, Esther Puente M (2011a) Organic carbon supplementation of sterilized municipal wastewater is essential for heterotrophic growth and removin ammonium by the microalgae Chlorella vulgaris. J Phycol 47:190-199.

Perez-Garcia O, Escalante FME, De-Bashan LE, Bashan Y (2011b) Heterotrophic cultures of microalgae: Metabolism and potential products. Water Res 45:11-36.

Pollari M, Rantamäki S, Huokko T, Huokko T, Kårlund-Marttila A, Virjamo V, Tyystjärvi E, Tyystjärvi $\mathrm{T}$ (2011) Effects of deficiency and overdose of group 2 sigma factors in triple inactivation strains of Synechocystis sp. strain PCC 6803. J Bacteriol 193:265-273.

Pollock S V, Pootakham W, Shibagaki N, Moseley JL, Grossman AR (2005) Insights into the acclimation of Chlamydomonas reinhardtii to sulfur deprivation. Photosynth Res 86:475-489.

Posadas E, García-Encina PA, Soltau A, Domínguez A, Díaz I, Muñoz R (2013) Carbon and nutrient removal from centrates and domestic wastewater using algal-bacterial biofilm bioreactors. Bioresour Technol 139:50-58.

Pruvost J, Van Vooren G, Le Gouic B, Couzinet-Mossion A, Legrand J (2011) Systematic investigation of biomass and lipid productivity by microalgae in photobioreactors for biodiesel application. Bioresour Technol 102:150-158.

Pulz O, Gross W (2004) Valuable products from biotechnology of microalgae. Appl Microbiol Biotechnol 65:635-648.

Rantamäki S, Tyystjärvi T (2013) Light acclimation of triple inactivation strain of group 2 sigma factors in Synechocystis sp. strain PCC 6803. In: Advanced Topics in Science and Technology in China. pp 455-458.

Rasdi NW, Qin JG (2015) Effect of N:P ratio on growth and chemical composition of Nannochloropsis oculata and Tisochrysis lutea. J Appl Phycol 27:2221-2230.

Rashidi B, Trindade (2018) Detailed biochemical and morphologic characteristics of the green microalga Neochloris oleoabundans cell wall. Algal Research 35: 152-159.

Ratti S, Giordano M (2008) Allocation of sulfur to sulfonium compounds in microalgae. In: Khan NA, Singh S, Umar S (eds) Sulfur assimilation and abiotic stress in plants. Springer Berlin Heidelberg, Berlin, Heidelberg, pp 317-333.

Razzak SA, Ilyas M, Ali SAM, Hossain MM (2015) Effects of $\mathrm{CO}_{2}$ concentration and $\mathrm{pH}$ on mixotrophic growth of Nannochloropsis oculata. Appl Biochem Biotechnol.

Redfield AC (1934) On the proportions of organic derivatives in sea water and their relation to the composition of plankton. In: James Johnstone Memorial Volume. The University Press, pp 176192.

Rees TA V., Cresswell RC, Syrett PJ (1980) Sodium-dependent uptake of nitrate and urea by a marine diatom. Biochim Biophys Acta - Biomembr 596:141-144.

Renou S, Givaudan JG, Poulain S, Dirassouyan F, Moulin P (2008) Landfill leachate treatment: Review and opportunity. J. Hazard. Mater. 150:468-493.

Riaño B, Hernández D, García-González MC (2012) Microalgal-based systems for wastewater treatment: Effect of applied organic and nutrient loading rate on biomass composition. Ecol Eng 49:112-117. 
Rijstenbil JW, Derksen JWM, Gerringa LJA, Poortvliet TCW, Sandee A, van den Berg M, van Drie J, Wijnholds JA (1994) Oxidative stress induced by copper: defense and damage in the marine planktonic diatom Ditylum brightwellii, grown in continuous cultures with high and low zinc levels. Mar Biol 119:583-590.

Rippka R, Deruelles J, Waterbury JB, Herdman RY, Stanier M (1979) Generic assignments, strain histories and properties of pure cultures of cyanobacteria. Microbiology 111:1-61.

Ritchie RJ (2006) Consistent sets of spectrophotometric chlorophyll equations for acetone, methanol and ethanol solvents. Photosynth Res 89:27-41.

Roessler PG (1990) Environmental control of glycerolipid metabolism in microalgae: commercial implications and future research directions. J Phycol 26:393-399.

Rojsitthisak P, Burut-Archanai S, Pothipongsa A, Powtongsook S (2017) Repeated phosphate removal from recirculating aquaculture system using cyanobacterium remediation and chitosan flocculation. Water Environ J 31:598-602.

Roselet F, Vandamme D, Muylaert K, Abreu PC (2019) Harvesting of Microalgae for Biomass Production. In: Alam M, Wang Z (eds) Microalgae Biotechnology for Development of Biofuel and Wastewater Treatment. Springer, Singapore: pp 211-243.

Ruan Z, Prášil O, Giordano M (2018) The phycobilisomes of Synechococcus sp. are constructed to minimize nitrogen use in nitrogen-limited cells and to maximize energy capture in energy-limited cells. Environ Exp Bot 150:152-160.

Ruiz-Marin A, Mendoza-Espinosa LG, Stephenson T (2010) Growth and nutrient removal in free and immobilized green algae in batch and semi-continuous cultures treating real wastewater. Bioresour Technol 101:58-64.

Rwehumbiza VM, Harrison R, Thomsen L (2012) Alum-induced flocculation of preconcentrated Nannochloropsis salina: Residual aluminium in the biomass, FAMEs and its effects on microalgae growth upon media recycling. Chem Eng J 200-202:168-175.

Saito K (2000) Regulation of sulfate transport and synthesis of sulfur-containing amino acids. Curr Opin Plant Biol 3:188-195.

Schmidt A (1988) Sulfur metabolism in cyanobacteria. In: Packer L, Glazer AN (ed.) Cyanobacteria. Methods Enzymol 167:572-583.

Selvaratnam T, Pegallapati A, Montelya F, Rodriguez G, Nirmalakhandan N, Lammers PJ, van Voorhies W (2015) Feasibility of algal systems for sustainable wastewater treatment. Renew Energy 82:71-76.

Spolaore P, Joannis-Cassan C, Duran E, Isambert A (2006) Commercial applications of microalgae. J Biosci Bioeng 101:87-96.

Stensjö K, Vavitsas K, Tyystjärvi T (2018) Harnessing transcription for bioproduction in cyanobacteria. Physiol Plant 162:148-155.

Stoica A, Sandberg M, Holby O (2009) Energy use and recovery strategies within wastewater treatment and sludge handling at pulp and paper mills. Bioresour Technol 100:3497-3505.

Strickland JDH, Parsons TR (1972) A practical handbook of seawater analysis. Second edition, Fisheries research board of Canada, Bulletin 167, Ottawa, Canada.

Su HY, Chou HH, Chow TJ, Lee TM, Chang JS, Huang WL, Chen HJ (2017) Improvement of outdoor culture efficiency of cyanobacteria by over-expression of stress tolerance genes and its implication as bio-refinery feedstock. Bioresour Technol 244:1294-1303.

Suda S, Atsumi M, Miyashita H (2002) Taxonomic characterization of a marine Nannochloropsis species, N. oceanica sp. nov. (Eustigmatophyceae). Phycologia Volume 41: 273-279.

Sukenik A (1991) Ecophysiological considerations in the optimization of eicosapentaenoic acid production by Nannochloropsis sp. (Eustigmatophyceae). Bioresour. Technol. 35:263-269.

Sukenik A, Carmeli Y (1990) Lipid synthesis and fatty acid composition in Nannochloropsis sp. (Eustigmatophyceae) grown in light-dark cycle. J Phycol 26:463-469.

Sukenik A, Carmeli Y, Berner T (1989) Regulation of fatty acid composition by irradiance level in the Eustigmatophyte Nannochloropsis sp. J Phycol 25:686-692. 
Sunda W.G. (2006) Trace Metals and Harmful Algal Blooms. In: Granéli E., Turner J.T. (eds) Ecology of Harmful Algae. Ecological Studies (Analysis and Synthesis), vol 189. Springer, Berlin, Heidelberg.

Sutherland DL, Turnbull MH, Craggs RJ (2014) Increased pond depth improves algal productivity and nutrient removal in wastewater treatment high rate algal ponds. Water Res 53:271-281.

Terauchi AM, Peers G, Kobayashi MC, Niyogi KK, Merchant SS (2010) Trophic status of Chlamydomonas reinhardtii influences the impact of iron deficiency on photosynthesis. Photosynth Res 105:39-49.

Thurston R V, Russo RC, Vinogradov GA (1981) Ammonia toxicity to fishes. Effect of pH on the toxicity of the unionized ammonia species. Environ Sci Technol 15:837-840.

Tripathi BN, Gaur JP (2004) Relationship between copper- and zinc-induced oxidative stress and proline accumulation in Scenedesmus sp. Planta 219:397-404.

Ugwu CU, Aoyagi H, Uchiyama H (2008) Photobioreactors for mass cultivation of algae. Bioresour. Technol. 99:4021-4028.

Vavilin V, Xu H, Lin S, Vermaas W (2003) Energy and electron transfer in photosystem II of a chlorophyll $b$ - containing Synechocystis sp. PCC 6803 mutant. Biochemistry 42: 1731-1746.

Vines HM, Wedding RT (1960) Some effects of ammonia on plant metabolism and a possible mechanism for ammonia toxicity. Plant Physiol 35:820.

Volgusheva A, Kukarskikh G, Krendeleva T, Rubin A, Mamedov F (2015) Hydrogen photoproduction in green algae Chlamydomonas reinhardtii under magnesium deprivation. RSC Adv 5:5633-5637.

von Alvensleben N, Stookey K, Magnusson M, Heimann K (2013) Salinity tolerance of Picochlorum atomus and the use of salinity for contamination control by the freshwater cyanobacterium Pseudanabaena limnetica. PLoS One 8:63569-63569.

Wagh AS (2016) Chapter 4 - Phosphate Chemistry. In: Wagh AS (ed) Chemically Bonded Phosphate Ceramics. Second edition. Elsevier, pp 51-60.

Wan M, Jin X, Xia J, Rosenberg JN, Yu G, Nie Z, Oyler GA, Betenbaugh MJ (2014) The effect of iron on growth, lipid accumulation, and gene expression profile of the freshwater microalga Chlorella sorokiniana. Appl Microbiol Biotechnol 98:9473-9481.

Wang B, Lan CQ (2011) Biomass production and nitrogen and phosphorus removal by the green alga Neochloris oleoabundans in simulated wastewater and secondary municipal wastewater effluent. Bioresource Technology 102: 5639-5644.

Wang B, Lan CQ, Horsman M (2012) Closed photobioreactors for production of microalgal biomasses. Biotechnol Adv 30:904-912.

Wang L, Min M, Li Y, Chen P, Chen Y, Liu Y, Wang Y, Ruan R (2010) Cultivation of green algae Chlorella sp. in different wastewaters from municipal wastewater treatment plant. Appl Biochem Biotechnol 162:1174-1186.

Wang W (1991) Ammonia toxicity to macrophytes (common duckweed and rice) using static and renewal methods. Environ Toxicol Chem 10:1173-1177.

Wang Y, Stessman DJ, Spalding MH (2015) The $\mathrm{CO}_{2}$ concentrating mechanism and photosynthetic carbon assimilation in limiting $\mathrm{CO}_{2}$ : how Chlamydomonas works against the gradient. Plant $\mathrm{J}$ 82:429-448.

Wijffels RH, Barbosa MJ (2010) An outlook on microalgal biofuels. Science 329:796-799.

Wijffels RH, Kruse O, Hellingwerf KJ (2013) Potential of industrial biotechnology with cyanobacteria and eukaryotic microalgae. Curr. Opin. Biotechnol. 24:405-413.

Wilkie AC, Mulbry WW (2002) Recovery of dairy manure nutrients by benthic freshwater algae. Bioresour Technol 84:81-91.

Zavrel T, Faizi M, Loureiro C, Poschmann G, Stuhler K, Sinetova M, Zorina A, Steuer R, Cerveny J (2019) Quantitative insights into the cyanobacterial cell economy. eLife 8: e42508.

Zavrel T, Sinetova MA, Buzova D, Literakova P, Cerveny J (2015) Characterization of a model cyanobacterium Synechocystis sp. PCC 6803 autotrophic growth in a flat-panel photobioreactor. Eng. Life Sci., 15: 122-132. 


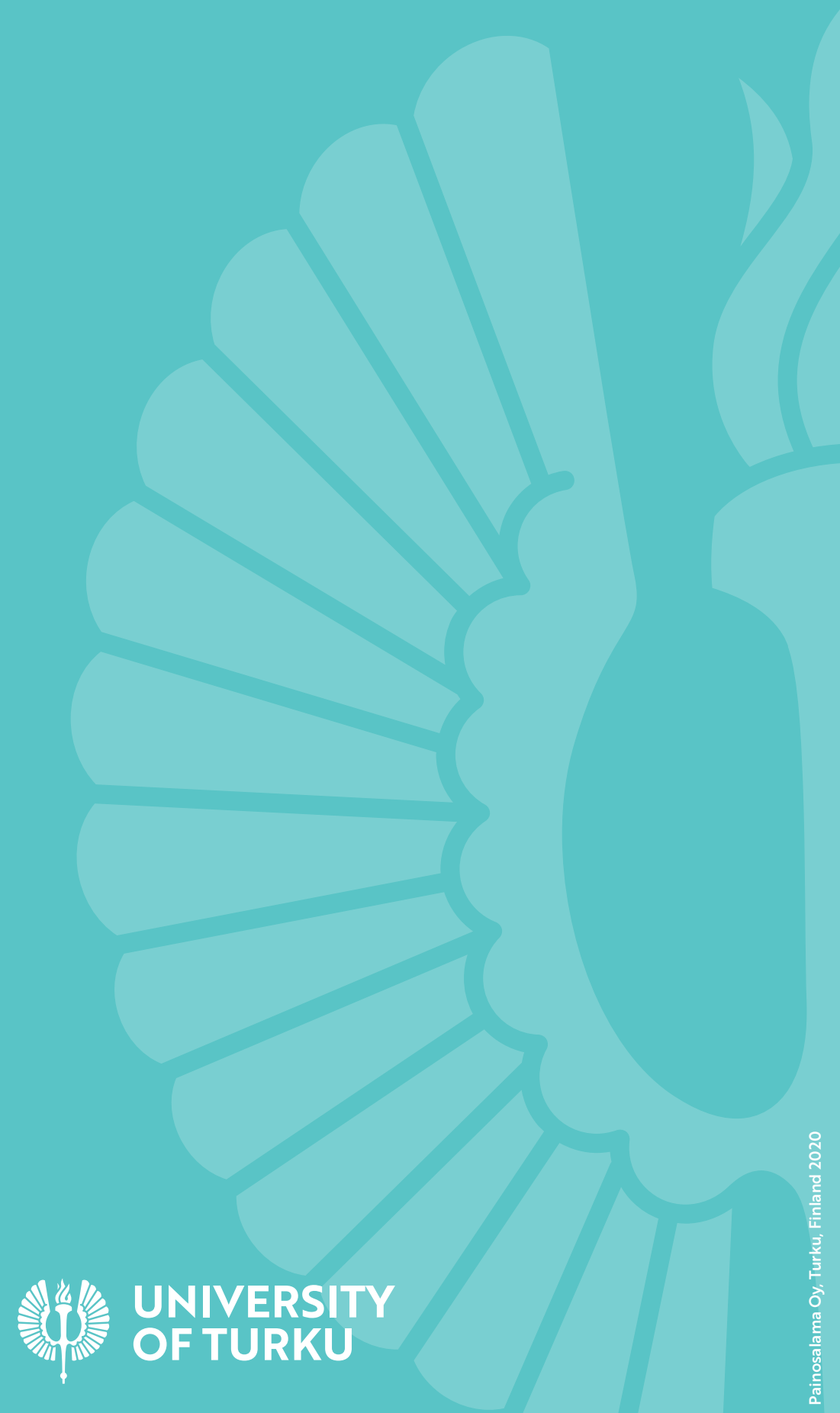

ISBN 978-951-29-8094-9 (PRINT) ISBN 978-951-29-8095-6 (PDF)

s. ISSN 2343-3175 (Online) 